\title{
Relevant Factors in Sustainable Urban Development of Urban Planning Methodology and Implementation of Concepts for Sustainable Planning (Planning Documentation for the Master Plan Skopje 2001-2020)
}

\author{
Emilija Sofeska*
}

Faculty of Architecture - Skopje, Ss Cyril and Methodius University of Skopje, Skopje, Republic of Macedonia Cinning Methodology and Implementation of Concepts for Susting Methodology an Documentation for the Master Plan Skopje 2001-2020). SEE Archit Des. 2015 Jan 26;2015:10003. http://dx.doi.org/10.3889/seejad.2015.10003

Key words: sustainability; sustainable urban development; models of sustainable urban; development; sustainability factors; criteria for sustainability; sustainability indicators; compact city; decentralization; sustainable transport; planning

Correspondence: Emilija Sofeska. Faculty of Architecture "Skopje, Ss Cyril and Methodius University of Skopje, Skopje Republic of Macedonia. E-mail: emmysof@gmail.com

Received: 20-Dec-2014; Revised: 27-Dec-2014; Accepted: 18-Jan-2015; Published: 26-Jan-2015

Copyright: @ 2015 Emilija Sofeska. This is an open-access article distributed under the terms of the Creative Commons Attribution License, which permits unrestricted use, distribution, and reproduction in any medium, provided the original author and source are credited.

Competing Interests: The author have declared that no competing interests exist.

\begin{abstract}
Cities as complex and multilayer systems are part of a sustainable policy, because they are huge consumers of resources and show clear signs of unsustainable behavior. Cities around the world today are faced with intense degradation, pollution, overpopulation, etc. Sustainable development refers to the environmental, economic and sociological processes in the city and its physical structure. Researchers and planners are therefore encouraged to think about the city that will focus on self-regulation. Therefore challenge for this research. This research paper explores the relationship between urban development and sustainable development through the relevant factors and indicators in the methodology of sustainable urban planning. The knowledge obtained should help considers and methods for encourage sustainable urban planning thought in the Republic of Macedonia.
\end{abstract}

The subject of this research is implementation of sustainable concepts and how they affect the methodology of urban planning. In this sense, the focus is on identifying the indicators and factors relevant to sustainable development where the aim is to systematize the concepts of sustainable urban development and operationalization in urban planning documentation and development of the city Skopje.

This paper attempts to encourage research and further deepening the methodology of sustainable urban planning. Given the nature of this research work consistently are observed ambitions that I had in conducting and systematization of the factors that reflect sustainable urban development, while, in exposure to the material and setting up of the thesis, parallel are reviewed several aspects that are distributed concentrically and are embedded in the concluding observations of the actual state of the model implementations in the planning of the city of Skopje. 


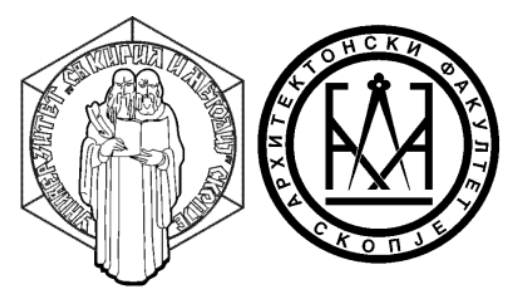

UNIVERSITY "ST. CYRIL AND METHODY" - SKOPJE

FACULTY OF ARCHITECTURE - SKOPJE

RELEVANT FACTORS IN SUSTAINABLE URBAN DEVELOPMENT OF URBAN PLANING METHODOLOGY AND IMPLEMENTATION OF CONCEPTS FOR SUSTAINABLE PLANNING

(PLANNING DOCUMENTATION FOR THE MASTER PLAN SKOPJE 2001-2020)

- Master thesis -

Candidate:

Emilija Sofeska
Mentor:

Prof. d-r. Vladimir Arsovski 


\section{RELEVANT FACTORS IN SUSTAINABLE URBAN DEVELOPMENT OF URBAN \\ PLANNING METHODOLOGY AND IMPLEMENTATION OF CONCEPTS FOR \\ SUSTAINABLE PLANNING}

(PLANNING DOCUMENTATION FOR THE MASTER PLAN SKOPJE 2001-2020)

Keywords: sustainability, sustainable urban development, models of sustainable urban development, sustainability factors, criteria for sustainability, sustainability indicators, compact city, decentralization, sustainable transport, planning documentation for the GUP Skopje 2001-2020 year ...

A big thank you to all my friends and colleagues, that's helped me to accomplish my thesis. Special thanks to my mentor, Prof. Dr. Vladimir Arsovski for his unselfish and professional support and assistance in the preparation of this paper, for the suggestions that he give me and especially for his willingness to cooperation in terms of internet web- necessary communication. A big thank you, I also express to prof. Dr. Jasmina Siljanoska for her unselfish willingness to coordinate the necessary procedures in the preparation of this paper, valuable suggestions, assistance in gathering the necessary documentation and bibliography. For support during the preparation of this paper, for the stimulus that she always gives me, especially thank prof. MSc. Gordana Atanasoska. Express my greatest gratitude to my family, all my loved ones and whose immense support and understanding what I felt, though physically far from them in moments of emotional weakness, effort and hesitation.

Emilia Sofeska 


\section{INTRODUCTION}

Sustainability is contemporary and current topic in the world and the interest to explore in this area is warranted. Sustainable global politics today clearly outlines its goals for recycling sustainable development that will include saving energy and resources, and towns will only be recoverable, recyclable and maintain. The three basic principles of sustainable development: internal generational equity, inter-generational equity and trans-border liability. These are principles that have profound international political dimension. Internal generational equity is mean of tackling poverty, which is one of the primary causes of degradation and distortion of space and sustainability would mean equal distribution of resources according to the common needs of all. Principle or inter-generational equity recalls that when we undertaking any activity in the space we should be responsible for future generations and their needs. Finally the principle of trans-border responsibility actually means global environmental responsibility through the treatment of resources, climate change, pollution etc.

The global objectives of sustainability, in large part, are related to sustainable urban planning, because $40 \%$ of the world population lives in cities. Cities as complex and multilayer systems are part of a sustainable policy, because they are huge consumers of resources and show clear signs of unsustainable behavior. Particularly alarming is the situation in big cities with huge population, which pushing cities in condition or selfdestructive. Researchers and planners are therefore encouraged to think about the city that will focus on self-regulation. Therefore challenge for this research.

Today it is unthinkable to plan the development of a state and society without implementing the concepts of sustainability both in socio-economic terms, but also in social terms. An important part there covers urban development which without society cannot function. Cities around the world today are faced with intense degradation, pollution, overpopulation, etc. Sustainable development refers to the environmental, economic and sociological processes in the city and its physical structure. This research paper explores the relationship between urban development and sustainable development through the relevant factors and indicators in the methodology of sustainable urban planning. The knowledge obtained should help considers and methods for encourage sustainable urban planning thought in the Republic of Macedonia.

The modern city is an ecological phenomenon of the 21st century in which reality tends towards unsustainability. The basic idea of this research is the challenge to encourage sustainable development in cities that are growing faster today than ever, as well as encourage of responsibility and commitment to humanity in general. The subject of this research is implementation of sustainable concepts and how they affect the methodology of urban planning. In this sense, the focus is on identifying the indicators and factors relevant to 
sustainable development where the aim is to systematize the concepts of sustainable urban development and operationalization in urban planning documentation and development of the city Skopje.

This paper attempts to encourage research and further deepening the methodology of sustainable urban planning. As to the content of this paper, the shaping idea that led me was to cover the most important aspects of urban sustainability and development, through the study of existing models and opportunities for urban development, resulting from the criteria and indicators defined in international laws and documents for sustainability and methodologies of modern urban planning.

The first chapter of this paper in reference to the definition of the elements and stakeholders of sustainable development and sustainability thought. This is accomplished by defining sustainability and chronology of urban development and thought for sustainability of cities through time, i.e. the formulation of basic concepts that include sustainability, environment and animal problems in it; ecological footprints; challenges of sustainability by defining the key elements and factors for sustainable development, efficient use of energy and resources, ecological dimensions of urban development, determining the characteristics of ecosystems and the opportunities of the city as ecosystem .

The second chapter analyzes the ecological theories and concepts for the development of urban thought that are embedded in international documents, acts, resolutions, declarations, strategies... for protection of the environment. Also, in the second chapter are given models and opportunities for sustainable urban development. It is a model of sustainable self-organized system; the model of strong sustainability; model of polycentric urban development; model of compact city; model of transport-oriented development in focus spots and the model of sustainable transportation. In these models are grounded relevant factors for sustainability and implementation of sustainable development in the urban structure through sustainable urban strategies, economic and social trends, decentralization and limits of growth, centralization and compactness. All these aspects are presented and analyzed through the experiences from specific areas in the world (Australia, UK, etc...) and specific projects (urban eco villages, etc...) which are an important basis for evaluation and possible targeting of their operationalization in our environments.

Classification and systematization of the concepts of sustainable urban development exploring opportunities to establish appropriate methodology for urban planning and are given in the third chapter. Criteria and indicators for sustainable urbanization are superior methodological procedures that produce relevant qualitative and quantitative assessments of the sustainability of the city. In this section are perceived the size, shape and coefficient of expansion of the urban environment, use of space and land use, population density and construction, organization of traffic as an indicator of sustainability, identification, cultural, historical and natural (ecological) context. There are also considering the state of 
biodiversity, its values and the importance of the relationship between the urban environment and bio-region. The third section discusses the key elements of sustainable development and planning of the urban structure which could further influence the shaping of legislation and planning strategy for the city in the direction of sustainable development.

The fourth chapter gives the relevant factors that may affect the methodology for planning sustainable urban development of Skopje. The assessment begins with a chronology of town planning and analysis of the situation in the general urban planning documentation for Skopje 2001-2020 year. The analysis which is conducted gives the model of urban development that is implied by the planning documentation, compared with the analyzed models for sustainable urban development in the second chapter of this research. Significant is the analysis of the planned urban structure of the city using methodological procedures that produce relevant qualitative and quantitative grades, that are seen through criteria and indicators for sustainable urbanization of the third chapter, recognized and unrecognized in the general urban planning documentation for Skopje 2001-2020 year. Thus the, attempt to operationalize the concept of sustainable development in our environment is with possible implementation through proven models for sustainable urban development, followed by the conclusion for the conditions and sustainable opportunities for the future. Thereby this paper presents a specific contribution to the follow up of sustainable urban development in the methodology of urban planning in our country.

Given the nature of this research work consistently are observed ambitions that I had in conducting and systematization of the factors that reflect sustainable urban development, while, in exposure to the material and setting up of the thesis, parallel are reviewed several aspects that are distributed concentrically and are embedded in the concluding observations of the actual state of the model implementations in the planning of the city of Skopje. 
INTRODUCTION $\ldots . .$. I

CONTENT.....V

1 DEFINITION OF STAKEHOLDERS OF SUSTAINABLE DEVELOPMENT AND CHRONOLOGY OF THOUGHT FOR SUSTAINABILITY .....1

1.1 Key elements of sustainable development and ecological dimensions of urban development ......1

1.2 Environmental problems, the challenges of sustainability and sustainable development factors .....5

1.3 Treatment the ecological aspects through the historical development of cities...11

1.3.1 Pre industrial period .....12

1.3.2 Post-industrial period ......18

2 ECOLOGICAL THEORY AND COMPARATIVE ANALYSIS OF THE MODELS AND SYSTEMS FOR SUSTAINABLE DEVELOPMENT .....23

2.1 Diversification of ecological theories according relevance of the factors.....23

2.1.1 Theories founded on relevance of population, social and societal factors.....23

2.1.2 Theories founded on relevance to energy resources and technological development, and economic and environmental (un) balance in cities.....25

2.2 Models of urban structure arising from environmental theories.....27

2.2.1 Decentralization and polycentric urban development.....28

2.2.2 Coherence and compact city.....29

2.2.3 Transport oriented development at focus spots and centers of transit.....31

2.2.4 Sustainable transport .....32

2.3 International documents regulating environmental protection .....33

2.3.1 Global charters and international declarations .....34

2.3.2 European documents and sustainable development of European cities ....39

2.4 Operationalization of sustainable urban development implemented in the examples from the world.....41

2.4.1 Stockholm sustainable city.....41

2.4.2 Plan of London 2004: a compact city - adequate space.....42

2.4.3 Asian compact cities.....43

2.4.4 Australian compact cities.....43

3 QUANTITATIVE AND QUALITATIVE PARAMETERS AND INDICATORS TO OPERATIONALIZE SUSTAINABILITY .....45

3.1 Implementation of urban policies for sustainability .....45

3.1.1 Economic and social processes of sustainable urban policy ....45

3.1.2 Criteria for the control of spatial sustainable development .....46

3.2 Parameters and indicators for sustainable city development .....48

3.2.1 Level of development and limits of the growth of urban environment .....48

3.2.2 Use of land and buildings .....50

3.2.3 Population density and construction .....50

3.2.4 Traffic organization .....52

3.2.5 Identification, recognition and adjustment .....54

3.2.6 Recognition of the value of biodiversity .....56

4 ANALYSIS OF THE GUP PLANNING DOCUMENTATION SKOPJE 2001-2020, AND PERCEPTIONS OF INDICATORS AND MODELS FOR SUSTAINABLE DEVELOPMENT .....58

4.1 Analysis of the general urban planning documentation Skopje 2001-2020 year and planning assumptions for sustainable urban development .....60 
4.1.1 System of settlements, population and major urban functions that follow .....61

4.1.2 Urban greenery, sport and recreation.....67

4.1.3 Infrastructure, categorization and concept of traffic network.....68

4.2 State of the city through study and observation of indicators for sustainable development .....71

4.2.1 Built of the urban environment .....71

4.2.2 Usage of space and land use .....72

4.2.3 Population density and built up.....75

4.2.4 Traffic organization.....80

4.2.5 Identification, recognition and adjustment of built structures .....81

4.2.6 Recognition of the value of biodiversity.....83

4.3 Possible future models of sustainable urban development Skopje ..... 83

4.3.1 Polycentric model of sustainable urban development of the city of Skopje.....84

4.3.2 Model of sustainable urban development of the city of Skopje as a compact city .....84

4.3.3 Transport oriented model of sustainable urban development of the city of Skopje .....85

4.3.4 Model of sustainable transport in the city of Skopje.....86

CONCLUSION .....87

BIBLIOGRAPHY $\quad \ldots . .95$ 


\section{DEFINITION OF STAKEHOLDERS OF SUSTAINABLE DEVELOPMENT AND CHRONOLOGY OF THOUGHT FOR SUSTAINABILITY}

\subsection{Key elements of sustainable development and ecological dimensions of urban development}

Environmental protection, renewable energy and energy efficiency are used now more than ever before and are synonymous for modern living in developed countries. The natural environment is where we all live and development is what we do in order to improve our stay in the environment. Sustainable development refers to the many social fields, affecting the population, agriculture and biodiversity, industry, energy use and energy resources, global warming and climate change, pollution, etc... (Fig. 1)

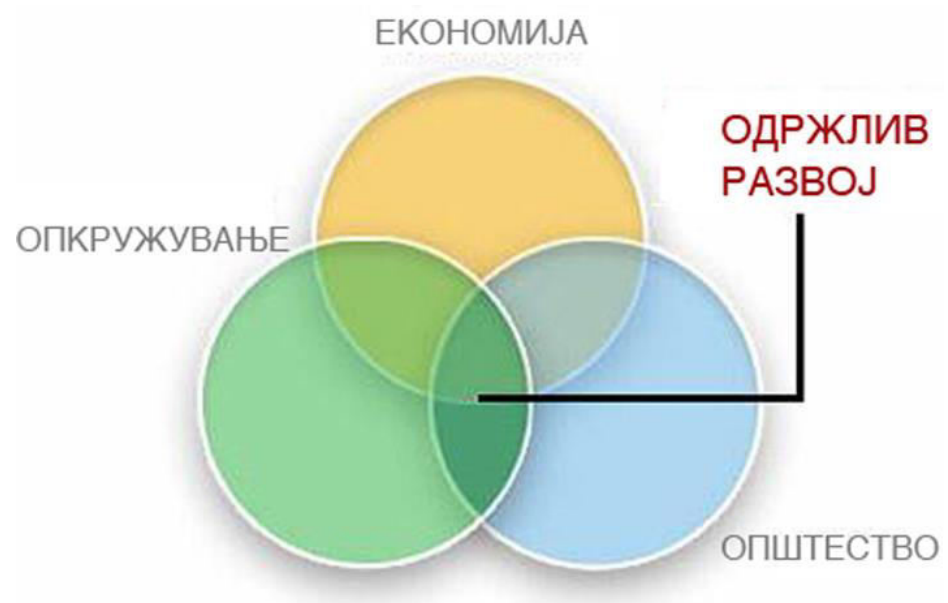

Fig. 1 Triad of sustainable development

Sustainability today is the main goal of every national and international policy. What is more important is that any other movement for sustainable development is linked with the urban environment or the idea of a sustainable city. Given that, all factors of sustainability are equally important, it seems that urbanism is a unique discipline that connects and unites them all. The development of a vision for a sustainable city means setting goals that depend on the needs of the community, the environmental, social and economic values . It is not a one defined static state, but a process that changes with the changes in society, the institutions and culture of living. ${ }^{1}$ What are lost in the modern world are not only natural processes and resources that support life, but feel that this is not just "human world".

Urbanization is a process which itself means changes in social, demographic, technological, economic and social terms. This process goes parallel with the economic expansion in the space in which man exists. The global economic system developed urban lifestyle with developed telecommunications, manufacturing and trade, a system in which there is a flow of information, energy, capital, goods and people. The combination of

\footnotetext{
${ }^{1}$ Where do we want to be?, Green Communities program (US Environmental Protection Agency) http://www.epa.gov/greenkit/intro3.htm.
} 
advanced technology and developed infrastructure allows recovery of the cities into flexible spaces. Large cities have the largest capacity of educated population, have focus on transport infrastructure, have developed industry and ever-expanding industrial areas, multiple housing sales etc... Sustainability should help the world in creating a new generation of awareness that will create a better future for the next generation. Sustainability as a vision for development must take into account a range of ethical questions about our relationship to nature and future generations through the promotion of social equality and justice.

\begin{tabular}{|c|c|c|}
\hline $\begin{array}{l}\text { Концепт на } \\
\text { одржлнв развој }\end{array}$ & $\begin{array}{l}\text { Прннципи на } \\
\text { одржлив развој }\end{array}$ & $\begin{array}{l}\text { Принципи на } \\
\text { одржлив урбан } \\
\text { транспорт }\end{array}$ \\
\hline $\begin{array}{l}\text { Остварување } \\
\text { на потребите } \\
\text { на сегашните } \\
\text { генерачии }\end{array}$ & 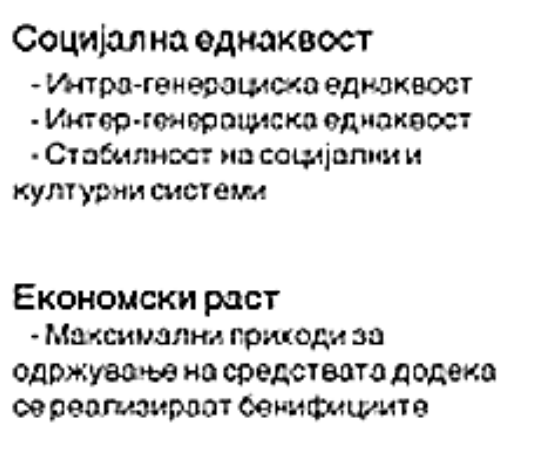 & 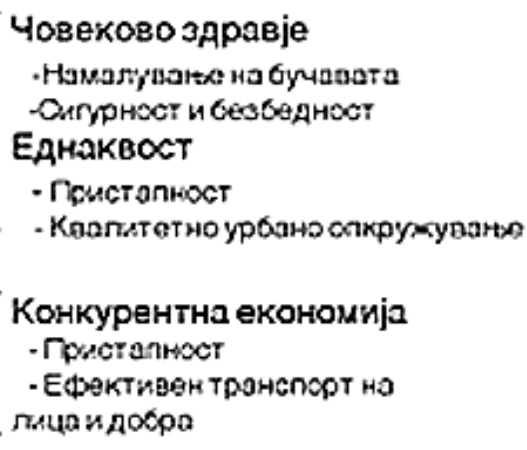 \\
\hline $\begin{array}{l}\text { Можност на } \\
\text { идните генерации } \\
\text { да гиостварат } \\
\text { своите потреби }\end{array}$ & 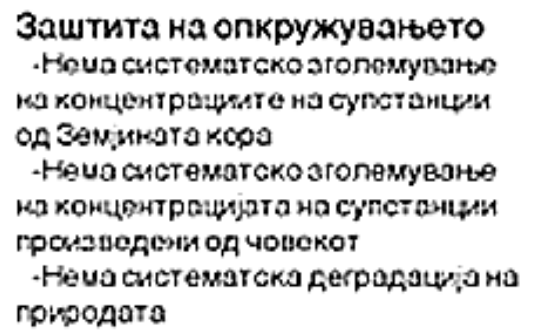 & 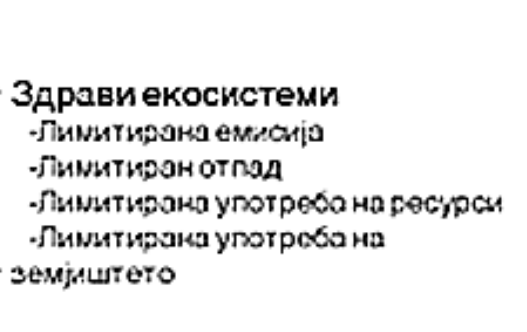 \\
\hline
\end{tabular}

Table 1: Concept of sustainable development

The energy crisis and conventional energy sources are the cause of developing awareness for energy conservation and environmental sustainability. Energy is the most important and necessary for social and economic development, and provides conditions for quality of life. Modern planning is a multidisciplinary activity and requires modeling of energy consumption through management and legislation relating to energy efficiency. ${ }^{2}$

There are various institutions dealing with sustainable development from academia, national and local government, international political institutions, international organizations, local groups, etc... Often research concerning global objectives of sustainability, ecology, "green" economy, efficiency and sustainability in the industry, but some research relating to

\footnotetext{
2 The certificate for energy efficiency (EPC) is introduced to help improve the energy efficiency of buildings. To see this:

http://www.direct.gov.uk/en/HomeAndCommunity/BuyingAndSellingYourHome/Energyperformancecertificates/DG _177026; http://en.wikipedia.org/wiki/Energy_Performance_Certificate\#EPC_Recommendations
} 
planning and land use, urban form and energy, sustainable transport, pollution etc... To all that, it is important to include the participation of the population and the development of democracy in order to evaluate the potential of institutions that support and propagate sustainable development. The research which is part of the plans and programs for sustainable development are related with the following major environmental problems ${ }^{3}$ :

- Water supply. The fact that half the world's population uses water that is not suitable for drinking ${ }^{4}$

- Using fuel and emissions. Most countries in the world don't use purifiers in emission of harmful gases produced by burning fossil fuels ${ }^{5}$;

- Soil erosion. Today occurs mostly as a result of the devastation of the land by cutting forests in order to obtain new agricultural land ${ }^{6}$;

- Forest exploitation. Necessary for global climate control and survival of the multitude of animal species. Their uncontrolled cutting, to 1990 include 1700 devastated millions of acres;

- Nuclear waste. There is no safe way to store nuclear waste which is more than 10,000 tons annually. Worldwide there are more than 430 nuclear reactors waiting to be closed in the next 35 years. The danger is even greater because of the illicit manufacture of pluto can be used in making weapons for terrorist attacks, and some countries in their policies yet have nuclear development plans;

- Population growth. The number of people in the world is 6 billion people, with an average annual growth of the population of 90 million. According to the UN Population numbers will continue to grow, which is expected in 2050 it amounted to 11.9 billion people. It pictorially shows the increasing number of people equal to the population of three new continents like Africa;

- Global warming. Research indicates that greenhouse gases and $\mathrm{CO}_{2}$ in the atmosphere causing global temperatures to rise by $3.5^{\circ} \mathrm{C}$ by 2100 . With such a rate of increase of temperature would cause melting of the poles of the Earth and increasing sea levels to $6 \mathrm{~cm}$ every 10 years that would have inundated coastal towns.

About 2.6 billion people or $40 \%$ of the world population lives in cities, where also concentrated everyday human activities and energy use are are. ${ }^{7}$ Cities are centers of social activity especially with the rise of mass production and consumption, but also with mass waste generation. In order to solve global problems of environment (climate change and global warming) is necessary to change from consumer-oriented development to recyclingoriented development. What is required of sustainable urban development today is characterized through several assumptions:

\footnotetext{
3 James Wines, op.cit., 31.

${ }^{4}$ The biggest problem have the countries of the Middle East, Africa and India that use only half the water needs for the large population and economic expansion.

${ }^{5}$ Most alarming is the situation in China, Africa and Eastern Europe, where the rise in the number of vehicles.

${ }^{6}$ Alarming is situation in China with 3,500 million tons annually eroded lands coming in rivers and lakes.

${ }^{7}$ Mike Jenks, Elizabeth Burton, Katie Wiliams, The Compact city: A Sustainable Urban Form? (Oxford Brooks University, Oxford, UK E\&FN Spon, Chapman \& Hall, 1996)
} 

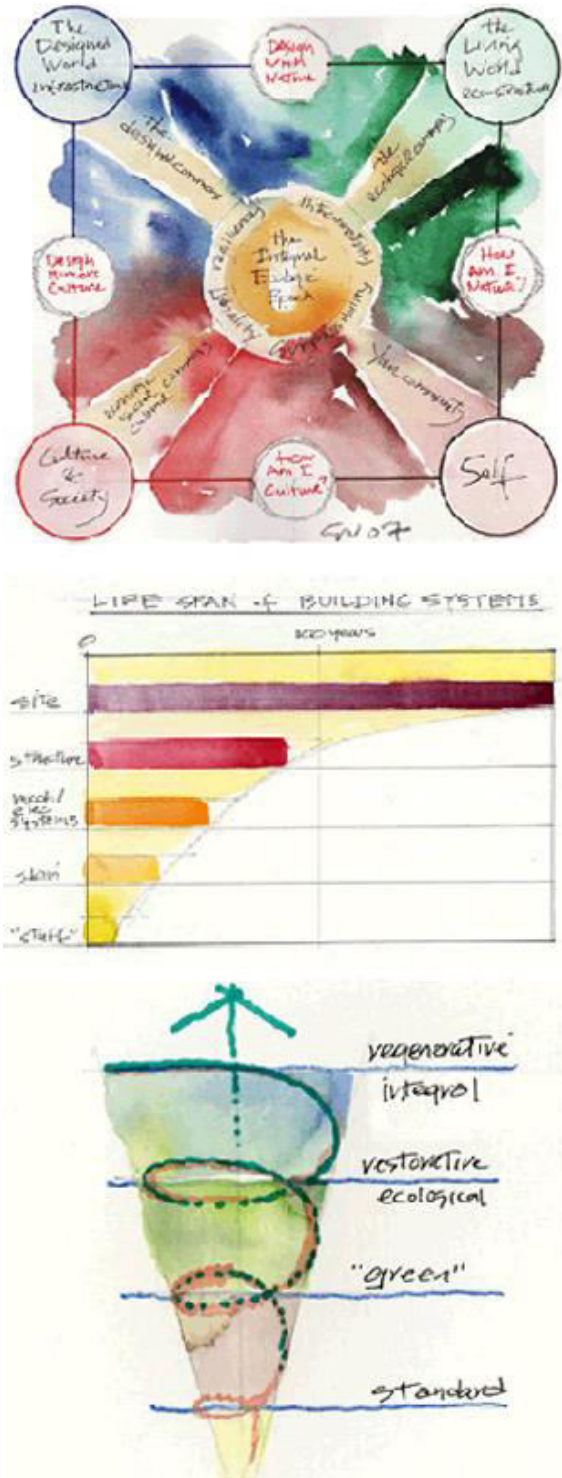

Сл.2 Дијаграми на филозосијата за одржливо градење на Сим Ван дер Рин (пионер во одржливата архитектура)

http://www.vanderryn.com/home.html
- Smaller facilities. Contemporary architecture is recognized through mega structures set on a large area, as a result of technological opportunity to realize. But as the problem of global pollution of the planet is growing, questionable is rise on mass production of residential buildings.

- The use of recyclable and renewable materials. Ecological guidelines suggest that should pay attention to use of recyclable materials for the construction as an intelligent choice, which developing the technology to produce and recycle, and will allow the architectural potential to be used consistently and repeatedly.

- Use of low-energy materials. This suggests use of structural materials with fully known specification of the products. Although seemingly looks that a mass production is good for the environment, however these products can be ecological suitable, but to contain dangerous chemicals and toxic wastes in their production and not to provide energy savings and pollution during transport to the place of installation.

- Water purification. Water is necessary for the maintenance of life on earth, but also as a raw material, is polluted at the most meaningless ways. Caring for clean water not only covers the creation of reserves, but the dirty water recycling and treatment and the lowest level, ie setting the wastewater system within the facility.

- Recycling facilities. This attitude towards building means regional integration in the pattern and scale of the surrounding cities, further history is kept alive and the identity remains preserved.

- Reduction of chemicals that destroy ozone. This problem is already known and the commercial market and economy take care in terms of blocking the production, sale and use of materials that destroy ozone.

- Preservation of the natural environment. Preservation and enhancement of the existing natural environment is at the top of the list of environmental concerns. Basically, the existence of a tree provides oxygen for four people. Existence of green spaces and landscapes in urban centers is the most important quality of living conditions in general. Most dangerous element in the destruction of the natural environment is the work of real estate to be controlled by all means of legislative.

- Energy efficiency.This indicates a growing interest in the use of alternative energy sources and alternative energy use: passive buildings, energy from the sun, wind, water, etc.. Allowing a reduction in the use of fossil fuels in accordance with the regional climate and existing features and contextual influences.

- Solar orientation. It's an important aspect contributing to the achievement of energy efficiency and available as an alternative source of energy. Current level of technology already provides an opportunity to use the grace of the energy potential of the sun.

- Availability of public transport. This is directly related to the need to reduce the use of private motor vehicles and favors the use of public transport as an opportunity to save energy and improve air quality in urban areas. Finding a solution for quick and easy access to public transportation systems has an immediate impact in the urban planning process. 


\subsection{Environmental problems, the challenges of sustainability and sustainable development factors}

The rapid growth and development that results in inequality in the use of natural resources, inefficient energy system and imbalance in socio- demographic system, leading to the emergence of global crises, but from the other side global politics and markets are main reasons to be blamed for unsustainable behavior. Since 1990, awareness of environmental problems is equal for all nations in the world, especially when it comes to global warming, pollution of soil, seas and oceans, the increasing number of environmental disasters, natural disasters and etc... The world today live in an era of information access and daily public opinion research, so population is aware of the problems by whom is faced nature and the challenges of sustainability is a reality worldwide. Have to be changed the course of anthropocentric ethics that puts human into the focus of all values, while the remaining wildlife serve as a resource. Life of the other species is also an important and sustainable development should provide conditions for their continued evolution. ${ }^{8}$

Significant amount of energy in the world is consumed for functioning of cities, with the largest percentage of $94 \%$ energy from non renewable sources and only $6 \%$ of renewable and alternative energy sources. ${ }^{9}$ To achieve the sustainable development of cities is started a strategy to encourage the construction of buildings that will be energy efficient ${ }^{10}$, as well as building cities with high density construction. Second, a particularly important aspect of energy use in the city is the transport where $23 \%$ of the fuel consumption is on the trip from work to home as $3.4 \%$ of the total emission of $\mathrm{CO}_{2} .{ }^{11}$ To overcome this situation in the world are already makes serious strides in designing new types of engines that produce fewer emissions.

Cities should be considered as ecosystems themselves, ie as systems with a flow of energy, matter and complex information systems. Ecosystems are characterized by abiotic and biotic components that create patterns and processes. They are nested together, and man is nested in them. The strength of the system is the focus of interactions and processes by which can be understood features of phenomena and complexity of living systems. The context is recognized as important, given that, each part can be studied in isolation from the others. Human social systems bring additional dimension in that balance. Sustainable socio ecological systems have all the features plus the features of ecosystems due to traditional

\footnotetext{
${ }^{8}$ If the total bio-capacity of the Earth (including sea and land) divided the entire world population would each receive 1.8 acre. Brundtland Report of 1987 calls for the human community to protect $12 \%$ of biological productive areas for the protection of 10 million species with which we share the planet. When will be subtract, the percentage of bio capacity each person gets 1.6 acres. Calculation can be done by Redefining Progress's Ecological Footprints Quiz, http://earthday.net/footprint/index.asp

9 James Wines, op.cit.

${ }^{10}$ With the rise of living standards also grows use of energy spent on heating and cooling of buildings. It is recommended facilities to be designed to use for climate conditions for warming, cooling and lighting of the space. ${ }^{11}$ Ibid.
} 
cultures and settlements: ethics based on strong emotional ties, psychological satisfaction and cooperative coexistence. It includes cultural, social, economics and political structures and processes.

Cities can be sustainable in the urban process if are modeled under environmental principles of form and function in a way that is aligned natural ecosystem. Features include ecosystem diversity, adaptability, interdependence, resilience, the capacity for regeneration and symbiosis. Cities are places where people live and are constantly connected to each other and to other living (biotic) species and in relation to non-living (abiotic) types. The city thus has similarities to any other ecosystem. In the cities along with the flora and fauna there are supra and infrastructure. Key structural and functional strategies that use ecosystem sustainability are presented in the following Table $2:{ }^{12}$

\begin{tabular}{|c|c|}
\hline Карактеристики: & Стратегии: \\
\hline Здрави (есрикасни) & $\begin{array}{l}\text { - Употреба на соларна енергија; } \\
\text { - } \text { Автотропност или регионален автотропен систем; } \\
\text { - } \text { Сочувување на енергијата; } \\
\text { - Конеграција зависно од функцијата; } \\
\text { - Контрола на ерозија; } \\
\end{array}$ \\
\hline Нулта отпадоци & $\begin{array}{l}\text { • } \quad \text { Циркулација на материјата; } \\
\text { Филтрација; }\end{array}$ \\
\hline Саморегулирање & $\begin{array}{l}\text { - Негативни повратни удари, отстранување на } \\
\text { отпадоци и функционална појава; }\end{array}$ \\
\hline Еластични и обновливи & $\begin{array}{ll} & \text { Разноликост; } \\
\text { - } \quad \text { Панархија (вгнездени адаптибилни циклуси) и } \\
\quad \text { еколошка меморија; } \\
\text { - } \quad \text { Позитивни повратни удари; } \\
\end{array}$ \\
\hline Флексибилност & - Мрежи. \\
\hline
\end{tabular}

Table 2: Features and strategies of ecosystems

Like any living system the human community also consumes water, matter and energy processing into a usable form and creates waste. That is way at which is describes the "metabolism" of the city. To be this metabolism more efficient should be reduced so called environmental prints. Ecological footprint is a measure of human demand on ecosystems based on consumption and pollution. Ecological footprints suggest the possibility of ecosystems to regenerate under pressure of human consumption, making it possible to assess how the Earth needs to transform waste into harmless, if humanity lives with today's lifestyle. The best way to determine the amount of ecological fingerprint of a city is to know the amount of consumed food, water, material goods and energy in a bioregion, particularly the assessment of bio capacity of the ecosystem. According to analyses of Wackernagel humanity increase the creation of waste in nature in terms of the productivity of bio capacity by $70 \%$ in 1961 to $120 \%$ in 1999. According to Living Planet Report 2006 by World Wide Fund for Nature, Zoological Societu of London i Global Footprints Network, shows that global

\footnotetext{
12 Peter Newman, Isabella Jennings, Cities as sustainable Ecosystems, principles and practices (Islan Press trademark of The Center for Resource Economics, Washington, 2008) Chapter 5:Modeling Cities on Ecosystems, 103
} 
environmental prints amount to 14.1 billion global hektars or 2.2 hectares per person of the global area in 2003 , while capacity produced bio 11.2 billion hectares of the world's surface , or 1.8 hectares per person. This means that waste has exceeded production for biodiversity 2.9 billion acres or 0.4 hectares per person.

Ecological prints are increasing daily with population growth for each new resident. Despite the fact that cities in such condition may become too small for its inhabitants, the analyzes show that in large cities there is less use of resources per capita than in smaller cities that have the same population density. This is due to the level of economic development and better public transport, and the fact that higher density leads to greater efficiency in the use of energy. Ecological prints dependents of population growth, on the one hand and are in direct connection with transportation energy on the other. This interdependence is confirmed with the fact that the high percentage of fuel use associated with population density. With the urban expanding of the city, increases the ecological prints. As a result there is increased traffic, which is directly linked to air pollution, noise and vibration. Furthermore, for the creation of new space, forests are cut and farmland and open areas are reconverted. Rivers in the city turn into drains of urban waste water and solid waste often delayed in landfills near cities.

Homeo-sphere is a sphere of human life, in which cities were dimensioned in the past that included distance that a person can walk, ie radius of 10 minute walk or across of 1500 - 2000m. With this measure, man is able to control and "possess" elements of the environment. On the other hand, the basic physical cell of a human community is ekistic unit that unites all functions: economic, social, cultural, religious, political and other needs and interests. Ekistic units contain a number of residential units that would provide housing. The physical structure of a settlement depends on it.

Once we are able to focus attention on the individual as a measure for shaping human settlements, we might say that ekistics establish the best possible balance between man and the physical structure of settlements; man and society, on the one hand, and the nature and settlement that created the man on the other side. ${ }^{13}$

One township seeks to establish because of the needs for its parts to connect and generate physical functioning whole. Originally first is set up public space, normally with circular shape (square) which with centripetal force distributes the remaining parts of the area. Thus form a prototype of the township with central square and radial streets that set as a model is acceptable for a city that provides conditions where prevailing pedestrian movement. Arrange the pieces of the city depend on the type of traffic, the journey time from one part to the other, and the cost of that transport. If in one space is entered highway or rail transport, then shape the city becomes more complex given that parts of the settlements concentrate on major roads or incline near them. Cities today are made up of old urban cores

\footnotetext{
${ }^{13}$ Konstantinos Apostolos Doxiadis, op.cit.,30
} 
with its population of natives and a host of new residents who either live in peripheral towns and suburban neighborhoods, or in the interstices of the neighborhoods and downtown or fills poor parts of cities and ghettos. In such a structured city there is a special and new lifestyle which involves reduction of public life, lack of culture, visual monotony and time spent in traffic communications.

The process of growth of cities is cumulative and permanent, and when once started it is difficult to set reversible. The limit of growth is based on the analysis of the total area of the city in terms of energy consumption and quantitative terms of the number of population by day and night. The limit of growth of the city means expansion of the city in terms of developed capacity of urban environment. Sustainability is an important factor in this process and appears in interesting shapes like: stabilization of high population density because of good transportation system; local bio- regional infrastructure; urban villages; modern system of local consumption and local economic development; networks of cooperation between local government business environment, population, environmental science, and social insurance policies and regional depending bio urban and rural communities. (Fig. 3)

There are three key elements relating to the limit of growth:

- The first element refers to the existence of aftershocks that are both positive and negative. When they are in balance the system is stable and if there is a predominance of either of them result in system instability.

- Another key element is the existence of resources such as agricultural land, for example, whose function can be attacked by erosion as part of the functioning of the system. Resources can restore its function. Recovery rate depends on the rate of degradation caused when limits are lost.

- $\quad$ The third key element is the global economic system composed of subsystems. It requires changes in some individual sectors, such as energy and agriculture, to be tied to changes in all other sectors. The solution in this case is impossible if is not affecting in other sectors, as well as address the consequences in all sectors.

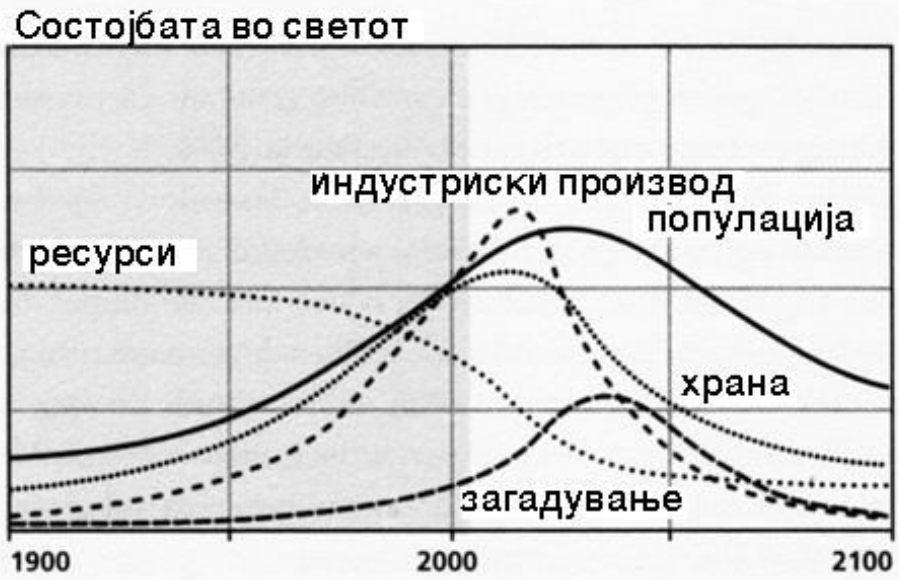

Fig. 3 Diagram of the limits of growth in the world

A Comparison of the Limits to Growth with Thirty Years of Reality by Graham Turner, http://pabitraspeaks.com/limit-to-growth-and-beyond-part-1/ 
Before the first appearance of reports on the limits of growth in 1972, there were slightly analysis on the actual situation in the world and reports concerning the development and technological objectives and models. According to the initial reports the world has its collapse to achieve to the end of the 20th century. Some modules of simulation models as limits of growth suggests that over a period of 250 years (ie around 2195 ) human population and many other living species will die out. ${ }^{14}$ In reality, the boundary of growth ending in 2100 and simulations suggest that humanity will not be destroyed, but will result in dramatic changes. Joncovici ${ }^{15}$ gives good scenario for the limits of growth where used data : population, birth rates and death rates, terms and services per capita ,food per capita, industrial products per capita, non-renewable resources and the continued pollution $\left(\mathrm{CO}_{2}\right.$, heavy metals , radioactive waste, organic pollution, nitrogen and sulfur oxides and all substances that destroy the ozone layer). The same data is envisaged scenario for the "stabilization of the World" which presents sustainable global average per capita level of material goods and equality in other levels, with equal distribution in developing countries. Future prospective considerations guide the direction to build new residences on the land which will be re-used, especially in those small towns that develop specialized. Populating the suburban and rural areas is particularly interesting for middle-aged residents provided with work and a family. With good traffic connection to work those areas provide better conditions for quality of life with the natural environment. The city centers remain to live elderly and young migrate using the services of the city for their own education, which inhabit small residential units. If this category of young people encouraged staying with the construction of the city centers will significantly boost the process of compact cities.

In the whole process planners have significant place. Planners need to know to assess whether the development of an area may be sustainable and with which goes to the most sustainable urban form, and knowing what type of intensity can be the most sustainable in a specific location. It is particularly important to anticipate the limits of development and methods for determining capacity. Charles Landry ${ }^{16}$ recommended several guidelines that should be followed:

- The city should not be trying to be the most creative city in the world, but should be the most creative in his world. This means that every place has something special that can give;

- The city should highlight local cultures and characteristics, but also to be open to the outside world;

- The city should involve ordinary people in decision making in order to place something unusual;

- $\quad$ City need to learn from the best global practice and not just with copying but with their own creative adaptation of these examples;

\footnotetext{
${ }^{14}$ Moffatt, 2001

15 Joncovici, 2003

${ }^{16}$ See the: http://en.wikipedia.org/wiki/Charles_Landry, ( Charles Landry, The Creative City: A Toolkit for Urban Innovators, (Earthscan, London. 2000) ; The Art of City Making, (Earthscan, London. 2006)
} 
- The city needs to look at its economic projects as added value to the local community and environment;

- $\quad$ The city should use its imagination if want to maximize its potential;

- The city should put up for public inspection all public goods resulting from the identification of the site and surroundings.

One of the key things about the city is sustainability organization on its core functions: housing, work and leisure. The development of the use of land so far in the foreground puts element of housing for the assessment of quality of life. Integrating other activities in residential areas could result in more rational use of land, and in densely built urban areas can be developed non polluting light industry. The city can provide restructure-development plan policy, market- oriented public sector, reasonable density of development, creation of new classes of land use and development of mixed uses.

Cities represent environmental phenomena of the 21st century. At the beginning of last century, the city represents a significant spatial potential for economic development.

With the advent of the 21st century, for the first time in human history half of the world population, which is more than 6 billion inhabitants, lives in cities. The way urban need for food, water, shelter and social organization are met, not only will determine the course of human civilization, but many more will determine the future of this planet. ${ }^{17}$

Cities must establish a clear link with bio region which is the only place where "there is life" where are more precisely defined the natural, geographical, climatic, hydrological and ecological boundaries with characteristic flora and fauna and the specific and topographic structure. To solve the problems of the city and surroundings need new ideas for living in harmony with nature, change the conventional ways of thinking and change of human activities. These changes would mean a change in systems of production through industrial transformation, a change in living people's attitude towards the phenomenon of sustainability.

\footnotetext{
${ }^{17}$ Lois Sweet, Healthy cities for the urban century (International Development Reaserch Center Briefing No.4), http://www.idric.ca/wuf/ev-25775-201-1-DO_TOPIC.html.
} 


\subsection{Treatment of the ecological aspects through the historical development of cities}

For most of the early civilizations nature was force to which people are related with fear and respect. ${ }^{18}$ The man begins to live in the city about 8000 years. By then a man's life was connected to the village which fully satisfy common needs. The main feature of the cities of the past is static. Cities were built within the city walls. Even at the time when the walls are losing importance of defense, the cities retained their static. When cities were expanded under certain influences ${ }^{19}$, they were expanded not dynamically, but were examined their size and changed in some critical historical period when the city changed its functions or its meaning. They were small towns with a few thousand residents. What is important for these cities is that existed a balance of all the elements that make up a township, a balance between the natural and landscape features, functions and physical structure.

The city of the past, despite being static and small, had a very simple structure where to man its citizen - allowed to grasp it easy and to move without difficulty in a way that matched all his needs and adequately manage the life city. ${ }^{20}$

After the great scientific discoveries from the 16th to the 18th century, Western society with its developed economy began to believe in the illusion that nature can be processed through technology exclusively for commercial benefit. This leads world to techno cetrism, which destroys the previous mutual relationship between humanity and nature. Strong urban expansion of cities occurred with the appearance of rail, and already in the 19th century, cities are beginning to spread rapidly. Thus the basic feature of the city to be static disappears and appears dynamic city. It is a parallel process with which also follows rising population in cities. ${ }^{21}$

Man in the primitive village community lived in harmony with nature, living from nature, but allowing the nature to live. City civilization with industrialization has changed the relationship of man to nature: it imposes entitled to conquer nature (Bacon, 1975) to know how use natures rules, in order to convert them to use for itself. Thus starts to ruin and destroy and its devastation today know no bounds. ${ }^{22}$

The civilization in which the world lives today is marked by large cities. The dimensions of these cities are "superhuman". Now the city has no one center, but more of one. Modern cities are systems of cities that dynamically grow and absorb additional population.

\footnotetext{
18 There are two ways in which towns historically developed. The first is the natural way in which people just starting to build and the physical structure creates and develops spontaneously. A second way is artificial, where the city is built under a previous scheme of streets, squares and urban blocks, where objects are inserted by the sense of order from the planner.

${ }^{19}$ Expansion of Athens influenced by emperor Hadrian, or enlargement of Konstanitinopol during the reign of emperor Justinian

20 Константинос Доксијадос, Човеки град (НОЛИТ, Београд, 1982), 279.

${ }^{21}$ Athens lasted about 3000 years with less than 50000 inhabitants and in the last 100 years the number of residents increased by 2 million people.

${ }_{22}^{2}$ Руди Спек, Град по мјери човјека (ИТРО, Напријед, Загреб, 1987), 75.
} 


\subsubsection{Pre industrial period}

The cities of the past were organized in a simple and natural way. First were homogeneous, complete and very small. Until the 18th century, no city in the world had more than 50000 inhabitants. With so small population and no technical means of transport, the size of the city is spread on a length greater than $2 \mathrm{~km}$ length or distance that person with walking can reach for twenty minutes. These cities were therefore tailored to the man. Man felt free, developed attitude toward construction and expressed feelings toward the city, established intimate relationship with the place. The architecture of the civilizations that lived in one place rarely been responsible for environmental problems often caused them conquerors. Residents of the city their life adapted to the conditions of the natural environment, and any single pollution of drainage water and sanitary waste.

The earliest archaeological records of civilization developed in agriculture, landscaping and political center with developed trade belong to 8000 BC Jericho. The culture that has developed in Jericho had developed a sense of its environment, which used the natural riches. There was irrigation system for watering that enabled sustainable balance between the land which is cultivated and other natural vegetation. When Jericho came under the Sumerians in 3000 BC city experienced environmental cataclysm. In order to get a larger area for trading, system of canals was demolished and moved to nearby land by destroying vegetation. In a short time, due to heavy rains, erosion occurred which filled the canals, and the water has been contaminated. Soon agriculture began to decline, leading to an economic crisis and decline the whole culture. These scenarios follow the history of civilizations, which is clearly shown in numerous archaeological remains in urban areas.

Oldest ecological thoughts, notes and views of the world come from the writings on the Sanskrit alphabet in Sumer and Babylon, especially taking into account the purity of drinking water and the way it should be purified with boiling fire, warming in the sun or potting the heated iron into it. Egyptian civilization in the period from 4000 to $2000 \mathrm{BC}$ developed its own irrigation system and using the periodic behavior of the Nile and as agricultural land used fertile soil that was flooded by the river. There had been made land drainage, diversion of water channels, built bridges, dams etc... The facilities were built as shelters and closed House using natural resources of climate, the need for ventilation and protection from the sun. Impact of Middle and Far East in these ancient times of human civilization is great. From Mesopotamia is dating the first written document of principles and rules for construction of cities. The Epic of Gilgamesh, mythological hero, gives the principles of building cities, and particularly highlights the relationship between built with the green part, and the city links with its surroundings. ${ }^{23}$ Sumerian civilization had a major impact on cities in ancient India and

\footnotetext{
${ }^{23}$ Characteristic of Mesopotamian cities is that among them for the first time is met a regular draft plan related to the division of land, and the position of canals for irrigation and drainage. Since that time is preserved plan for city
} 
China. According to their beliefs, life is a reflection of unlimited natural harmony. It is particularly interesting that in ancient India there were books dedicated to architectural theory and construction of cities. Such treatises are Manasara or Shilpa Shastra; where 70 heads contained detailed descriptions of the construction of villages and towns, and with the same attention are shown ways of explore the selection of territory and the most suitable place for the construction or location. In ancient China there were laws that protected certain territories as a kind of national parks. ${ }^{24}$

Natural geographical factors are one of the main factors that influenced the creation of the ancient city. The first urban settlements occurred in areas with favorable natural and geographical conditions for existence of people with primitive tools to work, ie where there was a possibility of direct water use and water power for irrigation. It was a period of strong urbanization of certain parts of Ancient Greece and it is the first time in the history of European soil to develop the theory of architecture and building cities. Greek philosophers interested in the questions how to build an ideal city - state, according to those records are built numerous cities and colonies on the Mediterranean coast. Greek civilization and culture also plays a significant role in anthropocentrism. For them the center of the universe is the human mind what lies at the foundation in philosophy of Western civilization where man is placed over nature. There are numerous of records from old ancient thinkers and philosophers such as Hipokrit, Theophrastus and Aristotle, further Lucretius, Virgil and Kolumela who wrote the laws that ruled the ancient cities and that particular care about the different environmental situations such as control of the degradation of the waste of certain trades (silversmiths, blacksmiths), noise regulations etc... Aristotle says that the main goal of creating human settlements is to provide happiness and safety of their residents, or human settlements must be "human" and for its content and quality. According Hippodamus, the ancient city states should have 10,000 residents and the city to be organized in orthogonal scheme, the method that was perfected by the Romans. This method puts the two main streets normal to one another. ${ }^{25}$ What is even more important in the geometrical method of city planning is not so much its geometric accuracy, as in the aspects and climate characteristics. There is written evidence from Hipokrit where suggests that the healthiest orientation is east, and if this orientation can not be achieved, then it is recommended south orientation of the buildings.

Especially notable are the writings of Vitruvius, which is the most important ancient theorist of architecture and urbanism through with his ten books on architecture, ie the first

Nipur by the river Euphrates, presumably 1500 years BC where there was one of the Seven Wonders - Hanging Gardens of Babylon, which confirms the cult of greenery.

${ }^{24}$ A similar prohibition existed in Inca who forbid access to the island Guano the period when nesting birds produced exceptionally good fertilizer.

${ }^{25}$ One street has east-west (cardo maximus), and the other has a north-south (decumanus maxsimus) 
systematic attempt to present the principles of urbanism and architecture. In those records, he paid attention to the technical equipment of the cities, especially devices that hygiene infrastructure as the first set in planning and building cities.

Open (average) space between porches are decorated with greenery, because walk on such space is very beneficial to health, especially to the eyes ... you need to build a very wide and beautiful promenade. They should be constructed so as to be always dry and clean. ${ }^{26}$

This suggests that we should take account on what kind of land will set the city in order to prevent disadvantage on health.

Firstly is the choice of quite a healthy place. It should be elevated without fog and frost, oriented to the sky where neither is hot nor cold, but moderate. ${ }^{27}$

He was considering the natural environment, observing the entire wildlife, quality of drinking water, the buoyancy of the rivers etc...

Architects need to know medicine, why because inclination of the sun, the Greeks call "climate" air in the area can be healthy or polluted, also to know about usability of water, because without these conditions can not be build any healthy neighborhood. ${ }^{28}$

With the strengthening of Christianity in early medieval, philosophy and science of Ancient Greece disappears. Atomism and analytical skills become dangerous for the church and its notion of the world, where it celebrate the spirit of holiness and control the masses. Medieval in humanity is period when there is separation between man and nature. From the man was not expected to take care of nature, but only to worship and glorify God according to the rules and wishes of the church. In his book "Religion and the Rise of Modern Science" Reijer Hooykaas author explains the key role of the Lord:

The Bible knows nothing of "nature", known only to the "monster" that is absolutely dependent on the origin and existence of the desire of God. In connection with that the nature is adored as God's work and as proof of the existence of the Creator. ${ }^{29}$

Byzantine Empire was formed with the disintegration of the Roman Empire and Byzantine cities in large part represent a continuation of the ancient city. The best model was city Constantinople by Constantine the Great in the 4th century, which was built up and spread without a plan, but under Islamic influence, without building zoning . From that time is known Zeno law where despite regulations for width of streets, number of floors of the buildings etc ..., provides strict regulations concerning the utility and hygienic arrangement of cities. Byzantine cities accepted types of oriental palaces with both internal courtyard atriums decorated with rich foliage, and presentes for the first time a spacious public parks as a new urban element. In the Middle Ages were written data which determine the laws and rules

\footnotetext{
${ }^{26}$ Марк П. Витрувиј, Десет книги за архитектурата, Прев. Љубинка Басотова (ЗУМПРЕС, Скопје, 1998) Книга 1, 49.

27 Ibid

${ }^{28}$ Марк П. Витрувиј ор.cit., 31.

29 James Wines, op.cit.,54
} 
governing for the disposal of garbage, sewage, septic tanks. It is known that in Byzantium during Justinian existed zoning of craftsmen, glass blower, metal processors and workshops for making weapons ... which have been displaced from towns to stop them to pollute the environment as a threat to human health.

Islamic cities are characterized by irregularity and informality. The rules for construction are directly related to the rules and principles of the Koran. ${ }^{30}$ It is particularly important to emphasize the environmental sense of the city's residents and caring for water, given the climate of Arabia. It involves collecting rainwater and drainage, construction of drainage channels and collection, the important thing is that any neighborhood can use water according to their needs. It also has built and separate drainage system for wastewater.

In Europe was created new feudal social system that gave special feature of cities. The first medieval buildings were linked to monastic orders. They form communities ${ }^{31}$ that are grouped around a monastery or cathedral. At the time of feudalism, the gardens were built in monasteries and churches, and often they were botanical gardens for growing medicinal herbs. The new urban culture nurtured many new towns developed around castles or blasted over old cities. Feudal European cities had small numbers of inhabitants, the largest and most prominent of 8-10000 people. Europe stood at about 30 million inhabitants in 1000 years, and the figure in the next 150 years has increased by $40 \%$. This increase in population meant increasing settlements. Thus fortified cities with a cathedral in the middle and defensive walls become narrow to accept new people, so was started with cutting the nearby woods and building settlement outside of fortresses, turning the land into arable agricultural land. As was city growing were formed more and more concentric rings around the central core, new rings were formed by streets and buildings along surrounded with new fortifications. ${ }^{32}$ Since 11 th centery until the 14 th century established European cities were becoming bigger and bigger centers of commerce, thus buildings were built with schematized content. There are no known written sources about medieval views of urbanism. However there are some records that indicate the relationship between government of the city and the natural environment and hygiene-health conditions in cities. One of the first laws for urban hygiene was adopted in Great Britain in 1388 years which prohibits the dumping of waste into rivers, streams and other waters. ${ }^{33}$ In Britain in the 13th century and 14th century are

\footnotetext{
${ }^{30}$ According to these principles there is a public street that is available to all (Shari) and smaller streets that are co-owned by all those who live along that street and moving them is limited (Fine).

${ }^{31}$ One of the first in Europe are Irish monastic communities

${ }^{32}$ Sophisticated medieval fortified cities were bastille. These are cities that have formed within the royal palaces and estates. Bastille were built around the established churches were organised rectangular in plan with dimensions $400 \mathrm{~h} 220 \mathrm{~m}$. It is essentially a network plan with five parallel streets and alleys normal four of them.

${ }^{33}$ There is also a record year of 1348 years where it notes that cholera spread through medieval Europe only because of the bad sewage system that was below the standards of those from ancient Rome, because the wells that gather and clean drinking water were lower than septic tanks. Also street drains were opened and entire sewage flowing through the streets which were seldom been paved, so here wastewater and rainwater is mixed with the faeces of domestic animals.
} 
seen protests against the use of coal combustion creates smoke that pollutes air. In the late medieval period, specifically between the years 1241-1669 years were formed a so-called Hanseatic cities. ${ }^{34}$ This association forms a multitude of European cities, including 90 in London and Brussels, Bergen and others. Hanseatic cities sorted for trade, and in his physical structure containing approaches, roads and streets that have been adapted to the movement of traders, warehouses were seeking special requirements for construction and special hygienic and technical conditions for the storage of goods, and a host production workshops.

During the Renaissance comes to humane treatment in the new social order, and it brings a new attitude to the environment. The Renaissance is the period of $1300-1600$ years, it frees the human mind from medieval dogma and there is great interest to the ancient culture and art, and therefore new concepts in architecture and urbanism. In Florence for the first time after ancient period, buildings were built with equal heights, right squares, churches with domes etc..., and also was planned every part of town. Renaissance planning begins and is marked by the great theoretician of architecture Alberti who notes: "... if the city is a noble and powerful, streets should be straight and wide, which will bring an air of majesty and size ..." Alberti, following the example of Vitruvius, created his ten books on construction, which examines the relationship of climate and natural conditions, the choice of the site for construction, recommendations defense of cities, construction of streets , bridges , canals etc... He writes for the functional breakdown of the city, more precisely about separating the housing from production zoning primarily for hygienic health reasons. Alberti favors constructions built in greenery and fresh air. He conceptualizes towns as comfortable and functional housing, with spacious squares and separate areas for crafts that pollute the environment: blacksmiths, leather tannery etc... Alberti emphasizes further that orthogonal streets are beautiful but not human, because during the winter is exposed to winds that are unpleasant for people who walk on them or whose houses are along them, until during the summer make the city warmer since that above them are not hanging shadows of objects. Again was revived the design of the gardens during the Italian Renaissance and thanks to Albert who in their records of the year 1450 years pointed to the significance of the relationship greenery and architecture.$^{35}$ Significant is the work of 25 books about building who wrote Averlino called Filarete. He was the first man in the history that draws the city in the form of octagonal star. ${ }^{36}$

\footnotetext{
${ }^{34}$ Named the Hansa, which in fact was an association of German merchants of Lübeck and Hamburg.

${ }^{35}$ Theorists in the renaissance urbanism contributed most to develop the concept of radial city center with distinct core, though not to neglect any ideas Filarete for linear city and Leonardo satellite cities, which will reappear 300 years later.

${ }^{36}$ The city has a plan in the form of octagonal star, also set by the eight winds, with towers at the angles of the star city gates and entry of internal angles of the star. In the center is placed a rectangular plaza with cathedral on
} 
Leonardo da Vinci occupies an important place among theorists of the Renaissance ideal cities. The drawings for the reconstruction of the ideal city of Florence are inspiring even today. He for the first time in the history of urban planning worked plans of entire provinces from aerial perspective. Interesting are entries of Leonardo da Vinci that provides multiple levels of roads and under road channels in order to reduce noise, so pedestrians would move at the highest level. It is the first time in history to predict the separation of traffic and even at different levels.

Baroque adopted park as an urban element in the city or its surroundings. Baroque cities are characterized by systems of straight and broad streets etc. avenues and boulevards as the main axis of the city from a compositional point to another. The space between the objects increases. Aveniite represent axes that lead to squares where set fountains or monuments. Often at the head of the axis were formed palace that permeated garden with impressive sizes, pools and fountains. From one center city gets more and appear polycentric plans with its squares and important buildings.

French urban thought in classicism, not only keeps centric scheme, but appear more complex compositions of interconnected squares. Ideal in the epoch of classicism was a plan with straight streets (the ancient ideal of the city). Diderot and D'alembert were written for it. Utopians are those who first began to consciously think and write about building cities, not only as a physical structure made up of streets and buildings, but as a human environment and social groups. The ideas of social utopians are from a time when capitalism was in its infancy and has no environmental problems with such as scale today. First among them is Thomas More in his book "Utopia" , which poses several important questions concerning the optimal size of the city with a steady network that will allow servicing and connecting the various functions of the city. Writes about the ideal society without classes in which he passes the idea of a clean environment on the island of Utopia. The buildings would be at three floors as best number of levels in residential spaces for each family and set in green gardens.

Thomas J. Campanella with his work "The City of the Sun" ${ }^{37}$ talks about the town placed in well sunny areas in seven circles. Owen writes about cities that communities will have 2000 to 2500 people , and commune lies on a square terrace with facilities on the rim of the terrace, as the interior remains free and serves for vacation, where there should be a public bath and greenhouse. These ideas he partially achieved in the settlement New Lanark in England. The buildings of the settlement are located in greenery. Similar considerations have

one side and on the other bank. Among them there are other public buildings. On the ground floor the streets and squares are defined by colonnades.

${ }^{37}$ The buildings would be constructed with structures of walls and floors that actually are murals which have recorded the whole human knowledge and phenomena in nature, as a screen linked to the information, which resembles today's Internet access. 
and Charles Fourier who criticized the shortcomings of the cities. He provides high buildings "falansterio" set in foliage or forest. The building has a common room, and the jobs are in the vicinity of buildings housing so that residents could be dealing with agriculture and crafts in the nearby natural environment. ${ }^{38}$ In particular it should choose the location that needs to be terrain by the river. This settlement has to be built in three concentric zones mutually separated by green areas. Although, many of the ideas seem naive, utopians however have significant contribution to the development of theoretical thought about the city and many ideas are still waiting to be embedded in the organization of some future human settlements . Failure of socially utopians is that at the city they were looking as a separate model, and ecological thought were accomplished by entering of the foliage.

\subsubsection{Post-industrial period}

Industrialization that started in the 18th and 19th centuries modify environment like no other period of human existence. James Watt in the middle of the 18th century, precisely in 1784 in England, creates steam engine with twofold effect. The steam engine has placed factories in the cities and the places that had a sufficient amount of coal and water to produce steam. Changing the system in a bourgeois-capitalism leads to a change in interpersonal relationships and even greater pollution.

Industrialization, the main creative force of the 19th century, created the most skewed urban complexes that the world has ever seen. Even the quarters of the ruling classes were overcrowded and dirty. ${ }^{39}$

Industrialization leads to increasing population in cities, especially immigration of workers who lives in unsanitary conditions. ${ }^{40}$ Also, the development of cities in that period is random, so that they are overpopulated cities. The main aim was industrialization and rising production, but also appeared first environmental problems, which cause reactions in the first theorists of urbanism. ${ }^{41}$

In 1800 London becomes the first city of millions worldwide. The settlements are growing and complicated. Dependence of the city from the village decreases, so people are attracted to the idea of living in the city that causes a rapid increase in cities and population density in the same. The development of science and technology caused industrial revolution that

\footnotetext{
${ }^{38}$ Each such community would have 1620 people or 810 doubled exactly as they are extensive classified human characters.

39 Д-р. Мара Џукановиќ, Еколошке димензије у изграџивању простора (од книгата на Мамфорд Луис “ Градот во историјата", Sine loco, 1984) 17

${ }^{40}$ It is due to the rapid spread of typhus. The workers lived in closed streets and yards, without enough light, air and water of poor quality. According to data from 1864 and 1865 in the UK were spread various diseases: smallpox, typhoid, cholera, scarlet fever.

${ }^{41}$ The appearance of Darwin's theory of evolutionary development and relations between living organisms through the food chain meant also the appearance of the ecology in the year 1868. Infringement of that dynamic reciprocity releases effect of self-destruction hidden in every living being.
} 
challenged the relationship of man to nature has ordered to the benefit of man. The entire progress is focused on the exploitation of nature and its resources without recovery and reproduction. Begins emerge pollution problems of air and water, destruction of nature and resources. The changes are numerous and occur faster. All these changes alter the shape of the city that reflects its function, its landscape, but also its inhabitants. Railway and automobile traffic appears. Improved transportation vehicles that moves faster than humans change the look of the city. The new capital thus obtained parameters and scale according to a new matrix of moving traffic means ranging from $5-200 \mathrm{~km}$ per hour. The structure and shape of the city should respond to emerging infrastructure needs and permanently to upgrade. Industrial cities are developing rapidly, especially in Europe. Cities that had previously accounted populated by 100,000 residents grow over 5 million, and already after 50 years that figure reach 13 million. Parallel is occurs the concept of zoning of urban areas. It means anticipating the correct data in figures and deadlines as a territory would be urbanized. Thus were exercised overlooking of New York which has to collect 77 million with a density of 4,000 inhabitants/hectare, or Chicago with a number of 5500 inhabitants/hectare land. Such zoning has considered the city as a surface structure in order to perform more intensive use of land for construction. ${ }^{42}$ Hectic growth of industrial cities causes theories that advocate the introduction in city laws and regulations for building, and even police for building. Before the end of the 19th century, to urban development legislation and the art of designing cities, appears the theory to big cities, but also anti urbanism theories that reject the idea of a big city, which has led the world in the 20th century to crossroads of ideas and theories for a big city, small town, optimal city, anti city etc...

Cities throughout the 20th century reaffirmed its complexity, which is characterized by loss of the ability of residents of synthesized understanding of the elements of the city. The evolution of the city cause loss of balance with man.

On our way to the extreme specialization for the problems how working the settlements, we neglect the basic reason for which settlement occurred: human happiness, the happiness which man finds the balance between self and other elements of their neighborhood. ${ }^{43}$

In the early 20th century urban planners and architects are already concerned with the growth of cities especially with the appearance of cities in the future. Large industrial city became a real phenomenon as a system of settlement. Tram, metro underground traffic system, the first lift etc.., were appeared, which shorten travel time for city residents to home or to the workplace. In 1910 in London held a conference that examined the problems of urbanism and Eugène Hénard in his scholarly work "City of the Future" specifically highlights

\footnotetext{
${ }^{42}$ Closing stages in the development of European theory to regulate the city in the 19th century gives Viennese architect Otto Wagner who along with Shtiben works on Reconstruction of Vienna. It means the end of the academic urbanism that has long matched the aspirations of the bourgeoisie.

${ }^{43}$ Доксијадис Константинос, ор. cit.,23
} 
the impact of the development of science and technology to the future development of cities. In 1922 however, the Paris Autumn Salon, Le Corbusier, Auguste Perret and Jeanneret show their city of 3 million people of which 1 million are located in the city itself, and 2 million in the green suburban area. The basic principles of this city of the future were in the removal of the perimeter building blocks by city streets formed corridors, increasing the density of development in the city center, and thereby increasing the green areas by building towers skyscrapers in greenery and classification of traffic and movement in several levels. In this direction are the ideas of Le Corbusier and his "Radiant City". The conception of the city is such that the city is developing along a clear axis whereby certain areas such as housing , work, recreation center have spare spaces to expand their normally axis. Auguste Perret predicts skyscrapers, so called, cathedrals of the modern city, where Paris would be a green zone with a width of $250 \mathrm{~m}$ where will be built 100 skyscrapers with 300 apartments.

In 1928 is maintained International Congress of Modern Architecture CIAM which is set the basic principles of the organization of urban space, thus urban planning should lead basic city functions: housing, work and leisure into harmony to each other. In that period, the main culprits of pollution were factories and the charter requires their isolation from the green belt housing. Each object must be set in the greenery to get sun, air and space, besides provided space for parks, forests, sports fields, stadiums, beaches etc...

After the Second World War appear multitude of theories relating to metropolitan and megapolisite. One of those projects is the project of Kenzo Tange for expand theTokyo Bay residential complex by built 5 million of the spiked at the depth of $8-15 \mathrm{~m}$, where the radial network of communications of Tokyo will be replaced by a single linear street scheme, that has to successful unification of spatial structures which are separated among themselves and to encourage the mobility of the population. The mobility of the population requires more modern variant features of the plan, which is symbolically called Metabolis.

Parallel with theories about the development of cities as giants cities, were evolved thought about small cities or optimal towns. ${ }^{44}$ Best idea passes Ebenezer Howard in the book "To-morrow: a Peaceful Path to Real Reform", (Garden Cities of To-morrow) where for the first time he joined several urban concepts from different eras, and retains the positive ideas and rejects negative. ${ }^{45}$ According to the ideas of Howard later English urbanites Raymond Unwin builds first garden city Letchworth and suburban park neighborhood Hampstead in London. Concept of cities gardens wielded circular shape with radial and concentric scheme of star image streets, central park in the city and around the circular zones of social

\footnotetext{
${ }^{44}$ Antecedents of this idea existed since ancient times when Plato spoke of a small town with lots of greenery in and around the city. Furthermore in the 19th century to the idea incline Claude Leduc, Buckingham and Robert Pemberton.

${ }^{45}$ This mainly concerned the project City of settlers by Professor Marshall, land use project of Thomas Spence and the Sample town of Buckingham.
} 
buildings, palaces and circular zone of residential building with green zone and education facilities. Welwyn Garden City in England and satellite towns around London as Harlow and some others are built on that way.

Particularly important are the concepts of zonal towns as Sozgorod by Nikolai Miljutin where is applied the principle of the linear zoning, more precisely oneway zoning functions of city traffic, industry, green zone, housing, area for rest and recreation, utility area, administration and traffic again at the end. Linear suburbs are built around Madrid and along its railway. Thus are developed suburbs Soria and Mapa, which are located at the main railway line to Madrid.

In the contemporary urban thought, especially to what sustainable development means certainly is significant Frank Lloyd Wright with his spatial concepts town the Broadacre City and ideas of organic architecture. He is representative of de-urbanism theories and provides decentralization of American capitals by the major traffic arteries and integration of that system of settlements by the arteries themselves.

Notable is his opinion on the architecture of modern America:

Here there can be no organic architecture until you create an organic society. We can build several buildings for those who understand what we we consider under organic, but we can not create the present architecture of such a society like today.

In his projects he use the full potential of the building to make a sequel to its natural environment in terms of creating forms that are a reflection of the contours of the topography of the environment and use of materials derived from the region. He also connects the functional role of architecture with the processes which are taking place in nature as a parallel to human behavior; in a way like man has needs of light, darkness, protection, selfcare, etc... He is a pioneer in what is called "organic architecture."

The world today is perceived through the mass media: television, film, computers ... The search for post-industrial architectural language in the past two decades leads to a complex and unclear expression. The new era of information and information technologies creates a need for new ideas and concepts for the building environment, which requires a radical change in the iconography of architecture and urbanism today. Today's postindustrial era begins in the late 60 s of the last century where Po-Mo movement rejects modernism as retrograde and inhuman architectural tradition, but the alternatives offered are not as prevalent as those criticized. Today in the world working multitude architects whose buildings are innovative and distinctive. At the same time a number of avant-garde movements oppose such developments architectural thought. In 1990 more begins to actualize sustainable development that is slowly but surely includes planners. And it would be good if planners would know their boundaries defined action. Now is important for most of the planners to determine the urban form for the future, which form will be affordable and sustainable. The 
models should be investigated to the possibility of implement in social groups and to have the opportunity for create sustainable urban environments that will last for years. Even the "green movement" that began in 1990 is now in danger because of its commercialization through the houses with a garden on its roof, heat pumps use and potential friends of the Earth. If a style means the product of identification of the epoch, then 90's are in time when the architectural elitism which relates to sustainability and the environment. Today architecture has a single purpose, to make a step from "ego-centric" to "eco-centric".

Sustainable architecture is reduced to three conditions - first is to foster motivation for survival with nature, secondly, to build shelters so that ecological principles will be part of their objective, and third, to point out the deep philosophical conflict which asks do we really deserve the luxury of existence in which we acknowledge the use of the environment. ${ }^{46}$

This moment in the architectural evolution means transformation of mental awareness as separate living isolated from the natural environment to be replaced with the awakening of consciousness and a sense of 'oneness' with nature.

\footnotetext{
46 James Wines, op. cit., 20
} 


\section{ECOLOGICAL THEORY AND COMPARATIVE ANALYSIS OF THE MODELS AND SYSTEMS FOR SUSTAINABLE DEVELOPMENT}

\subsection{Diversification of ecological theories according relevance of the factors}

Ecology and ecological are terms that constantly mentioned as a theory and movement against environmental pollution and action to preserve nature. Ecology as a scientific discipline emerged in 1866 as a sub - discipline of biology by German biologist Ernst Haeckel. ${ }^{49}$ In the early 50 s was necessitated to define the field of study and it will be referred to as ecosystem. ${ }^{50}$ Ecology is a holistic science that synthesizes the system as a whole, which contains elements of various natural and social sciences. It is a multidisciplinary science for environment that unites: biology, medicine, geography, sociology, economics, demography and low ... where architecture, urbanism and planning are important parts of functioning ecosystem.

The fact that the environment is in danger and that the material and energy resources are exhaustible, encourages thoughts for solve environmental problems. There are numerous theories and models in the history for this relationship to environmental problems, so considerations are increasingly oriented to the phenomenon of economic growth, technical progress, population growth, consumption of food and raw materials, urbanization etc.

\subsubsection{Theories founded on relevance of population, social and societal factors}

A number of theories, opinions and ideas about environmental problems indicate the population as one of the main causes of the ecological crisis. More precisely causes of ecological imbalance lies in increasing the number of residents. Also, some theories point directly to the social order and international policy on environmental issues and institutions that will control and implement.

- Bentham's theory - This theory is set about 170 years ago as a theory of environmental protection in order to promote the production. Theory staged Edwin Chadwick $^{51}$, who was a follower of the utilitarian philosophy of Jeremy Bentham. Basically this theory states that the idea of creating peace and order among the poor workers will ensure the interests of capital, or providing better living conditions for workers means better health and labor, and with comfortable habitat will fosters employee morale. Although the

\footnotetext{
${ }^{49}$ Then under the ecology was appointed branch of zoology that deals with the relationship of individual animal species with their organic and inorganic environment. In the early 20th century ecology is increasingly concentrated in the middle of the living individual species and their mutual relationship in that environment. For this see: http://www.jstor.org/pss/1929981; http://en.wikipedia.org/wiki/Ernst_Haeckel; http://en.wikipedia.org/wiki/Ecology\#cite_note-Odum05-1

${ }^{50}$ Environment is called ecosystem or bio-geo-cenosis. The ecosystem is a complex system composed of living organisms and the environment in which they are in mutual causal relationship. It is a system of transfer of energy, matter and information. Different actions provide feedback mechanisms within the system to control the number of organisms and their growth. Д-р. Мара Џукановиќ, op. cit.,7

${ }^{51}$ For this see: Edwin Chadwick, "Chadwick's Report on Sanitary Conditions", (excerpt from Report...from the Poor Law Commissioners on an Inquiry into the Sanitary Conditions of the Laboring Population of Great Britain (pp.369-372) Made by Laura Del Col for The Victorian Web. http://www.victorianweb.org/history/chadwick2.html, 2009-11-08).

${ }^{52}$ Д-р. Мара Џукановиќ, ор. cit.,26
} 
idea is not induced by human reason, this theory still has some environmental significance . As such spurred the formation of the idea of creating green gardens.

- $\quad$ Population theory by Robert Malthus - Robert Malthus, English clergyman and bourgeois economist, in 1798 outlines his theory that the proliferating of the population is with its geometric progression, while increasing the production of food varies with arithmetic progression. Therefore, reducing the birth rate of the working class and other lower social strata are basis to overcome the problems. Although inhuman theory, the fact that advocates limiting population growth speaks for its "vitality".

- $\quad$ Theory of limit growth of global balance - zero growth - Appears 1968 in Rome by a group of economists, sociologists, geneticists, politicians and heads of research centers worldwide. The problem of environmental pollution and rapid demographic growth are problems that affecting the whole world and approach to their solution has to be global. A team of researchers from MIT (Massachusetts Institute of Technology) led by Jay Forrester analyzed the interaction between investment in industrialization, environmental pollution , depletion of natural resources, population growth and quality of life.$^{52}$ Rapid population growth and industrial development are in interdependence with nature which is limited. The pace with which started population growth and exploitation of natural resources and energy, already in $\mathbf{2 0 2 0}$ was predicted ecological crisis with a catastrophic proportions. Stabilization of the number of residents with leveling the birth and death; stabilization in capital investment by controlling the level of depreciation in respect of the underlying investment, reduction of environmental pollution, and so on... have offered solutions to environmental problems.

- Theory of organic growth - appears 1974 represented by Mihail Mesarovic ${ }^{53}$ and Eduard Pestel. Growth and development are addressed by "versatility" , which cost the various structural and functional environments. According to this theory, the world is divided into 10 geographical areas with different characteristics and differences in socio- economic structure, industrial development, pollution of the environment, the development of techniques that control processes in environmental, political and social development, as well as differences in the geophysical, demographic climate and so on ... features. Although divided world is in constant interaction, so in case of interruption that affect only certain areas at certain times, other areas are activated to help. Environmental problems are physically inseparable and unlimited, which makes unnatural division and realization of this theory impossible.

- Theory of geographical access - According to this theory only "geo-ecological" approach can give solutions to the complex problems of rational use of natural resources and environmental protection. The main connection is the interdependence of the state and

\footnotetext{
52 Д-р. Мара Џукановиќ, ор. cit.,26

${ }^{53}$ For this see: http://systemsbiology.case.edu/participants/faculty/Mesarovic.shtml
} 
nature, with planning based on optimal terms of socio-economic position of the state, society and nature.

- Theory of decentralization of social systems - Theory originated by a group of scientists from the UK that the solution of environmental problems seen in the decentralization of the social system. The individual in modern terms is separate and anonymous with no control of his behavior. People who live and work in an environment naturally have a greater responsibility for their environment. Ecological problems according to this theory it is possible to solve by the decentralization of environment that limits the number of residents, by limiting the development of technology and industrial production, by improved hygiene settlements, by increasingly using knowledge and by used the results of scientific research. Economic growth has been stable at a certain level of development, there is limited food production, limited consumption of energy resources and managing them is according to the available reserves.

\subsubsection{Theories founded on relevance to energy resources and technological development, and economic and environmental (un)balance in cities}

A number of theories suggest technology, engineering and development, as well as depletion of energy resources, as factors that disrupt the balance in the ecosystem. In another group of theories, economic growth, interests of capital not taking care of the interdependence of the elements in an ecosystem, wherein occur consequences of environmental degradation.

- The theory of Rachel Carson - Rachel Carson ${ }^{54}$ in 1952. indicates the dangers of excessive use of pesticides. She advocates greater scientific research and information on the effects and consequences of the application of pesticides. Although only applies to the impact of pesticides, this theory is important because it examines complex ecosystem and disturbance of the balance of its elements the use of pesticides.

- $\quad$ Theory for the price of economic growth - appears in 1967 . Mishan ${ }^{55}$ by claiming that the economy, the production and pricing of the products is not included in calculating the damages caused by that product or pollution that occurs in the living environment as a consequence production. In such circumstances, instead of the desired growth is happens declining social status.

- Theory of transforming of the international movement - is emerging as a critical analysis of world economic trends whereby the main problem points to the unequal distribution of wealth between rich and poor nations. In addition, the proposed political and economic reorganization of the world in the form of international solidarity where every

\footnotetext{
${ }^{54}$ For this see: http://www.rachelcarson.org/

${ }^{55}$ For this see:

http://books.google.com/books?id=d0ZG9yzlsOsC\&pg=PA18\&lpg=PA18\&dq=miSHAN+1967\&source=bl\&ots=xE 0wyvgGIZ\&sig=BjTzqe34I8v8vutE8xN1kIwT2Fk\&hl=en\&ei=CGuPTND7Jc_FswaY1e3mCw\&sa=X\&oi=book_resul t\&ct=result\&resnum=2\&ved=0CDcQ6AEwAQ\#v=onepage\&q=miSHAN\%201967\&f=false
} 
developed countrie should allocate each year $2-4 \%$ of their national income to poor countries for food, education and housing.

- Theory of a permanent state ${ }^{56}$ - based on the energy approach in the analysis of socio - economic problems. These problems stem from the energy resources of the planet, their limitations, the way they are used and the possibility of their exhaustion. This theory doesn't forecasted size of future development, but limit the growth with the limit of exhaustion of natural resources on the planet. It implies that technical and technological growth is possible in form as much as there are stocks in the energy sector. This theory introduces a mutual relationship between energy, economy and ecology, and in the field: energy storage, reducing the amount of energy and maximum efficiency in use of energy sources.

- Theory "level of living " - For this theory the reason for the poor state of the environment are the methods of managing economic development. This theory stems from scholars of socialist countries under the "level of living " means: measure and character of recognized social needs, the level of satisfaction of those needs and socially recognized conditions for their satisfaction. In addition of that, one of the basic needs that have to be satisfy is a need for quality of the environment, even if necessary at the cost of reduced economic growth. The main idea of this theory is that ecology and economy are a common system in which lies the survival of man.

- Optimum economic theory - This theory is based on the idea that the minimum traffic costs for pollution prevention and costs to compensate losses caused by pollution when the rising costs of pollution are equated with reducing the cost of compensation for losses from pollution. This means that the economic optimum level of pollution allowed is limit pollution, or the highest limit allowed the social optimum level of pollution .

- Theory of technology "the culprit" 57 - A major factor causing ecological crisis is the development of industrial technology, and environmental degradation caused by : the density of population, the level of achieved progress and the degree of utilization of modern technique. Environmental degradation occurs when is increased population density, the traffic is densified; increasing take-over of land and the growth of unproductive land use . Commoner deemed is necessary to restore the use of natural resources, in order to prevent environmental degradation. He sets four laws : everything is connected and mutually influence each are,everything affects everyone and everything has to go somewhere. No facility that is built should be seen as fully completed, because the environment is constantly changing and it as part of the environment is affected by these changes. Simultaneously with the construction and modification of a particular environment must be taken into account the

\footnotetext{
${ }^{56}$ This theory representing Elizabeth and Eduardo Odom

${ }^{57}$ Set by Barry Commoner:

http://www.c250.columbia.edu/c250_celebrates/remarkable_columbians/barry_commoner.html
} 
natural laws that are also environmentally friendly laws, and not to disrupt elements of the ecosystem. It means adapting to nature, to natural laws. Everything is taken from nature must upgrade to avoid large degradation.

- Theory of Guest Ehrensvard ${ }^{58}$ - According to this theory because of the current population growth and unlimited exploitation of resources, the world is brought to the level that will cause world hunger. It is necessary to take measures on a global scale in order to move from an industrial economy to rapid development of agricultural economy in the future. In this sense, the savings in all areas of our everyday life, recycling waste and encouraging scientific research on nuclear fission and genetics which advocate this theory, it is historic impossible post-industrial era to be returned to the level of agricultural development.

\subsection{Models of urban structure arising from environmental theories}

There is no doubt that the city is the dominant type of human settlement, especially given that, the half the world's population is settled in the cities and urban life is the leading form in all environments. For that growth and development is responsible material welfare of society, which is the driving force and corrector of all global processes. According to Jane Jacobs 59 " societies thrive as much as advancing their cities." Increasing urban population is closely tied to the relocation of the population, particularly the rural abandonment and resettlement in urban areas. With such a rate of migration very soon $90 \%$ of the world's population would live in urban areas. Cities that abrupt and rapid increases have major problems with environmental pollution. The most important element here is the human dimension that must be taken into account. Currently $60 \%$ of the world's population already lives in urban areas, of which $65 \%$ live in cities with more than 2.5 million inhabitants. It is expected that already in 2020 the world population will be 8 billion people. ${ }^{60}$ Although are in constant growth, large cities tend to turn into megapolis with over 20 million inhabitants, but it is expecting the largest new urban growth projected to occur in smaller cities with 100,000 to 250,000 residents that absorbed many rural areas.

Sustainable urbanization also need to recognize new spatial models and models of mobility. Urban development couldn't be based on standardized models. The possibilities for developing are specific for each city and have to be established in terms of the context and the region. Urban development should be conducted in cooperation with the public and community, social priorities, the establishment of urban form and care for the local environment. Measures of urbanization should be reorientirani thus create maximum effects with minimal use of resources. Residents should be encouraged to build cheaper and

\footnotetext{
${ }^{58}$ Set by Guest Ehrensvard

${ }^{59}$ American sociologist

${ }^{60}$ Peter Newman, op cit.
} 
healthier houses and flats for housing. Cities have to plan their expansions in order to meet the emerging needs of the expanding residential areas, spaces for sport and recreation spaces for playgrounds and space for agricultural production. ${ }^{61}$

\subsubsection{Decentralization and polycentric urban development}

Polycentric urban development is actually a decentralized urban development. The globalization on the world stage brought networked cities, synonym for capital growth (overpopulation, over-consumption, over-construction ...). Polycentricism basically has the idea of spreading around multiple centers that will develop social and economic activities. Everyone in modern society appears in three forms: as a citizen, as an individual consumer and as an individual in a democratic environment. It integral means political and economic freedom on the one hand and the right to a decent life and provides conditions for its fulfillment on the other. Justification for spatial decentralization should therefore be considered in the context of providing physical, social, manufacturing and service infrastructure in an integrated space that provides low cost life and work.

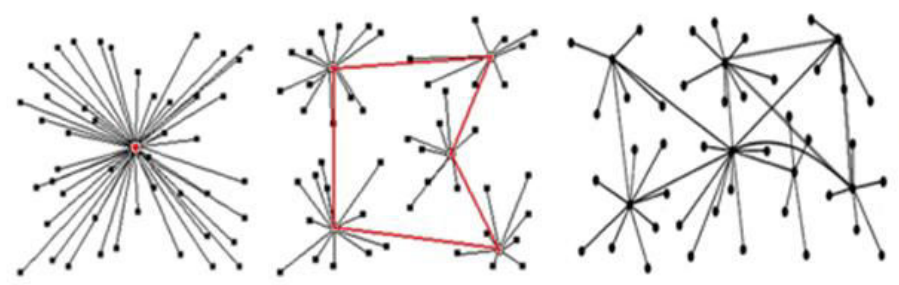

Fig. 4 Decentralized - polycentric urban development

Modern means of communication create assumptions for decentralized - polycentric urban development. ${ }^{62}$. Polycentric urban development is based on the idea of a space where dominate multiple centers. (Fig.4) This model begins its development in the 1970s of the last century over decentralization of economic activities, growing mobility of capital, labor and technology progress. Polycentricity refers to the morphology of the urban centers, the composition and the relationship of urban centers in the urban hierarchy. The urban hierarchy would mean both urban ecology, so that cities produce all the specialized products and services, and supply the local market and the suburbs. The polycentric structure of cities constitutes the functional specialization of cities allowing balanced production with very low costs and low transport costs. An example of successful polycentric developed urban region is Randstad in the Netherlands where it is complementary specialization of cities: Amsterdam tourism, finance and transport; the service sector in Utrecht; Hague as an administrative center and a port of Rotterdam.

\footnotetext{
${ }^{61}$ Urban agriculture as a model for sustainable cities - urban agriculture in order to improve the nutritional value and health standards of the poor in cities, cheap, fresh produce and more space for agricultural production.

62 Инклузивен град, Валентина Иваниќ
} 
The size of the city is in negative correlation with fuel for transportation. This applies especially to the rural areas which are attached to their cities where people work. That people use cars to pass this distance. One of the ideas is to create an urban environment that will ensure a quality life is with re-creating small neighborhoods like the so-called new urban villages decentralized geographically and institutionally. In this case it is not about city gardens, but geographically dispersed communities that containing houses with enough space around, so people can deal with agriculture and to produce food and other goods necessary for life. The traditional life there would be complemented by new telecommunication related life as a modern model and quality of life .

What is problematic in decentralized environments is the need to bring electricity to the same level as in urban areas which made the whole procedure more expensive. Also, it is unclear how much human dimension have high development of telecommunications and the Internet social activity services that are inevitable for decentralized urban development. As part of the economic growth in developed countries there is a need to raise living standards, which also increase the number of dwellings. It requires more space, private and public, which should provide a wealth of diverse activities.

- Example 1:

Ireland is a country which proved that is possible polycentric development. Mono-centric spatial structure of Ireland in exceptionally long period produce overpopulation of Dublin and inefficient use of the potentials in regions that are remote from the capital. Polycentricity in Ireland is the third generation of regional policy. The first was dispersive, the second was aimed at a concentration of certain industries and the third is focused on urban centers as engines of development of the country. Ireland during economic boom directed all efforts to be competitive, especially focusing on Dublin, while now thinks about urban development .

Urban patterns of the European Union show model "center - periphery" and referring to "the Pentagon" ( limited space between five major cities London, Paris, Milan, Munich and Hamburg). Such cities are Madrid, Barcelona, Rome, Vienna, Berlin, Stockholm. Another category of cities are those that are relatively large, competitive, having a scientific base, but weak when it comes to the number of residents or availability. These include Helsinki, Oslo, Düsseldorf, Geneva, Cologne, Dublin, Athens. A third category is the cities with low competitiveness and availability as Prague, Warsaw, Budapest and Bratislava.

\subsubsection{Coherence and compact city}

Urban sprawl is usually followed by functional specialization of certain areas of shopping centers, recreational zone, zone for housing, industrial and craft parts that drastically reduces the ecological capital of small and large cities. This model of urban development means wasting energy and damage inflicted on the environment. Cities should be coherent and compact ( inclusive towns ) with the aim urban area to become simpler, affordable and stimulating for their citizens, regardless of their social status, age and health condition. Focus is on inclusiveness in urban centers that act as machines that need to pull the economy forward. 
The idea of a compact city ${ }^{63}$ (centralization) originate from Europe, particularly first theory is mentioned in the Commission of the European Communities in 1990 as a mixture of various socially sustainable features that will concentrate future development. It should significantly reduce the need for motor traffic that in turn will gradually reduce the emission of harmful gases into the air. This idea promotes the use of public transport, walking and bicycle use. The idea of a compact city developed a new methodology of urban planning of cities, which in the 21st century under the influence of new challenges and enormously increasing urban population. The compact city model answers on the relationship between the density and intensity of development. ${ }^{64}$ Compact cities ${ }^{65}$ are characterized by medium and high density built environment with mixed functional and public open spaces, with certain limits of growth and planning in accordance with the protection of natural resources outside of urban areas. The compact city is homogeneous phenomenon. Creating a compact city include intensification of built parts ${ }^{66}$. Intensification is a dynamic process. A development can be sustainable to certain limits, but not over that restrictions. For example, increasing the number of households in one area can cause pressure at the utility activities, water supply , electricity, gas etc. ., thereby is necessary to introduce new technologies that would increase capacity and thus is possible sustainable development. It should be understood the boundary between acceptable compactness and overcrowding. There is no difference by locality from one place to another.

The concept of a compact city covers three areas: urban designing, urban space and social structures. The compact city model contains the following features:

- Centre with the historic core;

- Development of high population density;

- Development of various urban functions;

- Services and utilities: hospitals, parks, schools, recreation and entertainment.

The compact city should be developed around the centers of commercial and social activity that is desirable to gravitate towards public transport. Thus developed focal points with its own public space and parks with greenery. In large cities mass transportation system enables rapid urban traffic by connecting of one centre to another bypassing the local communications that operate only locally. This traffic system is easily controlled and is associated with local rail lines, subways, electric buses, trolleybuses, trams etc... At the local

\footnotetext{
${ }^{63}$ In 1970 was promoted the idea of a compact city as a city with a circular shape and a population of 250000 inhabitants in about $3 \mathrm{~km}$ radius.

${ }^{64}$ The density is a quantitative measure and represents the number of residential buildings in relation to one area While the intensity as a measure gives the subjective possibility of building or creating urbanity.

65 The first form of eco compact city set in Brussels in the awarding of the European Prize for Architecture in 2008 by Foundation for Architecture. Then was shown the city 250000 inhabitants and built space over 2000ha. The aim is to create forums for cities and city government, public and private contractors, architects and construction engineers to spread the culture of eco compact city to create a better environment for social, economic and cultural life. Eco compact city is organized as a forum in different cities each year, prepares international exhibitions for the best examples of Eco compact cities worldwide, and annually publishes book on eco compact city. Eco compact city can be built anywhere with respect to local climatic, geographical and cultural conditions. ${ }^{66}$ Development of existing parts, expansion, increasing the number of residents, increased traffic, increased use of land ...
} 
level such hierarchical separation of traffic leads to opening more space for pedestrian movement. In such a neighborhood evolving social function where people will experience a contact person where the person expresses their local culture .

The compact city concept is found today mostly in Europe, America and Japan, as in other industrialized countries and in developing countries in Asia. The compact city can affect the improvement of the existing situation. Objects can be coherent with the urban weaving, to be re-used and to improve that provides a positive image for the city. Furthermore however, the migration of new residents in the city encourages cultural development, new activities need to be met through cultural offer. Intensification of urban areas means social cohesion and community spirit.

The compact city cannot keep up some patterns for different social and economic needs in different parts of the world. There are some certain technical solutions that can be shared. The solutions have to come from the qualities of specific locations. In some areas built environment may require rehabilitation care, somewhere open spaces must be in a way to protect and preserve, somewhere open spaces may have erosive action and should intensify their construction etc... Understanding the differences and responsibility to them is the key element in providing solutions and potential for success. In Europe, many cities do not suffer from lack of compactness, but from extinction, so urban intensification is seen as urban renewal should encourage people to return to the cities. It requires a political campaign that will people drive to return to the cities, to accept life in high density, mixed land uses and functions, as well as investment in public transport.

\subsubsection{Transport oriented development at focus spots and centers of transit}

Today's urban structure in the world looks like that in rare cases is possible implementation of only one model of town. The model of transport-oriented development in focal points gives a kind of sublimation. Modern cities are economic agglomerations with continuous transport. The development of transport facilitates decentralization and migration boosts concentration. Always between these two extremes there are centers and transit zones which are always those who are planning, economic and social uncontrolled. Sustainability implies their integration with the availability of services, utilities, local government, social control and community involvement.

People have the right to choose where to live. There will always be people who will choose to live in a compact city and those who will choose to live in suburban areas. But many people will opt to live in areas that are centers of transit. New urban development enables the creation of such centers. The reason is that it will come to the dislocation of social activity outside the urban core, but still in the area that represents the transit zone. Thus around the city core area which is ideal for business and administration will create a circular layer that will balance and creates a new kind of social scheme. Since the 1980s in 
many European cities began to populate new residents and it usually grouped ethnically. Their arrival in the cities and settlements is directly related to previously newcomers residents who usually live outside city cores and moving into a transit zone. These residential areas are simply inserted between the centers and settlements. Such is the case in London where there are new residential zones between Brixton and Kreid and settlements Streatham and Norbury. Such transit zones and their settlement can concentrate social problems: crime, poverty, drug abuse and social unrest, similar to what a ghetto in the world's great metropolises ${ }^{67}$. Beside, these transit zones are places where have to go in and out of the city, people, goods and infrastructure relating to suburban areas. These roads are important artery connecting the city with suburban environment and need to be controlled . Especially is important place for living and the availability of necessary services such as schools, shops, etc... Their unavailability increases the need to travel by car. If these services are local $^{68}$, then they are unobtrusive and affordable for the community and to them can come with a pedestrian movement. The availability affect of different modes of traffic behavior. The best effect is achieved by combining activities. Some may occur locally, and for some is necessary travel with a motor vehicle. Both groups of residents and those who live in downtown and suburban areas and those occupied in transit zones are naturally set of each population located in its zone. It is normal to talk about ekvilibrium, and it means the social control and forcing the group to join the lifestyle of the other ${ }^{69}$

\subsubsection{Sustainable transport}

The model of sustainable transport takes the dimension of city transport as the basis for integrated planning. Transport infrastructure should be planned in the context of regional networks provided by modern transport technologies. It means acceptance of green technologies and vehicles that are energy efficient, clean and affordable. At the same time, mobility should mean connection to all parts of the cities, especially when it comes to public transportation. This model also suggests a measurement design in human measures, specifically suggests the use of alternative types of transportation: bicycle and hiking. Socially is difficult acceptable to reduce greatly car traffic ${ }^{70}$. So first you it has to change public opinion, before be introduced through legal measures by the government. It takes the input of new infrastructure in the city that will refer to collective transport. Therefore most

\footnotetext{
${ }^{67}$ The regulation of the dangers of residential transit zones need to make social control and with the police. Solving social problems must be in the zone. First off, if is solved the social problems of the area will be prevented leaking in the other two zones, downtown and suburban areas.

${ }^{68}$ According to some research some services such as post offices, dry cleaners always attend local, some as children's playgrounds, parks are visited more often if you are located locally.

${ }^{69}$ Individuals living together with other become organisms in natural process of creating social equilibrium. It is considered as a separate and stable urban scheme, originating from social Darwinism and determinism of the environment. Basically contains Darwin's theory of survival of the species. The match between the individual and property owners create stable sociological town. The tendency is to create a concentrated pattern in space (according to the Chicago School from 1920 that developed the theory of urban ecology). According to Darwin's theory, social benefits for the surrounding and area will be taxes, rents, pricing, personal desires and social control of all expressed as natural law.

${ }^{70}$ Looks like, the private car is very important in psychologically sense, for pleasure, privacy, personal control and representation that it provides.
} 
acceptable are underground structures that are expensive as an initial investment. Experts believe that the introduction of the subway and railways are an important factor for improving the collectivization of transport; about private automobiles, significant progress will be achieved if are set electric cars (hybrids, electric vehicles , etc...).

Transport determines the relationship between the size of the settlement and traffic behavior. In areas where the population is shrinking, growing use of traffic (due to suburbanisation), while the increase in population (centralization) strongly promote public transport. Sustainable transport can therefore be viewed in two ways : by reducing travel or limiting the impact of the increased traffic flow by developing the capacity of the streets, the combined use of transport means, change the transport modules and finally technological change in transport equipment. Planners have the task to establish effective transportation in traditional urban forms. Transport infrastructure must be planned in the context of regional and national networks.$^{71}$

Detailed analysis highlight the differences between urban size and travel for work and when not working. Traffic for coming to work in the rapidly growing areas reduces the number of population. This suggests that a relatively small cities can provide satisfying certain needs and services, but only major centers in major cities provide various job opportunities. To reduce the use of vehicles and reduce the need for long journey can be made of peripheral relocating of various businesses. Finally the fundamental question is whether the policy should be conducted in terms of reducing travel or to limit the consequences it causes .

Sustainable transport is supported by a number of Western countries . In Britain began a trend of increasing public transport which provides energy efficiency to obtain certain privileges. City bus traffic in cities in the UK was privatized and it has a huge impact on the traffic flow. In this sense the profitability of a particular bus depends on the number of passengers. Increase in passengers and users of public transport goes along with certain qualities. This includes the time needed to wait, time travel which directly depends on the length of the destination .

\subsection{International documents regulating environmental protection}

Today all governments in the world aspire to the concept of sustainable development in order to stop the startling perspective on humanity. It is a major policy objective of local, national and global level. Brundtland Report from 1987 seriously began the idea of sustainable development by setting up the basic analysis of the alarming situation and the danger of destruction of life over the next hundred years. Almost more than half a century,

${ }^{71}$ For this see: http://www.flevoland.nl/ ; http://ec.europa.eu/regional_policy/projects/stories/index_en.cfm 
the idea of sustainable development is followed through the multitude of international documents that define the criteria and factors for sustainability. The basis of sustainable concept is in the redistribution of resources between developed countries and developing countries, and equal access for all citizens in the world in planning the global sustainable development. However the most important responsibility is to the future as the primary goal of sustainable development.

\subsubsection{Global charters and international declarations}

The international community, together with the international architectural movement began with the pioneering attempts to declaratively indicate the need for simultaneous use and conservation of natural resources and the establishment of an interdisciplinary way of achieving goals. Thus for the first time at international level is discussed for what is now known as " sustainable development." The Athens Charter ${ }^{72}$ is Among the first new charter that advocates the values of human life versus process of spontaneously building the squalid, unventilated and unsolar closed urban blocks. It emphasizes the need for sun, space and greenery as three basic elements of urbanism ${ }^{73}$, and human needs are divided into four urban functions: housing, jobs, movement and recreation. The same time suggests isolating the plants from the housing forming a belt of greenery, each facility would receive enough sunlight, air and space.

\section{The International Conference on the rational use and conservation of Biosphere by} the $U N^{74}$ is the first meeting at the worldwide level of governments that is concerned with the problems of the natural environment and the importance of global nature. It is the first attempt to establish research of ecosystems, their great diversity and inequality worries about their potential. ${ }^{75}$ In this context, the man was placed as an integral part of most ecosystems in which he affect and from which influence he receives. Research should focus on the foundation of human ecology and his physical and social adaptability for change of any kind, from the simplest to the most complex, including high technology and urbanization. Research methods are envisioned to include: prevention, control, rejection of the possibility of harmful substances to come into contact with the natural environment, analysis of consumption and accumulation, as well as a reduction in the level of presence and impact of harmful substances into the environment. Special care was taken to obtain education for natural resources at all levels through specialists that are environmentally oriented. This included the pursuit interdisciplinary training in national and international training centers.

\footnotetext{
${ }^{72}$ Established at The Fourth Congress Of Architect of the World in Athens 1933

${ }^{73}$ Д-р. Мара Џукановиќ, ор. cit.,46

${ }^{74}$ On the initiative of the United Nations, from 4 to 13 September 1968, in Paris was organized International Conference on rational use and conservation of the biosphere.

${ }^{75}$ UNESCO has set a goal to develop a plan for the World program that will include ecosystems, ecophysiological and bio-climatic range of ecosystems, natural and semi-natural, artificial or cultural, in all climatic and geographical zones.
} 
As much as the awareness of maintaining environmental was developing in quality in planning and management of human settlements, the countries in the world had been invited to share internationally all information on problems covering their areas and the solutions they offer. At the UN conference in Stokhlom ${ }^{76}$ was made an Action Plan for human environment. ${ }^{77}$ Planning, improvement and management of urban and rural human settlements are predicted for the whole natural environment or produced by $\operatorname{man}^{78}$, so policy development through spatial plans, architectural design, technical standards, criterias etc. to focus on stopping the process of degradation of the environment. Norms and standards in urban planning and building were recommended to be according to the specificity of the middle, its natural and cultural conditions. Here should be mention the eleven principles of the Charter of Machu Picchu ${ }^{79}$. Charter recommends techniques and methods of planning of cities and regions which has to be adaptable to all levels of the arrangement of spaces as wholes, by directing the order and characteristics of their development. The new lifestyle pushed to remove the functional division of cities into sectors, at the expense of common multifunction integration. In designing of residential buildings importance should be given to human contact, quality of life and close relationship with the natural environment. The main target and The Warsaw Declaration ${ }^{80}$ was the adoption of standards for building by respecting national integrity, respecting the culture and the environment as a necessity for a new perception of the future and a new way of thinking by architects and planners. One of the most important principles of this declaration applies to architects, ${ }^{81}$ who need to interpret the values of human needs, taking into account the necessary integration of new and existing elements in the area to raise the quality of the urban landscape in terms of improving the high quality of residence.

Global awareness of the need for sustainable development is enhanced when the General Assembly of the United Nations ${ }^{82}$ set up a special commission to adopt reports on the situation in the surrounding environment and sustainable development. The task of the committee was to bring "The Global agenda for change" that can realize sustainable development also includes cooperation between developing countries and developed countries, particularly countries that are at different economic and social development level.

\footnotetext{
${ }^{76}$ United Nations Conference On The Human Environment, Action Plan For The Human Environment, Stockholm, 1972

${ }^{77}$ Д-р. Мара Џукановиќ, ор. cit.,44

${ }^{78}$ All development agencies whether international (such as the UN with its Development Program for National Banks), national or regional would have required assistance in activities with the available resources and assistance from governments for planning of new settlements.

${ }^{79}$ Environmental principles in the Charter of Machu Picchu

${ }^{80}$ Development And International Economic Co-Operation: Environment, Report Of The World Commission On Environment And Development, General Assembly, United Nations, 4 August 1987 (UN Documents Cooperation Circles, Gathering a Body of Global Agreements, Our Common Future, Chapter 2: Towards Sustainable Development, http://www.un-documents.net/wced-ocf.htm

${ }_{81}^{81}$ Д-р. Мара Џукановиќ, ор. cit.,52

82 on December 19, 1983
} 
The Brundtland Report 1987 - "Our Common Future"83 by The World Commission on

Environment and Development by $\mathbf{U N}^{84}$ was recommended humanity to begin to meet their needs in the present without thereby creating consequences that will burden future generations and without them left unresolved problems. Urban planning in this regard was placed before the challenge to facilitate the development, and to avoid destruction in the quality of life. At The UN World Summit held in Rio de Janeiro ${ }^{85}$ was adopted The Declaration on environment and development for new and equitable global partnership between countries and people, in a way that will equally cover all and protect the integrity of the global environment and development ecosystem. According to the final report " human beings are at the center of concerns for sustainable development with a right for healthy and productive life in harmony with nature. ${ }^{86}$ Thus development will provide equally satisfying needs and preserving the environment for future generations. ${ }^{87}$ The Rio Conference adopted Agenda $21^{88}$ for future challenges in the new century through a global consensus and political agreement at the highest level of development environment.

Program for sustainable urban development should include ${ }^{89}$ :

- Providing adequate shelter for all alike ;

- Improve management of human settlements ;

- Promotion of sustainable land use and sustainable management of the same ;

- Promotion of the integrated use of infrastructure : water, sanitation, drainage of waste water and waste management ;

- Promoting sustainable energy and transport systems in the settlements ;

- Promotion of settlement in areas that have been destroyed and devastated ;

- Promotion of sustainable technology and construction industry ;

- Promotion of human capacities and resources construction of new ones.

Agenda 21 specifically promotes sustainable land use. In that program is required to control the use of land for industry, agriculture, free green spaces, transport and housing. Each state should establish a strategy for dealing with inadequate housing and settlement, to establish regulations for access and land use, financing and the cost of construction and to support and develop sustainable building and settlement in balance with environmental program developed to eliminate displacement of rural areas. Agenda 21 also emphasizes for the first time, that sustainable urban development is possible with the development of sustainable technologies that will ensure protection of the environment, human health and

\footnotetext{
${ }^{83}$ The 14th session in Nairobi from 8-19 June 1987 adopted the report known as "Our Common Future", also known as the Brundtland Report. (Named after the chairman of the Commission, Brundtland form Norway.)

${ }^{84}$ World Commission on Environment and animal development "Brundtland Commission" of 1983 and Brundtland Report 1987

85 The UN World Summit held in Rio de Janeiro 3 - June 14, 1992 adopted a Declaration on Environment and Development, signed by 154 countries. Report Of The United Nations Conference On Environment And Development, General Assembly, United Nations, Rio de Janeiro, 3-14 June 1992,

http://www.un.org/documents/ga/conf151/aconf15126-1annex1.htm (Resolution Adopted By The General Assembly, Programme for the Further Implementation of Agenda 21, Nineteenth special session, , General Assembly, United Nations, 19 September 1997, http://www.un.org/documents/ga/res/spec/aress19-2.htm) Logical follow up to the Declaration adopted at the World Summit in Stockholm of 1972.

${ }^{86}$ Declaration on Environment and Development in Rio - Principle 1

${ }^{87}$ Declaration on Environment and Development in Rio - Principles 2 and 3

${ }^{88}$ Agenda 21 adopted by the Commission on Sustainable Development UN 1993

${ }^{89}$ Program Agenda 21
} 
quality of life. It emphasizes that sustainable urban development is impossible to realize without water supply, air quality, waste water, and solid waste materials. It would mean a sustainable infrastructure that encompasses environmentally friendly way of eliminating waste. Agenda 21 drew particular attention to the promotion of effective transport planning , particularly the use of land transport. Efficient planning of transport means encouraging nonmotorized transport modes, walking and cycling movement and quality and energy efficient public transport. Five years later, according to The Program for further implementation of Agenda 21 " Rio +5 " countries in the global environment was not realized programs that protect the natural environment. The energy efficiency of the world can save time while be find new sources of renewable energy. Program for further implementation of Agenda 21 " Rio +5 " indicates the need to systematically prepare all countries to use renewable sources of energy in harmony with social, economic, natural geographic and climatic conditions. It also continues to promote integrated transport policy, international cooperation and transfer of environmentally sound technologies in the sector of transport, integration and land use, and urban and rural planning. ${ }^{90}$

The basic principles prescribed by The Johannesburg Declaration ${ }^{91}$ on tackling poverty mainly relate to developing countries and promote the development trend of global solidarity through social and human development. ${ }^{92}$ Significantly is promoting partnerships between people living in rural areas and those in cities, development of facilities for publicprivate partnerships, sustainable knowledge and techniques for managing natural resources. The transport strategy includes the development of technologies for creating better vehicles which would be viable and should be socially acceptable and available, as well as the promotion of multimodal transportation system that includes a massive public transport and better urban transport by rail. The Kyoto Protocol ${ }^{93}$ complements all that and is an important international documents for implement policies and measures at the national level concerning the improvement of energy efficiency in various sectors of the national economies of the countries, for implementing the measures prescribed by The Montreal Process $^{94}$, and concerning the carbon cycle and the greenhouse effect, subsidies and tax

\footnotetext{
${ }^{90}$ Abolish the use of vehicles using leaded gasoline to reduce harmful effects on human health causes, reduce the emission of $\mathrm{CO}_{2}, \mathrm{CO}$, nitrogen oxides, and particulate emissions of organic compounds etc...

${ }^{91}$ Declaration of the World Summit on Sustainable Development in Johannesburg "Rio +10" 2002 (Plan of Implementation of the World Summit on Sustainable Development (Post Johannesburg The Future of the UN Commission on Sustainable Development, By Felix Dodds, Rosalie Gardiner, David Hales, Minu Hemmati and Gary Lawrence, Stakeholder Forum for Our Common Future, WHAT Governance Programme, Paper \# 9 , November 2002)

92 Improving the status of vulnerable population groups (women, youth, etc.) with social and health care and education. Inclusion of the persons with disabilities in activities for sustainable development.

${ }^{93}$ Convention on Climate Change at the United Nations - Kyoto Protocol of 1997 (Kyoto Protocol To The United Nations Framework Convention On Climate Change, United Nations,1998) The Protocol was opened for signature and subject to ratification, acceptance or approval by countries and regional economic integration organizations at United Nations Headquarters in New York in the period 05.16.1998-15.05.1999 and was opened for signature and after that period.

${ }^{94}$ The sixth meeting of the Montreal Process Working Group in Santiago, Chile in February 1995, ten nations agreed on a set of criteria and indicators for forest conservation and sustainable development in the world, delivered through the Declaration of Santiago. Participants in the working group were: Australia, Canada, Chile,
} 
and customs exemptions for activities that prevent emissions responsible for the greenhouse effect. Due to the global economic crisis is observed increase in global $\mathrm{CO}_{2}$ emissions by $3.2 \%$ which is $35 \%$ more pollution in 1990 years. It is assumed that by 2020 greenhouse gas will exceed the reference 1990 by $65 \%$. Thus increasing unsustainability that will increase the negative effects on the global climate sisitem. All signatories to the Kyoto Protocol are undertake that will individually or together work to reduce the emission of $\mathrm{CO}_{2}$ as an equivalent gas responsible for the greenhouse effect and that at least $5 \%$ of the level measured in 1990 the period $2008-2012 .^{95}$ It is assumed that the fast and effective action on reducing greenhouse gases by 2050 will be 10 times more .

The Jordan declaration ${ }^{96}$ leads to the prohibition of urbanization of agricultural land. Sustainable development is associated with protection and cultural heritage and unique character of towns and villages. This means that is positive each urban revitalization of cities, the establishment of so-called vibrant city with mixed uses. Simultaneously should strive to design cities to enable energy conservation and recycling, ${ }^{97}$ local independence of energy grid that would be decentralized when it comes to alternative energy sources. ${ }^{98}$ Materials used in construction should have a sustainable life cycle or what is possible to achieve technological innovation in prefabricated modular building systems that will make the facility available and inexpensive to build. The Declaration also emphasizes that the public should focus on the massive reducing of dependence on the car and investing in an inexpensive, efficient and convenient public transportation such as the introduction of so-called free green buses.

UN Programme for Human Settlements HABITAT ${ }^{99}$ sets "green" agenda that cities should encourage the development of renewable energy sources in order to reduce the cities dependent on non-renewable energy sources, increasing green infrastructure in cities and using local foods improving eco-efficiency by using waste as a resource, development of cities without slums etc... ${ }^{100}$

Forum for sustainable urbanization in the information age ${ }^{101}$ had intended to start a dialogue and exchange of experiences in improving the capacity of cities and local governments for planning, implementation, and management of infrastructure networks. The

China, Japan, Republic of Korea, Mexico, New Zealand, the Russian Federation and the United States.http://www.rinya.maff.go.jp/mpci/santiago_e.html ; http://www.fs.fed.us/global/pub/links/santiago.htm ${ }_{95}^{9}$ In exercise of regulatory obligations states have to reduce the negative social, economic and environmental impacts and reduce the negative effects of climate change finance and technology transfer, and emissions trading under strictly defined rules, principles and modalities, especially when it comes to developing countries . The methodology to be used should be that which is stipulated in the Montreal agreement or stipulated by the Convention on Climate Change at the UN . According to the protocol will be made permanent audit and control processes of global warming and climate change by the experts in that area

96 The Sustainable Jordan Declaration 2009, 15 June 2009.

${ }^{97}$ Solar panels, solar and thermal reports etc.

98 for example: the energy of the sun is not required distribution

${ }^{99}$ Planning Sustainable Cities, Global Report On Human Settlements 2009, United Nations Human Settlements Program, United Nations Human Settlements Program (Un-Habitat), 2009

${ }^{100}$ Less than $35 \%$ of the cities in the world have developed wastewater treatment, and 1.2 billion people lack safe sanitation and access to clean water is noticeable in poor urban areas.

${ }^{101}$ Conference on sustainable urbanization in the information age, the role of infrastructure in 2009 
objectives of the conference were to unite city officials to talk about their challenges for sustainable development and renewal by 2030 emphasized the need for discussion of practical solutions, exchange of practice in implementation of a sustainable planning in urban areas and mega cities; innovation models of ICT for sustainable urban planning, creating awareness of the role of ICT in the field of sustainable engineering, architecture and urban planning in the globalized world (transport, energy system, water).

\subsubsection{European documents and sustainable development of European cities}

The European Union is well positioned in the leading roles for the implementation of global sustainable development. It is one of the biggest market partners. Through its own evolution, the European model of integration is based on strategies that support stable economic growth, social development and protection of the natural environment. Investing in the future together with nearby neighbors is fundamental to long-term stability of the European Union. It will produce valuable experience in establishing these challenges globally ${ }^{102}$.

The European Council meeting in Helsinki in December 1999 The European Commission was asked to prepare a proposal for a long-term strategy for sustainable development which should be presented to the European Council in June $2001^{103}$. EU has adopted two strategies : one is The Lisbon Declaration adopted in March 2000 in order " to strengthen the EU as the most competitive and dynamic economy in the world based on knowledge, capable of sustainable economic growth with more and better jobs and greater social cohesion." And to it, in Gothenburg in 2001 was added to The Environment Council in a term with greater perspective in order to improve the quality of life now and for generations to come. These two strategies complement each other. However, from the adoption of The European Strategy in 2001 to its review in $2004^{104}$ a significant changes occur in EU. First Union has increased by 25 new members, followed by terrorist attacks, further enhancing globalization and changing global economy, visible signs of climate change and environmental issues.

In Europe is a strong trend of de-territorialisations, which contributes to increased congestion in cities and reduced quality of life. European research center in its program 2002 - 2006 year had intended to find a way to implement these guidelines into action in to order for improve efficiency in the transport system. It will include cleaner traffic system, better roads and infrastructure, intelligent systems in all models in order to make efficient infrastructure management. In Europe there has been spectacular growth in the use of cars.

\footnotetext{
102 The European Union is a signatory to the Rio Declaration of the UN since 1992, and the obligation of 19 - third special session of the General Assembly of the United Nations since 1997 to put together a strategy for sustainable development as part of the World Summit on Sustainable Development in 2002.

${ }^{103}$ Communication From The Commission, A Sustainable Europe For A Better world: A European Union Strategy For Sustainable Development, Commission Of The European Communities, Brussels, 15.5.2001

${ }^{104}$ Commission Staff Working Paper, Public Consultation, Review Of The EU Sustainable Development Strategy, Commission Of The European Communities, Brussels, 30 July 2004
} 
Between 1970 to 2000 the number of custom cars in the EU ${ }^{105}$ tripled from 62.5 million to nearly 175 million. Every day more than 10 ha of land covered by roads, especially in the areas and countries that are far from the periphery centers. The urban population however, requires a more efficient and rational urban transport in the form of urban transportation. Acceptance of sustainable development of urban transportation is the most difficult to implement. The journey should be thinking as a continuous action. This means that urban planners should consider intermodal transport system, the use of cars and public transport, and metro stations. It also need to encourage movement with the bicycle and is a great form of movement for short haul and fully involved in the transport intermodality . About $5 \%$ of daily trips in Europe are made by bicycle, which indicates that it is such vehicle unfairly marginalized. With most of that percentage participate in Denmark with $18 \%$ and the Netherlands with $27 \%$.

Leipzig Charter ${ }^{106}$ for sustainable European cities is a document composed and signed by the EU member states in order to establish common principles and strategies for urban development, taking into account the historical, economic, social and environmental backgrounds and experiences of European cities. Charter indicates a strong partnership between the cities and rural areas and between small, medium and large cities, without considering urban development isolated and separated for each city. Cities are focal points of regional development and responsible for territorial cohesion. Charter provides that the process of urban development should go beyond the boundaries of cities, should include all levels of government: local, national and regional responsible for the future of cities. In creating their living space and environment actively take part the citizens in the settlements.

With The European Urban Charter II $^{107}$, the Commission proposes manifesto for a new urbanity , a new approach to urban life where the social dimension should become a central activity of the sustainable strategy of the EU. Cities should represent places where everyone will enjoy the quality of life and availability of services, particularly in the education, health, culture and housing. The main goal is social and spatial cohesion, cities where people work and live multi regional, multi cultural, multi religious, which brings together people from all social strata on a daily basis. The ability to integrate cultural diversity in cities can be a strong foundation for developing the identity of cities. European cities are now the driving force of prosperity and stakeholders in the processes of globalization and the future economic growth of Europe.

Sustainable Development Strategy of the EU has to be a catalyst in institutional reforms and changes in the cooperative and the consumer behavior. Integrated urban development policy of European cities presumably creating and providing quality public

\footnotetext{
${ }^{105}$ White Paper European Transport Policy For 2010: Time To Decide, Commission Of The European Communities, Brussels, 12.9.2001

${ }^{106}$ Leipzig Charter on Sustainable European Cities, 24 may 2007

107 Evropska urbana povelja II, Manifest za novi urbanitet, Rezolucija 269 Kongres lokalnih i regionalnih vlasti Savet Evrope, 15. plenarna sednica, Strazbur, 27-29. maj 2008.
} 
spaces, created spaces and architecture, creating spaces for work, business or for tourism. It would mean the integration of architecture, urban planning and infrastructure with high quality environment, and historic buildings and public spaces must be protected as a cultural and architectural value ${ }^{108}$.

\subsection{Operationalization of sustainable urban development implemented in the examples from the world}

\subsubsection{Stockholm sustainable city}

Stockholm is a city recognized as " green and blue city " due to the large areas of greenery and blue sea around the islands on which the city is built. Stockholm today was the result of planning and development strategies of the last century. Since the 1920 s, the city began with activities for promotion of affordable and decent houses for their residents. An important part of that strategy was to buy land for development and also to protect the area provided for recreation. In the early 1950s was made the city planning development strategy. New suburban areas were planned along the metro line, thus each suburban area is specific neighborhood with social and commercial core, houses with large population density together with detached houses. Green structure was placed in the form of parks and green areas that divide neighborhoods from each other. In addition, significant was installation of infrastructure across the region, particularly heating, water and sewage. Significant investments have been invested in developing an efficient public transport system based on a network of metro rail lines and connecting suburban communities. Today the city is facing new challenges in creating sustainable modern city. City Council in 1999 approve new urban plan of Stockholm 99. In the process of developing the plan involved a multitude of citizens, organizations, local governments, companies-through public meetings and exhibitions of the plan. It is important to point out that Stockholm has a tradition of dialogue and discussion with citizens about their plans which is planned. As much as is increasing awareness of citizens it is easier to implement program sustainability and preservation of the environment. The idea is to reuse and redevelopment of old industrial areas and changing the existing infrastructure. Several of these areas for development will be connected with high-speed rail system that will enable the development of urban nuclei in places where rail meets metro lines.

\footnotetext{
${ }^{108}$ Baukultur - a set of cultural, economic, technological, social and environmental aspects that affect the quality of the process of planning and designing.
} 

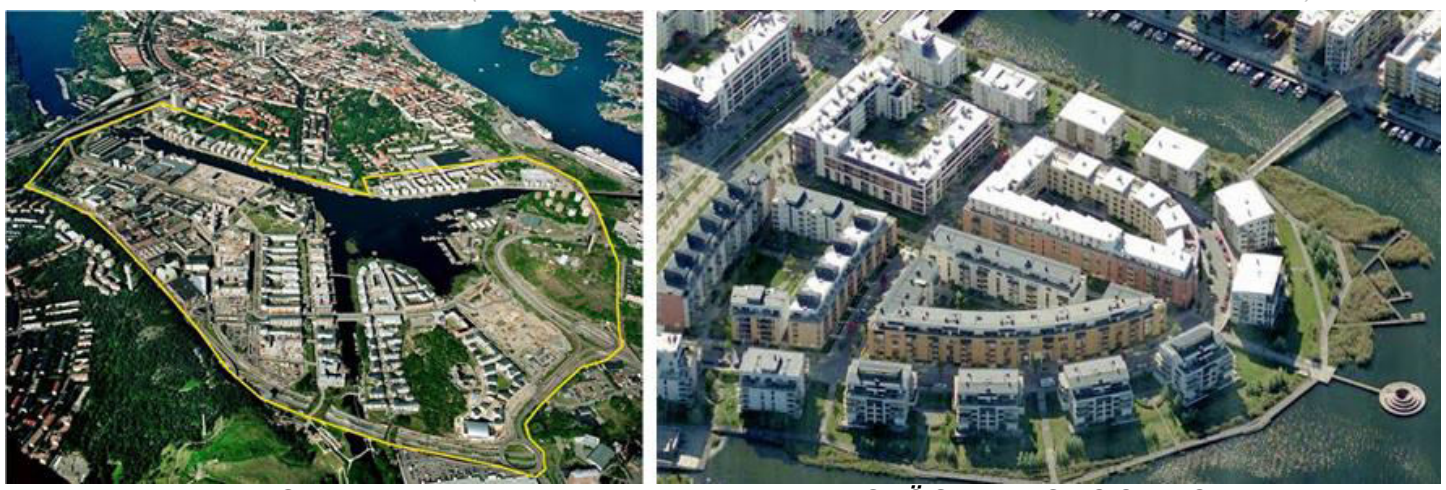

Fig. 5 Sustainable Urban Plan HAMMARBY SJÖSTAD, STOCKHOLM

The first area of development was the area of the old docks and industry that transformed into a modern part with 8000 apartments and population of 20000 residents. The area should have its own recycling model and treatment of waste and sewage. The plan includes a new subway line and a highly developed network of pedestrian movement and bicycle paths. Another area is Kista ( "wireless Internet Valley " ) where are placed significant leading companies in the telecom and Internet market and the Nordic world, and the largest pharmaceutical and biotechnology companies with research centers. In Stockholm $70 \%$ of the population used public transportation to get to work from their residence in suburban areas.

\subsubsection{Plan of London 2004: a compact city - adequate space}

The UK Government has already taken a decision for obligation by 2012 .with which the development of the cities will be reduced just in use of the already urbanized areas, especially land that is already polluted, not to reach for new spaces and natural landscapes with the aim of urbanization. Plan of London from 2004 is the first example in England of a new type of regional plan that promotes London as a sustainable city. Spatial London faces with changes in terms of housing population and increasing of employment. That would mean an increase by $10 \%$ by 2016 to occur with the new development in the existing city limits without expanding the environment. London will become more compact and will develop intensively .

London is one of the three financial centers in the world. Especially it is suitable for international migration which up to 100000 per year. According to current estimates the population in London is expected to grow to 8.2 million people by 2021 . London Plan contains 28 areas planned for sustainable development which is mostly located in the northeastern and southeastern subregion city. The eastern part of the city is a priority area for development by providing 850000 new jobs by 2026 people who would be nested in areas off Isle Dogs and Stratford City. New bridges over the Thames are envisaged for transport. Notable are the development plans relating to spatial changes for the Olympic Games that will be held in London in 2012. The plan was criticized for being too centralized and requires more polycentric development outside central London and improving the surrounding transport links, which will allow promotion of new local jobs. London suburban 
areas occupy $2 / 3$ of the total area of London and are essentially dependent on the transport car. The plan offers development of that suburban areas, particularly by improving the transport system and intensify the potential to the housing and employment in other areas .

\subsubsection{Asian compact cities}

Asian cities are basically with high-density built up, with use of small vehicles and high use of public transport. It is made a comparison of the nine most important Asian cities which are at different levels of development: Surabaya, Jakarta and Manila which in 1990 were low - developed cities, than Bangkok, Kuala Lumpur and Seoul were well developed and at the end - Singapore, Hong Kong and Tokyo were highly developed cities. Just Kuala Lumpur between all these cities has an average density of development and population similar to European cities. It is characteristic that in Asian cities with high population density occurs fewer vehicles per capita. The best example for that is Hong Kong where public transport covered $82 \%$ of the total motorized movement in the city in 1990 and only due to the high population density. Large population density allows some distance be pass with pedestrian movement without ever having used motor traffic of any kind. High density of population is the reason why Asian cities have high density of built up and small length of roads and fewer vehicles. In such circumstances, it is logical traffic capacity is less per capita unlike cities and regions with low population density. Some Asian cities have well- organized fast roads. In 1990 Hong Kong had a 4.4 m fast roads of 1 hectare of urbanized land, Kuala Lumpur 2.6m in 1985 and already $4.1 \mathrm{~m}$ in 1997 , Seoul in 1995 has $3.1 \mathrm{~m}$ per hectare and Singapore in 1990 has 3.3m per hectare. The rapid development of roads in these Asian countries speaks the comparation with data for the U.S. state of California where in $1990 \mathrm{3.9m}$ roads were fast roads on 1 hectare urbanized land.

Much of the residential neighborhoods in Asian cities are planned and designed for housing, but without mass use of cars and thus imposes public transport. The high level of motoriziranost is unacceptable for urban high population density. Therefore in Asian countries is a popular movement with bicycles and mopeds.

\subsubsection{Australian compact cities}

Planners envision a new future of Australian cities and towns just as compact development of high density housing opposed to traditional Australian type of living in suburban areas with low population density. In 1960 Australia started with the development of high density housing where households have the opportunity to be owners of individual flats in apartment blocks, so today approximately 3.5 million people live in densely populated areas and mostly in the cities. In Sydney there are over 40000 urban blocks containing 600,000 individual app that gives the city a population of 12.4 million residents . Statistics conducted in 2006 indicate that $23.9 \%$ of Sydney residents live in flats or apartments, and it makes the first round of the city, in the center. 

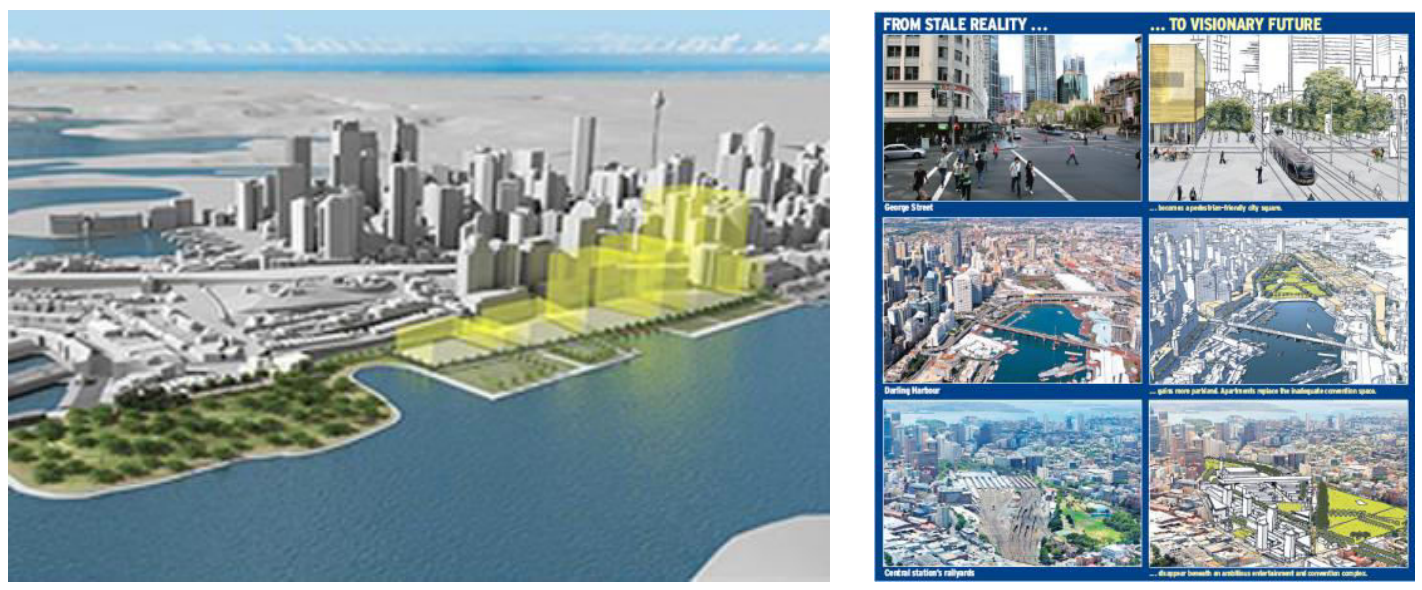

Fig. 6 Urban plan, Sustainable Sydney 2030

The plan is to build a new housing area with 1 million people ( 400,000 to 500,000 housing units ) in the next 25 years under the auspices of the Sydney Metropolitan Strategy. High density means housing in smaller apartments with one or two bedrooms which is atypical for Australian style of living . In the Sydney $70 \%$ of new homes coming on the market as part of a large densely built up. Urbanization and the need for urban consolidation is a global order that brings significant changes in the economy, politics, and social environment . If these plans are realized in 2030 about $45 \%$ of Sydney 's population will live in a compact city . 


\section{QUANTITATIVE AND QUALITATIVE PARAMETERS AND INDICATORS TO OPERATIONALIZE SUSTAINABILITY}

\subsection{Implementation of urban policies for sustainability}

The debate on finding a successful urban structure that will promote sustainability already has some history. Some countries in the world care too seriously, while others believe that researchers overestimated the situation and continue with unsustainable policy. The greatest justification for a change in process of planning cities has global warming. Global policy should be aware of the recession which is currently in the world and be ready for another catastrophic consequence. When it comes to a decline in the value of money, the first change comes in our common way of life. It isn't strange and unexpected for the public not to face with the facts, showing no sympathy to the government that conducts political and social changes which change the current way of living. Each mass reduction of greenhouse gases in the air will lead to dramatic changes. It should be accompanied by education and information programs. Life in energy efficient homes would include $90 \%$ of the reduction of emissions. ${ }^{112}$ The new lifestyle will refer to the greater sustainability with less visible use of transport, that means lower costs for heating and cooling , less pollution , more activity in the community, less motorized traffic and increased movement by walking and bicycle use.

Cities can contribute to their sustainable development by setting buildings with low energy consumption, diverse land use, population density and level of construction that provides economic provision in the division of using heating and cooling services and waste disposal. A significant reduction of motorized traffic which is also indicated that the use of fuels is three times higher in areas of low population density and construction, due to the socio - economic consequences, but also because of the use of the car for $50 \%$ more. Priority is given to transport strategies and pedestrian and bicycle movement, and strong promotion of the use of public transport. Public transport must include strict standards for noise and pollution. In the realization of all these changes is important to remember that the street still has a focal role in the social life of a city.

\subsubsection{Economic and social processes of sustainable urban policy}

Cities today are the driving force for economic growth. They grow as a result of migration of population from surrounding areas and other cities, because of the possibility of employment. Global urban population has doubled since 1900. Currently, the urban population increases by $1.78 \%$ per year. If the current trend continues the number of urban population by 2025 will be almost $2 / 3$ of the total population in the world. ${ }^{113}$ The most growth of population is in cities that have less than half a million inhabitants (53\% of the world's urban population) in cities between 1 and 5 million (22\%) according to the statistics of the

\footnotetext{
${ }^{112}$ Electricity consumed today the average is 2.5 tons, industry is 5.7 tons, 4.3 tons of traffic, while households is 3.4 tons. Clearly rationalizing household will bring a reduction of 2.5 tons on average per household.

${ }^{113} 90 \%$ participate in this process are most developing countries of Asia and Africa, where in the largest number is ongoing urbanization.
} 
UN - Habitat 2006. Also, only $9 \%$ of the urban population in the world lives in cities with over 10 million so-called mega cities. ${ }^{114}$ On the other hand, like all markets of the world, the real estate market is dynamic. When the population is growing or when moved, the demand of houses has increased and improved housing standards. These two things have changed qualitatively and quantitatively. Sustainable city should be able to accept changes in the real estate market. Real estate market is dynamic and something else, it is innovative. Sustainable city must have the ability to adapt to each new innovation. And finally, can be omitted the competitiveness when is discussing for the economic system. A company that wants to buy land in a city, where land is too expensive, usually continues searching in another cheaper city. The capital is moving internationally. Sustainable cities must be more attractive locations for investment than other cities.

Cities grow and develop for the most part as a result of trade. They allow humans to exchange goods and services as much as allow the social and cultural development. Cities have always shown by its economic and cultural values through architecture, public spaces, religious symbols, events and community service. Cosmopolitan cities provide various cultural exchanges and interpretations.

Cities are influenced by various fundamental changes - including climate change, water supply, distribution and supply of fuels, regional damage to the environment, loss of biodiversity. Cities are increasingly dependent on sustainability beyond their borders and their bio region. ${ }^{115}$ It is necessary to transform the city's economy as it would serve the entire bio region.

\subsubsection{Criteria for the control of spatial sustainable development}

Towns in the second half of the last century had clearly defined lifestyle: short period of education, stable jobs, and annual defined daily routine, and established a clear role in the political and social institutions, a relatively stable source of public revenue and low cost energy. Today the picture has changed. Education lasts longer, is more accepted concept of lifelong learning and that trend has implications for the long stay in the cities where mainly houses educational institutions. The society consists of a growing number of families of singles and individuals who chosen the city as the place for living, places where there are the opportunities for socialization. The process of spatial-functional integration instigated significant changes in the organization, arrangement and use of space. The establishment of the zone of industry and services in a linear form, organized longitudinally corridor of communication have an impact on the working uniform dispersion (product-service) stations in terms of the network of settlements and what is especially important, in terms of areas of housing. Socio-economic trends that cities face today are related to globalization, an aging

\footnotetext{
114 Today in the world there are only 22 mega cities, and there is a new phenomenon called meta-cities i.e cities with over 20 million inhabitants (Tokyo with 35 million people, Mumbai, Delhi, Mexico City, Sao Paulo, New York, Jakarta and Lagos are expected by 2020 to be over 20 million).

${ }^{115}$ For example, Los Angeles gets water from the Colorado River and Northern California, liquefied natural gas comes from Indonesia, electricity is produced by coal coming from the Southwest Four Corners area etc...
} 
population, the growth of social inequality, reduction of public resources and disruption of cities.

Cities are faced with mainly three challenges: demographic change, climate change and changes in the economic structure. Cities are responsible for $3 / 4$ of the world energy consumption; so that urban development is more and more need to go through energy efficiency programs. According to internationally accepted global sustainable urban development policy of the city should be planned around the following criteria: ${ }^{116}$

- Capacity of natural resources, renewable and non-renewable and their alternatives;

- The economic situation locally - decentralization;

- Existence of natural environment in the city as an aesthetic element;

- Investment in human resources through education, health etc.;

- Social condition of the residents in the city in terms of family and friendly relations, association in social groups and associations which will jointly commit to development of the city;

- Increase the quality of life through built equity in terms of facilities, infrastructure, public spaces ( playgrounds, parks ...);

- The approach to urban space from the current residents and responsibility to future generations;

- Interaction and equal treatment of the factors of sustainability : energy, economics, ecology and efficiency in social action.

The city of the 20th century was condition for the development of the global economy, while the tendency of cities in the new millennium is to encourage global sustainability. Laws for non destruction of matter and energy changes gives ecological unity, which modern civilized man disrupts with his social and economic activities. Aspects that conditioned ecological imbalances are: population, social policy, social structure, limits of growth, decentralization, utilization of energy resources, technological and industrial development, economic growth, etc... Global policy through international documentation actually reexamines the development goals of humanity. Sustainable urban planning therefore sees the city as a system that will brings interaction between the factors of sustainability: energy, economics, ecology and efficiency, social interaction and investment in the capacity of natural and human resources. In addition, the cities agreed use of uniform standards for the protection of the natural environment, appropriate legislation and agreements at global and local level. Sustainable development thus begins to be integrated in the planning and management of human settlements, and requires criteria for urbanization which will be reoriented from the usual methodology of planning. It would mean concern for the environment, social priorities of the public and the community who is involved and interactive in achieving sustainability. Integrated urban development policy means integration of architecture, urban planning and infrastructure in an environment that provides a high quality of life and sustainability. The best way for the implementation of integrated development policy is by engaging the local community in activities for sustainable urban regeneration. It covers the city that would regenerate naturally by focusing its urban planning to a model of a

\footnotetext{
${ }^{116}$ European Commission, Group Urban evolving capacities, urban dimension in EU policies 2010 (European Commission, B-1049 Brussels - Belgium);

http://ec.europa.eu/regional_policy/sources/docgener/guides/urban/pdf/urbanguide1_en.pdf
} 
sustainable form of city, innovation, rehabilitation of certain urban areas and sustainable urban infrastructure.

\subsection{Parameters and indicators for sustainable city development ${ }^{117}$}

The operationalization of urban form as a sustainable system includes indicators that consider the condition of the city in terms of sustainability. It covers analysis and the ratio of urban elements in the physical structure of the city. Criteria for sustainable development suggest a specific model of community development and urban area, ie determine the resources (natural and built), in favor of alternative and renewable resources; more efficient use of land; reducing pollution of the natural environment; encouraging recycling; protection of biodiversity; increased quality, standard and lifestyle of all groups of people; education and training in the field of sustainability; integrated approach to projects relating to sustainable planning, sustainable economies, social equity and sustainable management systems; collaboration and integration of institutions and individuals in solving the problem of equal access to necessary goods.

Indicators for sustainable development of the city should be measurable, to be comparable, to transformed, to warn and inform and be eligible for a sustainable urban policy. Each town or further more each part of the city has unique specifications locally and globally that due to the different way of uses resources, different historical and traditional foundation and lifestyle of the population. Monitoring of indicators relevant to sustainable urban form provides the basis for quantitative and qualitative conclusions and forecasts the development of cities.

\subsubsection{Level of development and limits of the growth of urban environment}

This indicator is directly related to the spatial development of the territory of the city. In planning the spatial development of the city's territory the limits of growth of the city are determined as measured and documented area of the city. Within these limits is possible to plan, control and monitor the development of the city. For control of urban sprawl in the context of the environment, need to be seen the condition of the existing installation, the opportunities provided by the use of abandoned anddevastated land and one that can change its purpose for the planned development. In addition, the generally accepted view is that it is necessary to avoid construction in green areas such as parks, green spaces, agricultural land etc. periphery because of the importance of the environment in urban, and certainly not to disturb the ecological system.

Shaping the cities need to adjust to the changes imposed by the needs of the construction, the standard and style of living. Cities that have given matrix can easily be changed, updated and adapted. Such is the case with urban perimeter block, unlike the modern cities where the parcels were lifted not allow reshaping without completely breaking

\footnotetext{
117 For this see: Towards a Local Sustainability Profile - European Common Indicator, http://ec.europa.eu/environment/urban/pdf/local_sustainability_en.pdf
} 
down and not consistent with the idea of sustainability. Thus, shaping the urban matrix can direct the selection of the physical structure of cities. It would mean the establishment of a small building plots with known property, the formation of street fronts, blocks yards etc... so the picture of city grow over time and stays alive.

Built up of the urban environment in accordance with the idea of sustainability should determine the appropriate limit the growth of cities in order to protect the natural environment, the city and surrounding greenery in the city. In that way to control development capacity, avoiding building new locations and use of abandoned and devastated land.

\section{- Measurement:}

The indicator is measured through the percentage of involvement of new areas and the use of unused land in the urban environment. Measurability may be time intervals depending on the decision of the planning documents (GUP, DUP, UP ...) for 10, 20 ... years.

\section{- Control:}

To check indicator for built up is necessary to determine the condition of increased population, the emergence of new economies and industries, business development which enhances purposes and the cost of the property.

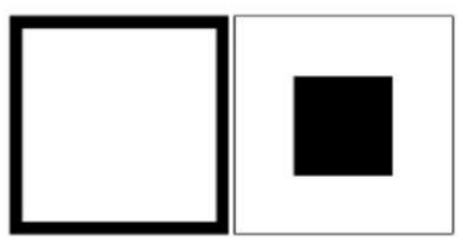

Означените црни делови од сликите имаат еднаква површина и ги претставуваат двата архетипа периметрален блок и отворен блок

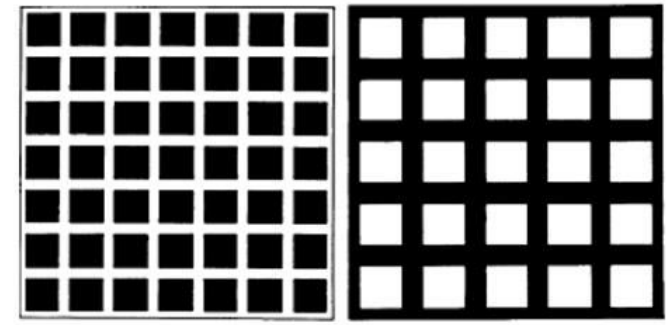

Двата урбани архетипа: периметрален блок и отворен блок
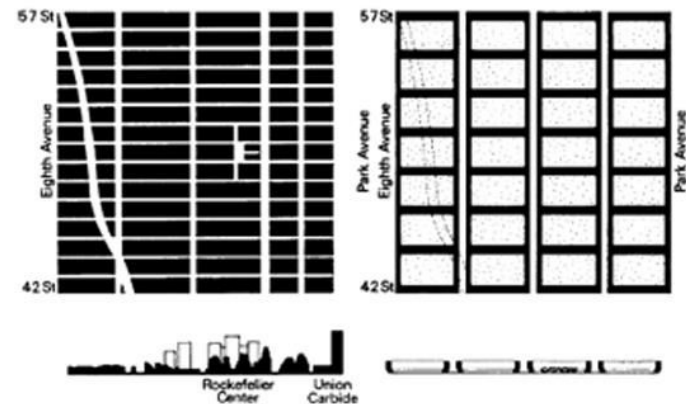

Промена на планот на Менхетн во Њу Јорк со периметрален блок на истата површина на земјата при што се намалува висината од 21 на 7м - дијаграм според Лесли Мартин и Лионел Март (Leslie Martin and Lionel March (gen. eds): Urban Space and Structures, Cambridge Urban and Architectural Studies No. 1. Cambridge: Cambridge University Преcc, 1972)
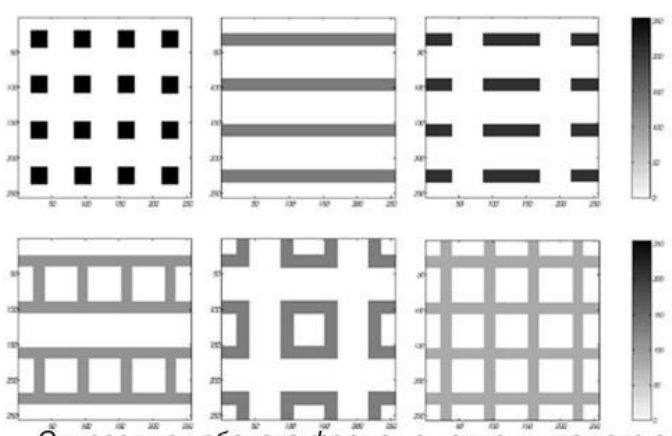

Односот на урбаната форма кон опкружувањето со анализирање на геометријата и изградената форма (Дигитален висински модел, DEM, Leslie Martin and Lionel March (gen. eds): Urban Space and Structures, Cambridge Urban Press, 1972)
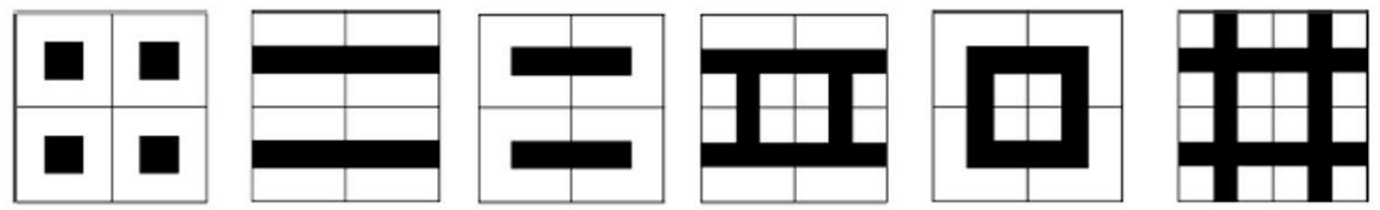

Развој на урбаната форма од лево кон десно: отворен блок, низови, терасести структури, терасест периметрален блок, периметрален блок, структра со одрормени дворишта (Leslie Martin and Lionel March (gen. eds): Urban Space and Structures, Cambridge Urban and Architectural Studies, N

Fig. 7 Diagrams of urban form by Leslie Martin and Lionel March 


\subsubsection{Use of land and buildings}

This is an indicator that refers to the many uses and activities immanent for nature of the city, necessary to meet the needs of the population. This implies a need for coverage with basic city functions and services relating to the protection of human health, providing education, social care and employment. It is important to ensure equal living conditions of all citizens in all parts of the city. Thus land should be used varied: housing, economy, transport, sport and recreation, green etc... Such a diversity of uses should provide vitality to parts of the city and the city as a whole throughout the day.

To ensure sustainable urban structure requires mixed uses within the community and within the viable distance. It is important to reduce the required travel by using motor vehicles. It is recommended communities with size of 8000-10000 inhabitants (neighborhood residents from 4000-5000) within a distance of $400-500 \mathrm{~m}$ and a density of 50 inhabitants / hectare, which would provide the necessary services and facilities of employment. In community with such parameters, opportunities for meetings and communications of residence provided the social life of the community.

Each new time brings new needs of citizens and how those needs enrich and grow there is a need to provide the spatial aspects of their existence and course requirements for their availability. For sustainable urban development is a significant the need of creating and enabling conditions for the use of open spaces (parks, gardens, sports areas, etc..) There is a direct relationship between good quality and open space and quality of life in an urban environment.

\section{- Measurement:}

Measurability of diverse land use and various purposes is possible with respect to the standards and regulations for specific content: rated capacity for housing, education and health, the percentage of service activities and service facilities for businesses, sports, recreation, culture etc... Measurability may be time intervals depending on the decision of the planning documents (GUP, DUP, UP ...) for 10, 20 ... years.

\section{- Control:}

To check indicator for purposes of space and land use need to check if provided all necessary services and services and their availability to the appropriate community. In addition, there should be no insurmountable limitations in the use of content to the community for who are directly intended, and also for the neighboring communities. It should be checked and sociability in the use of space.

\subsubsection{Population density and construction}

The density of population and built up are refers to planned and built buildings of a certain area, and the number of people living in that area. With the density is determined also and economy in the use of land and infrastructure, and density is also an important indicator to ensure the sustainability of a city. The determination of the density depends on the 
standards of a certain area in terms of the required areas for accompanying content and services (foliage, education, parking, retail, etc...).

The types of construction of buildings (houses and courtyard houses, residential blocks, multi-family residential buildings, etc...) directly reflects the density of built up and population density. Also, the density determines the typology of urban areas (suburbs, city blocks, etc...)

When it comes to density, the primary question is what does low or high density. Also in this issue there are different opinions on different parts of the world. According to the UK average net residential density for new construction accounted surfaces of 30-35 dwellings / ha or 70-80 people / ha, while the existing built-up area density is often greater. According to Burton 45 dwellings / ha is the maximum that can reach a residential community of 2 -story dwelling, which means complete housing in houses in row the front width of 5-6 meters and a garden of $80100 \mathrm{~m} 2$ (70m 60 - yard $1.5-2 \mathrm{~m}$ as front garden). Parking the car takes 1-1.2 volume of vehicle / dwelling. Furthermore, with a density of 50 dwellings / ha can be arranged habitats 3 storey block as angular and with a density of 55-65 dwellings / ha can be organize houses in row with a narrow front $5 \mathrm{~m}$ flats in blocks of 4 -storey. To determine the sustainable densities it is important to know the minimum densities that support certain public services. In the U.S. 17 dwellings / ha support frequent bus service, 22 dwellings / ha supports a network of light rail, and for 37 dwellings / ha support express bus services. So the conclusion would be to avoid building density of less than 30 dwellings / ha which makes inefficient use of land, at the expense of what should be encouraged residential development with a density between 30-50 dwellings / ha which allows more efficient use of land. ${ }^{118}$

An important goal of ensuring sustainability is making higher density of the parts of town that are low-density or were once suburbs. It is done by filling the spaces between and reconstruction, extension, upgrade, etc... Recommendation for optimal urban density is at least 40 dwellings / ha or 90-100 people / ha. If the density is greater than 60-70 dwellings / ha research suggests that there is not much savings occupation of land to increase the need for other purposes (schools, parks...). As to the centers of the cities, there are high land values and higher density is justified.

118 Дивна Пенчиќ, Урбаната форма според критериумите и параметрите на одржливиот развој со оценка на можностите за одржлив развој на Скопје, магистерски труд, Скопје, 2005, 31 


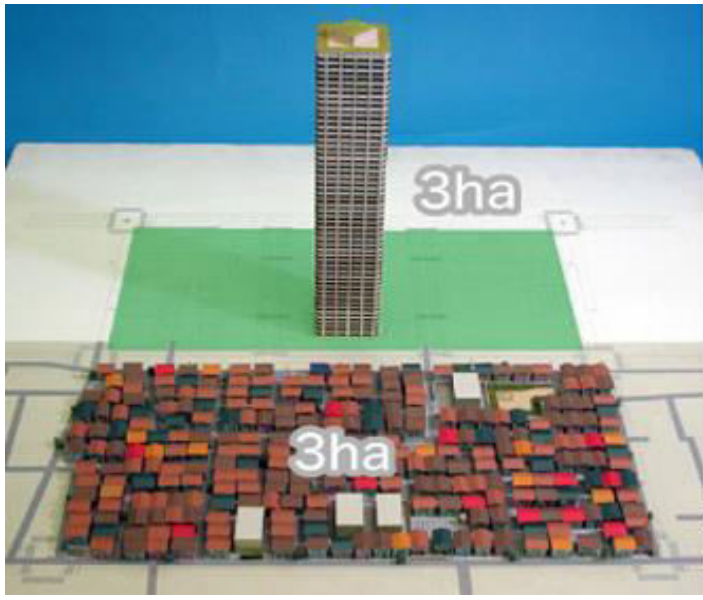

$800 \mathrm{~m} 2 \times 50$ floors $\times 75 \%=30.000 \mathrm{~m} 2=3$ ha

$100 \mathrm{~m} 2 \times 300$ houses $=30,000 \mathrm{~m} 2=3$ ha

Fig. 8 Comparative analysis of built up and occupancy of the same area of 3 ha

Density of housing could grow by more than $25 \%$ without having to make significant changes in the urban structure. Assuming you use public transport, reducing the space for parking and when conditions would remain traditional schemes of streets and given the form of buildings, housing density can be increased by about $19 \% .{ }^{119}$ All this can be achieved if planners are careful related to the setting of limits on the density with carefully selected design, controlled and pragmatic use of streets and public open spaces and greenery. Such an approach means economical use of land and infrastructure in terms of increased density in low-density areas of the city proper and the density of their position in relation to the city center.

\section{- Measurement:}

The density of development is a planning parameter that represents the relationship between the total built area of buildings and land area where buildings are constructed. (numbers of objects per hectare). This parameter can be calculated at different spatial sizes of the territory of the city and the city as a whole (urban block, ha, etc...). Density of the population is planning parameter that refers to the number of residents in relation to a particular spatial size of the urban area or city as a whole (number of people per hectare). Measurability can be intervals according to the adoption of Plan (GUP, DUP, UP...) for 10, 20 ... years.

\section{- Control:}

The check indicator can be achieved by examining whether this increased density provides economical use of land, infrastructure whether it is included in all city services and whether they support public transportation.

\subsubsection{Traffic organization}

Traffic is a major aspect in ensuring the sustainability of urban areas. Transport infrastructure creates spaces dominated by vehicles and is a space that is socially detached. To overcome this situation, and to reduce pollution generated by emissions from fuel

\footnotetext{
${ }^{119}$ Mike Jenks, op. cit. , 137
} 
combustion from vehicles, it is necessary to favor more sustainable transport patterns (walking, cycling, and public transport). The fact is that $90 \%$ of trips in one town are made by car while the other $10 \%$ are considered unimportant for policy development because they are taking in a very short distance. ${ }^{120}$ There are many numerical data that does not go in favor of car traffic and sustainability. Cars take up much room, so transport from one place to another for an hour by car can do 2500 people, while the same distance by rail would have passed the 50000 people, which means 20 hours of time savings. To that should be added and emphasized that the streets and parking spaces occupy $1 / 3$ of the area of the city. ${ }^{121}$

Expansion of motorization affect very harmful on the lives of citizens. The increase in traffic could affect the economic and social progress, but also because of increased air pollution, people are exposed to the disease. Big cities are facing traffic from the outside that creates additional traffic problems. The biggest problem with comes with parking. If on the big cities are considering through the time dimension, preoccupation of roads and parking spaces with vehicles, cars or public transport is constant throughout the day in the downtown area .

Sustainability of cities is seen in their ability to provide the opportunity for movement of citizens so that they can meet all the needs in the city without having motor traffic as necessary, which would remain necessary only for suburban areas. People should be forwarded to the greater use of public transport, which should be high environmental standards, preferably of electricity available to all places require travel. In addition, the cost of using public transport service should be a de-motivating fact for use of own vehicle as the dominant form of spatial communication.

Transit-oriented development (Transit-Oriented Development $\operatorname{TOD}^{122}$ ) is a concept that integrates transit in regionally level and generated compact communities with better quality life without complete dependence on mobility car. ${ }^{123}$ (fig.9)

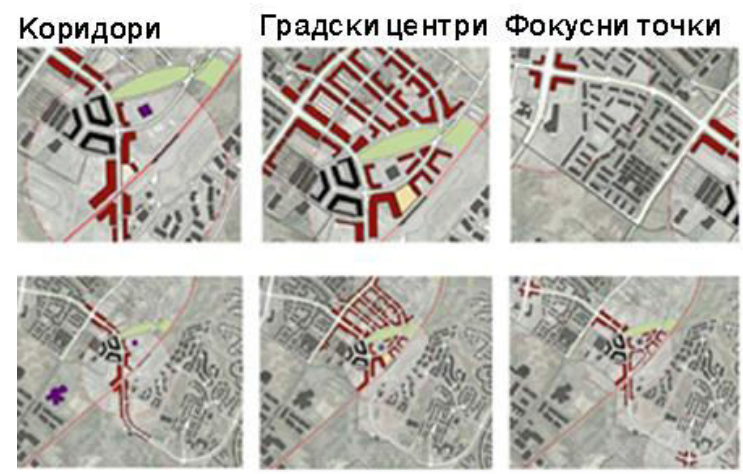

Fig. 9 Action Plan for Manassas Park, Virginija, VA (2007)

\footnotetext{
120 Mike Jenks, op. cit.

121 Peter Newman, op cit.

122 Фор тхис cee: http://www.transitorienteddevelopment.org/

${ }^{123}$ The shift to sustainable transport system is started up in the U.S. where transit is growing by $25 \%$ every ten years. Over 100 U.S. cities already built a new rail system in the last three years has already invested over 110 million dollars of new transport initiatives. A similar trend exists in Australia, Canada and Europe.
} 
The project offered ten "main street" corridors that include trees, increased width of sidewalks and creating pedestrian - friendly environment with a sense of place.

http://www.mwcog.org/transportation/activities/tlc/program/tod.asp

New investment in public transport options allow for acceptance of green technologies. It involves the use of vehicles that use fuels with a pronounced ecological and energy from renewable sources. Traffic as an indicator for ensuring sustainability, besides the component of mobility is important for the return of the human measurement of space, so that the reduced speed designed for pedestrian movement, cycling and using public transport to humanize the space.

\section{- Measurement:}

Traffic is an important indicator of pollution of the cities, especially bearing in mind the traffic intensity expressed through the annual number of kilometers by car per hectare urban land. Its size is an important factor for evaluating traffic that takes place in one city annually. Measurement of this indicator is simple: through passing the number of vehicles in one hour , minutes spent in traffic is at a standstill, minutes spent traveling from one particular point , minutes spent waiting for public transport, the number of vehicle users, length of roads in km etc... Measurability can be in intervals according to the adoption of plan (GUP, DUP, UP ...) for 5, 10, $20 \ldots$ years.

\section{- Control:}

To check how this indicator affects in sustainable urban development should be defined model of urban traffic system, which areas should be provided for traffic infrastructure and the types of vehicles, and reducing air pollution.

\subsubsection{Identification, recognition and adjustment}

Every town has a specific profile of human, cultural, historical and natural features. Uraban sustainable lifestyle involves a sense of connection with the place and the interconnectedness of the community. Collection, connection and distribution of information on social, cultural, historical and natural features of the city and bioregionot promote a solid foundation for designing sustainable solutions. This indicator is recognized around the socalled "spirit of place". It would mean in urban sense, transformation of urban matrices without they lose their distinctiveness. New construction or reconstruction should not change the city's image and continuity over time. Building on the basis of exciting features help to motivate and mobilize people and natural resources of the city in order to achieve sustainable development and regeneration.

The places that we know and love can become a place that will be part of our lives in the deepest levels. Furthermore, by developing a sense of place become able to take care of their environment, which grows into a sense of sacredness and value to certain places. ${ }^{124}$

${ }^{124}$ Peter Newman, op. cit., 145. 
Cities are places where there are a series of complex, human, political, economic, social and cultural values and institutional phenomena interlinked. Our site provides social and environmental world.

Cities need to recognize their cultural characteristics. This is best achieved by preserving important elements of the cultural identity of the city while performing changes in urban weaving, melting in bio regional culture and joining naturally defined region, membership in and out of one place. Such activity is difficult, especially because the needs to ensure integration of culture and nature and the nature of culture where animals and plants are equal members of the community and people. Every part of the city's land has a history. Recognizing and understanding the preceding cultures, cities have much to learn about their future. This process allows individual enrichment and fostering sustainable processes as people developing their relationships with living space. Spatial planning is one of the fundamental principles of ecological design, which begins with an intimate knowledge of the site, local conditions and characteristics and the people in it. If you have a sense of belonging to a place, then we can expect to continue to care not to destroy.

Designers and planners are increasingly inserted environmental elements that are present in a visual project. Bioclimatic design uses shape, structure, orientation, choice of material, constructive and living elements that will create objects that are responsible for local climatic conditions to be optimal. Also, the design should retain the recognizable features of the urban matrix. When we talk about sustainable development of the city means continuity in addition to the construction, reconstruction and new city facilities within their borders without unnecessary spread the environment. During the transformation of the space and the city should provide life and preserving the memory of the people who live here.

- Measurement:

Measurement of this indicator is by the amount and frequency of change of the urban structure, building models, but also by the quality and quantity of upgrades, updates, reconstructions etc...

\section{- Control:}

To check, you need to conclude the existence of continuity in the development, modification of the existing condition of buildings and spaces never realized, providing recognizable, formatting and aesthetic elements in the city, preservation of the urban matrix and most importantly the existence or creation of places in city where people want to live, that persist over time and are part of the collective memory and pride of the city. 


\subsubsection{Recognition of the value of biodiversity}

Biological diversity or biodiversity is a term that signifies the diversity of life on Earth, suggesting all kinds, generic diversity and ecosystems of a particular place. ${ }^{125}$ Biodiversity is a network of wildlife, in which man occupies an integral part and forms the basis for a healthy ecosystem that creates good conditions and maintains our lives physically, mentally and spiritually. All urban activities directly depend on healthy ecosystems and the biosphere. Urbanization profoundly affects the change of the state of the ecosystem, especially by changing the structure and functioning of the natural environment and the environment. The settlements are faced with a man who constantly change their needs and nature that destroys. When is achieved a balance between adaptation of human and nature and adjustment of the nature to human needs will be create a healthy settlement. ${ }^{126}$

Nature in the city is now recognized through what is called urban landscape as an expression of urban space. When discussing the urban landscape, commonly involves organized space, but should not be forgotten that the list includes water, air, land, and more recently and underground space. Greenery in the urban environment suggests a connection with the bioregion. It provides hygienic conditions and plays an important biological role in the exchange of oxygen and carbon dioxide, regulates temperature by cooling the air and increases its humidity. The greenery helps in reducing the noise in urban areas and absorbs dust and smoke. If green is presents by park or garden, it can have aesthetic values and meaning and social role, but certainly a positive influence on physiological functions in humans. City foliage, especially avenues of trees reduces impact noise by up to $25 \%$ which is significantly protection given that $80 \%$ of the noise in an urban environment is precisely the means of transport. Greenery mitigates the effects of wind, loads of sand and snow affecting mitigation solar mode. ${ }^{127}$

Urban development should incorporate the importance of natural areas and the protection of biodiversity. Planning and expansion of cities and regeneration of old urban areas reflect the increased satisfaction of human needs, but when it is necessary to develop and opportunities for people to make direct contact with nature. Cities can regain their connection with bioregion by developing strategies and initiatives for the protection of biodiversity in it and the wider region. The city can react in two ways: the first is cultural, which is necessary to recreate the true relationship between biodiversity and development of the city with respect and care for wildlife. That aspect can encourage the daily interaction with

\footnotetext{
${ }^{125}$ So far, 1.75 million known species assumed existing 14 million species of wildlife on Earth.

${ }^{126}$ Константинос Доксијадис, op. cit.,31

${ }^{127}$ Vegetation Protects against smoke and harmful substances and particles so they stick to the leaves of green because these substances are delayed in their movement and sediment. The amount of dust in the air depends on the air humidity and wind speed, and the area that the plants occupy and the type of plant, with absorption ranges from 0.5 to $5 \mathrm{~g} / \mathrm{m} 2$. The air purification indirectly increases the insolation.
} 
parks, urban farms ${ }^{128}$ and green architecture. ${ }^{129}$ Urban eco villages encourage this aspect and can provide a sustainable lifestyle. The city can nurture the cultivation of rare plants in botanical gardens and animals in zoos and appropriate reserves, and growing agriculture in city. There is an interest in modern integrated plant life in urban structures by placing the roofs, walls and terraces, as well as indoors. This way can be effectively influence the improvement of microclimate conditions and the convenience of using and stay in this area, and contribute to improving the quality of air inside and outside.
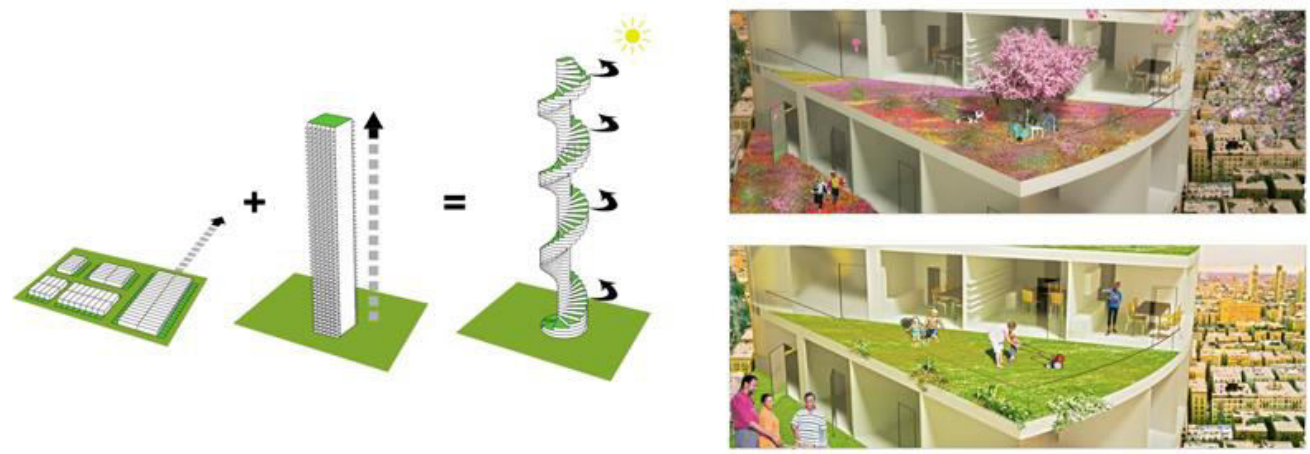

Fig.10. Shaping the cities under new sustainable urban patterns - vertical garden cities

The second way is physical, ie designing the infrastructure of the city to allow biodiversity to maintain and preserve its characteristics. Thus form bioclimatic controlled structures. It is a common occurrence greenery to be an integral part of the city superstructure and be included within the urban blocks, zones for recreation and sport, rest areas and boat, with what city strengthens its social character through informal meetings and communication between citizens.

\section{- Measurement:}

The indicator is measured through the percentage of capture new areas of greenery and the use of existing spaces with biodiversity and green table in the urban environment. Measurability can be intervals according to the adoption of Plan (GUP, DUP, UP ...) for 10 , 20 ... years.

\section{- Control:}

To check, you can conclude how biodiversity is represented in the city and where is missing and how you can upgrade. It should also be ascertained green environments and spaces, parks, walkways, recreational and sports areas, public spaces and green areas within the urban blocks and all other environmental qualities of the city.

\footnotetext{
${ }^{128}$ City farms are community projects in the city including the people who work with animals and plants in order to improve community awareness of agriculture, in particular awareness of people living in urban areas. http://en.wikipedia.org/wiki/City_farm

${ }^{129}$ Synonym for Sustainable design (also called environmental design) is the philosophy of designing physical objects and services in accordance with the principles of economic, social and environmental sustainability. This philosophy can be applied in the fields of architecture, landscape architecture, industrial design, interior design etc... http://en.wikipedia.org/wiki/Green_design ; http://en.wikipedia.org/wiki/Green_architecture
} 
4 ANALYSIS OF THE “GUP” PLANNING DOCUMENTATION SKOPJE 2001-2020, AND PERCEPTIONS OF INDICATORS AND MODELS FOR SUSTAINABLE DEVELOPMENT

Skopje has a centralized role in the urban development of the state. There is concentrated most of the urban population 506,926 people ${ }^{130}$, in an area of $225 \mathrm{~km}^{2}$. Skopje is the commercial and economic center where are all major economic activities, administration, education and institutions in the field of health, culture and sports. Thus Skopje is located high above all other urban areas in the state of the hierarchical scale of attractiveness. This attraction leads to a situation in which the city is increasing, thereby increasing its unsustainability.

The city in its history of growth going through spatial development cycles which ending in disaster, natural or caused by wars and conquests. Migration of large number of rural population in the city began in the late 18th century and early 19th century. At that time in Skopje is built the first railway, and in 1876 are associated Mitrovica - Skopje - Thessaloniki, and later in 1888 Belgrade - Skopje - Thessaloniki. The main axis around which the city becomes concentrated is north - south axis, the old train station and areas surrounding the river Serava, Kale, Topaana, Yeni neighborhood, Gazi Baba, Bit Pazar, Chair, Kardak neighborhood and through the right riverbank, Wallachia neighborhood, Gazi Mentesh ... the number of inhabitants in 1912 was 37000 inhabitants and was intensively inhabited the right bank of the river Vardar.

Once when Skopje became the capital of the Vardar Banovina in the period 1912-1941, and had a significant geo - political role and an administrative center, and the urban plans begin to be worked for the city, at the request of urban landscaping of the Kingdom of SHS (Kingdom of Yugoslavia). The north-south axis is related to radial - concentric ring around the Stone Bridge in the plans of architect Dimitrije Leko 1914 and architect Joseph Mihajlovic 1929. After World War II, Skopje again becomes geo - political center of the New Republic, which is part of the socialist state of Yugoslavia. Skopje became the capital of the Republic of Macedonia and the center of the wider region of southern Serbia, Kosovo and Metohija. Thus, begins the stronger migration of people and expansions of production facilities and industry. In 1948 is prepared General regulatory plan by architect Lujdek Kubesh, plan that clearly systematized urban areas and provides extensions to the east, west and north, and Skopje begins to identify its distinctive character. Residential areas were planned for the north, west and south east, the south side of the mountain range Vodno was allotted for major suburban natural and recreational area along with the City Park under the fortress and the hill of Gazi Baba, while the industry is planned along the Vardar River downstream of both coasts eastward. In this plan to the existing radial street system and the north-south axis clearly begins to be draws the dominant northwest - southeast axis. The preparation of

\footnotetext{
${ }^{130}$ According to the 2002 Census

ANALYSIS OF THE GUP PLANNING DOCUMENTATION SKOPJE 2001-2020, AND PERCEPTIONS OF INDICATORS AND MODELS FOR SUSTAINABLE DEVELOPMENT
} 
detailed urban plans in the following period the city began to grow rapidly. Many new neighborhoods are building Karposh, Proleche, October 11th ... and the city to the 1961 increases its inhabitants to 165,529 .

In 1963, the city faces major destruction in a devastating earthquake. After that is following a period of intensive construction in emergency conditions. In 1964 he was drafted The Basic Urban Plan for more intensive construction for an area of 9090 ha of land of which 4215 ha of land planned for a brand new development. The plan is prepared with the assumption until 1981 the population will increase to 350000 inhabitants and forming spatial zones for housing, industry, services, sports and recreation and transport. At the city were included suburban areas Gorce Petrov, Saraj, Butel, Drachevo, Radishani, Madzari and Singelich. In 1981 the number of people reached 505,930 inhabitants and exceeded expectations, due to the strong centralized role that the city had compared to other parts of the country, leading to a situation of unplanned construction, uneven and unsustainable development. The central part of the city after the earthquake remained unexecuted, although Kenzo Tange envisioned reconstruction in its plan on the downtown area. Much of that space, which is actually the most expensive and most attractive land, remains undeveloped and subject to devastate until today. Also, much of the installation emergency residential neighborhoods Taftalidze, Nerezi, Vlae, Chrome and others are the same till these days and are converted into residential zones with low density. While there is a completely unacceptable urban development in parts of Dukjandzhik, Dizhonska, Gazi Baba... Certain urban development can be seen in the establishment of residential neighborhoods Karposh, Kapishtec, Aerodrom, N.Lisice, Topaana, Chair, Butel and shaping the Southeast and Eastern Industrial Zone. Conversely, unplanned developed industrial and service areas are at the foot of the Zajcev Rid, village Vizbegovo and Momin Potok. This situation gives a picture of disorganized land use on the existence of so-called "Internal reserve" land in the downtown area, and plans are constantly evolving boundaries of the city region. Many of those unused spaces often plans intended for recreational or green areas, finishing with the occupied areas illegal and unplanned construction. Such types of spaces meet the belts around the river Vardar, Zajcev Rid, Gazi Baba, Chair, Topaana, and at the foot of Vodno... Devastated areas and unused parts of the former large industrial complexes such as FAS 11 Oktomvri, Fabrikata Treska, MZ Tito, Kozarata, Staklarnicata... With such unplanned urban policy, the central area is empty, and the city expands and merges with the surrounding suburban and rural settlements with lengthening and forming ring-shaped concentrated around long roads that follow the linear axis and the projection area of the city.

Since 1992 Skopje is the capital of the independent state of the Republic of Macedonia and regained an important geo-political role in the region and covers an area of 7088.60 ha urban area to the surrounding region 180705,53 ha and 444,760 inhabitants. Spatial concept remains unchanged in The Basic Urban Plan since 1985 only thing added to it is the 
suburbs and the city limits were expanded wildly over populated areas and surrounding neighborhoods.

\subsection{Analysis of the general urban planning documentation Skopje 2001-2020 year and planning assumptions for sustainable urban development ${ }^{131}$}

Skopje is the capital of the Republic of Macedonia and the biggest one, therefore, should strive towards sustainable development in urban planning. Sustainable development is increasingly a reality for us and our future development, especially for obligations the state has as a signatory to numerous international and European documents, conventions and declarations.

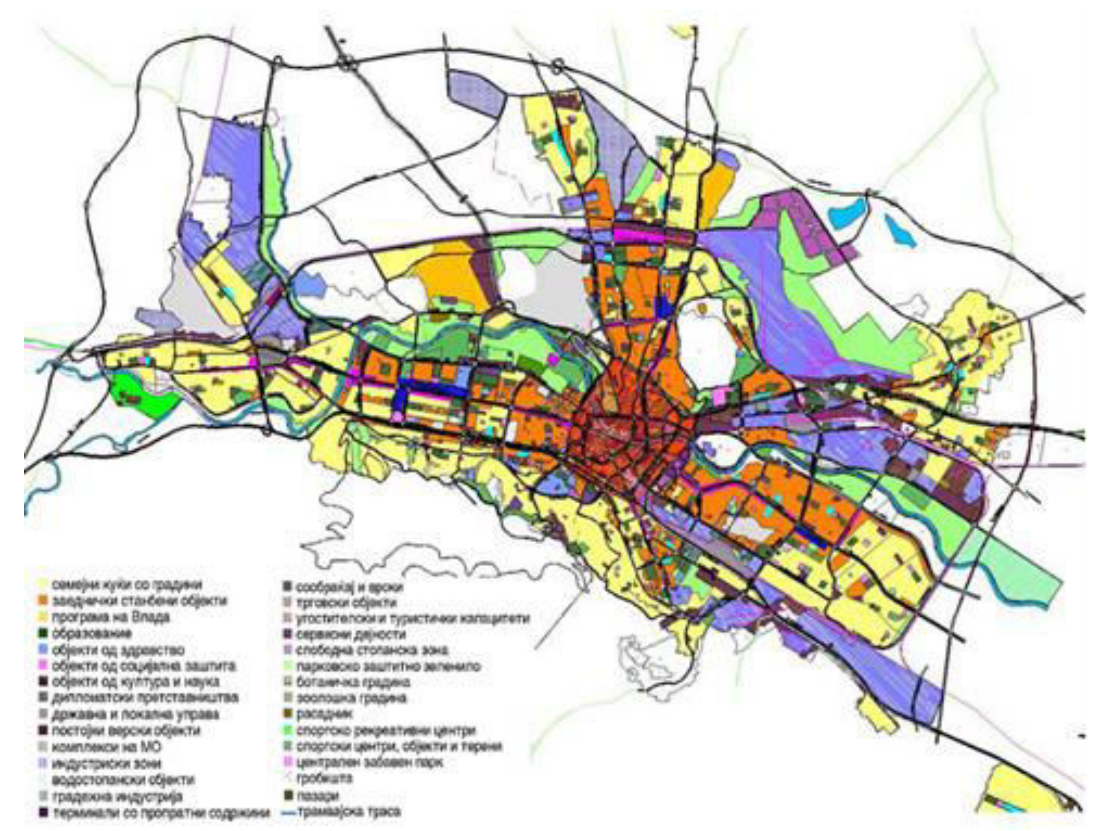

Fig.11 Synthesis display of the GUP Skopje 2001-2020 year

Analyzes that explore sustainable planning of the city of Skopje are relating to the model of urban development that is implied by GUP for Skopje year 2001-2020. (fig.11) In the process of determining the relevant factors for sustainable urban development in methodology for planning in Skopje, the identified indicators for sustainable development of the city will serve relating to urban form with its elements, and the spatial and physical characteristics allow continued urban growth.

Skopje is an urban agglomeration with a large concentration of population and functions. In terms of physical, functional and demographic growth the city has above average pace of development in the region. Skopje is extremely important transport hub on the crossroads of communication corridors internationally. Today's situation is such that the $1 / 3$ of the total

\footnotetext{
131 The working team of JP for spatial and urban plans; Nikola Bošković graduated. eng. arch., team leader; Mr. Saso Manas, graduated. el.eng., deputy director (General Urban Plan of the City of Skopje), June 2002, Skopje ANALYSIS OF THE GUP PLANIING DOCUMENTATION SKOPJE 2001-2020, AND PERCEPTIONS OF INDICATORS AND MODELS FOR SUSTAINABLE DEVELOPMENT
} 
industry in the country is concentrated in Skopje. That is the reason for the increase in population.

\subsubsection{System of settlements, population and major urban functions}

Skopje is demographic centralized city since there is a big difference between the city and the region. It is the result of previous centralized development in the state where the immediate neighborhood of the city did not fully use its potential and was influenced by the strong migration policy.

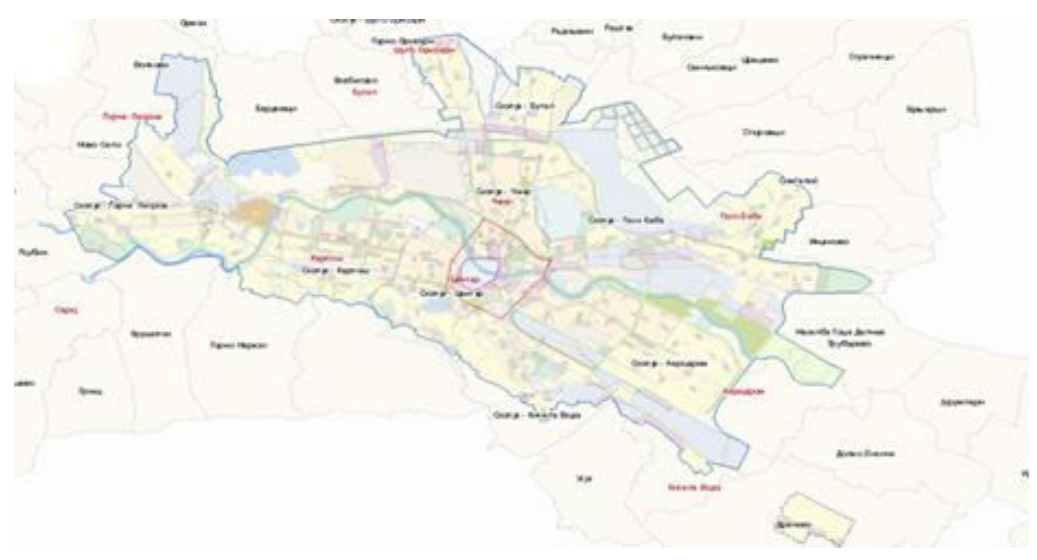

Fig.12 System of municipalities in Skopje

The City is located in the eponymous valley, particularly in the central and western part of Skopje field. It lies in the length of $22 \mathrm{~km}$ (Saray - Drachevo) and $11 \mathrm{~km}$ in width (Crniche Radishani) and covers an area of approximately 7,000 ha (within urban coverage). In Skopje valley exist 153 settlements, 28 villages $^{132}$ and the city of Skopje. Municipalities of Skopje (fig.12) occupy the largest area $(1,818 \mathrm{~km} 2)$ over other territorial-administrative units in the country, or $7.1 \%$ of the area of the country.

Skopje region has an average density network of settlements with an average $14.5 \mathrm{~km} 2$ surface settlement. Skopje region in terms of settlements is divided into four parts by hierarchy: the first level is close to the town of Skopje, the second degree are centers of rural areas, third degree micro centers or centers of neighborhoods and communities of fourth grade production areas.

\footnotetext{
${ }^{132}$ Bardovci, Bulachani, Creshevo, D.Lisiche, Drachevo, G.Nerezi, Upper and Lower Orizari, Grachani, Idrizovo, Indzikovo, Jurumleri, Kuchkovo, Ljubanci, Ljuboten, Nikishtani, Novo Selo, Orizari, Orman, Radishani, Rashtak, Singelich, Stajkovci, Strachinci, Trubarevo, Usje, Vizbegovo, Volkovo and Zlokukani ... (General Urban plan of the City of Skopje), June 2002, Skopje 
The structure of land in the City is as follows: total area of 33.408 ha or $100 \%$ of that productive land 26.078 ha or $78 \%$ and built (unproductive) land of 7330 ha or $22 \%$.

Industrialization most influences on the development of the city and is the reason for the expansion of a range of other activities such as the development of traffic, construction, housing, education, culture, economy, health, etc... (fig.13) Economy in transition had not enough used for inflexible economic structure, inadequate organization and sharpened economic conditions, rather than using the resources available to us and was slowed by a tendency to stagnation. Today is felt some decline in investment and disinvestment, technology for production which is outdated as a consequence lead to lost markets in the territory of the former Yugoslavia, Central and Eastern Europe. The economy also faces serious problems in ownership restructuring. The majority of new business entities are small businesses, but it logs the possible potential of initiatives for more efficient production and service delivery. This situation gives a positive mood when it comes to employment. The planning documentation of GUP envisages the development and restructuring of existing

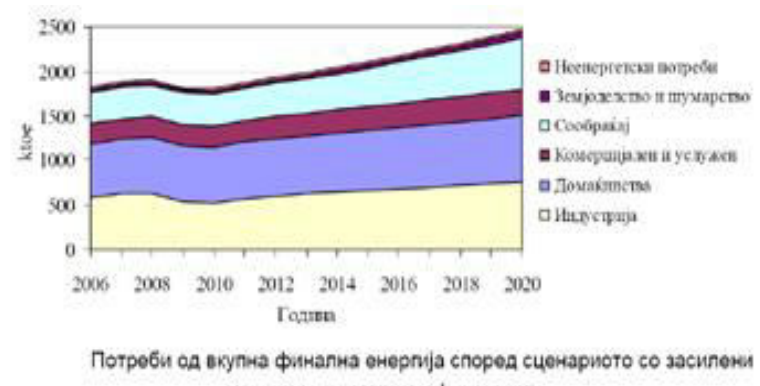
мерки за енергетска ефикасност

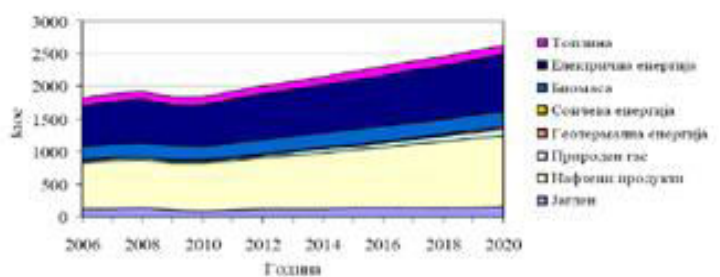

Потреби од финална емергуја до 2020 година според основното

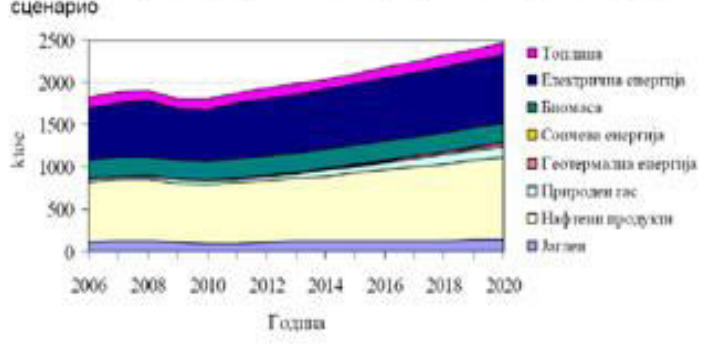

Потреби од финална енергија до 2020 година според сценариото со засилени мерки за енергетска ефикасност

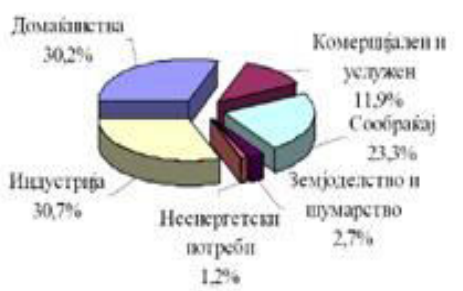

Прочентуално учество на секторите во потребите ор финална енергија sa 2020 година - сцонарио со засипоки морки за енергетска ефикасност

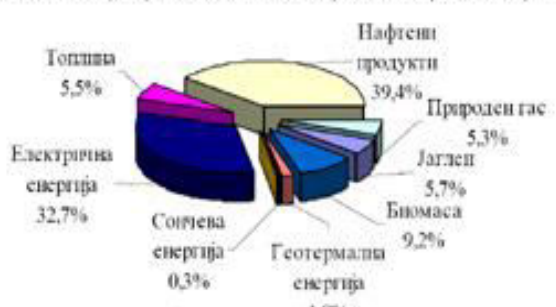

Процентуална распределба на потреби од финална енергија во 2020 година по енергенти според сценариото со засилени мерки за енергетска oфиeкасност production and primarily small and medium enterprises in the period from $2010-2020$ year and envisages create conditions for
Fig.13 Scheduling strategy for energy efficiency in Macedonia to 2020. the development of industrial production at an average rate of about 5.5. Existing industrial zones (South, Northeast, and West) are predicted to be formed taking into account sharpened criteria for environmental protection. Outside the scope of GUP is located north west industrial zone where should be built new facilities for industry base, but it does not 
preclude the need for the creation of a free zone with opportunities to build capacity with highly sophisticated and highly - profitable technologies what is of capital importance for the city and the country as a whole as an opportunity for faster economic development and involvement in contemporary global flows of operations in tough market conditions. Southeast zone by 2020 is predicted to grow only by smaller objects of secondary industry activities and services, which do not pollute the environment. It isn't possible extensions of this zone or reorganization, because it covers the wider area and is centrally located between the neighborhoods: Jane Sandanski, 11 October, Lisiche and Drachevo (Fig.14)

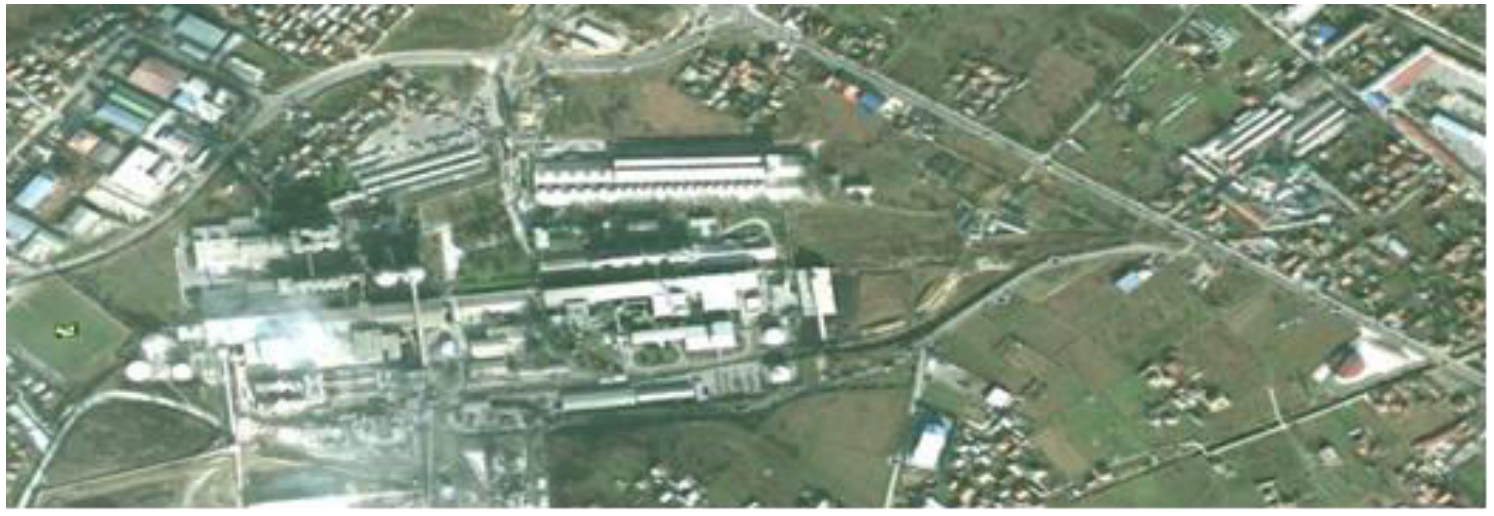

Fig.14 Cementarnica

The function of housing is a very important element in the regulation of urban space. Thereby basically is providing the conditions for human life. Housing as the most eloquent element of modeling the urban structure of the city affects the environmental regulation of the city. According to the Census of 2002 in the city recorded a total of 163,745 apartments. Analysed by municipalities most apartments are in general Kisela Voda $(29,01 \%$ of total housing), followed by municipalities Center (21, 23\%); Karposh (16,62\%) etc... (Fig.15)

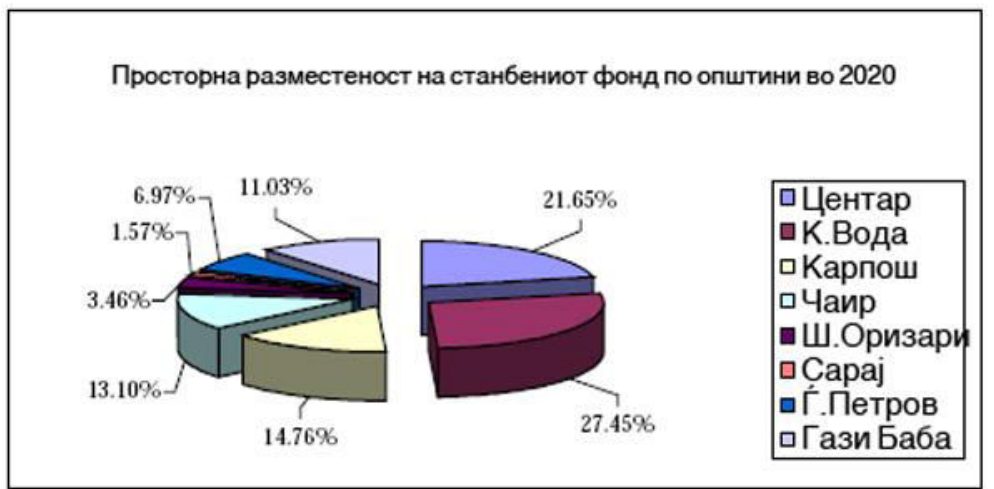


Проекција на станбените потреби на Скопје за планскиот период до 2020година

\begin{tabular}{|l|l|}
\hline Број на жители во 2020 година & 458.897 \\
\hline Број на домаќинства во 2020 година & 131.557 \\
\hline Постојни станови во 1994 година & 120.869 \\
\hline Постојни станови кои се задржуваат & 114.901 \\
\hline Нови станови по основ на замена на субстандардни станови & 5.968 \\
\hline Нови станови по основ на пораст на неаселение & 19.025 \\
\hline Нови станови по основ на отклонување на станбен дефицит & 260 \\
\hline Вкупно нови станови за град6а & 25.253 \\
\hline Вкупно станови во 2020 година & 140.154 \\
\hline
\end{tabular}

Fig.15. Projection of the housing stock in 2020 and housing needs by 2020.

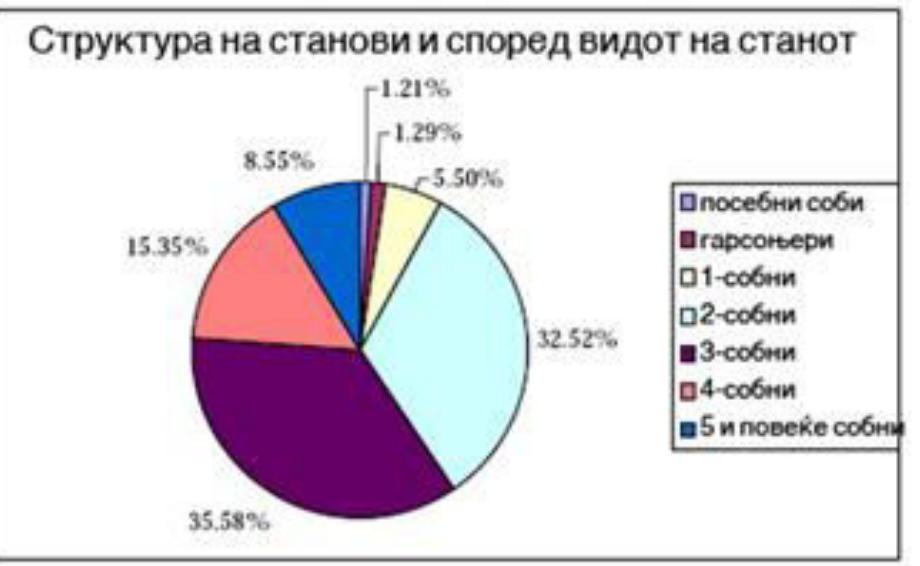

Fig.16. Structure of the housing stock in Skopje by GUP

Skopje is characterized by a diverse structure of residential font: individual freestanding residential buildings with their own plots, residential buildings in rows with their own plots, closed and semiclosed perimetric blocks as multi-family buildings, freestanding blocks and towers as multi-family buildings with one or more entres. The average floors of buildings housing is $1+1.5$. (Fig.16) Total net constructed area of apartments is $8,053,714 \mathrm{~m}^{2}$ that is accounted for average or flat surface equals $66.60 \mathrm{~m} 2 /$ flat. ${ }^{133}$ Territory covered by housing in Skopje is $45 \% .{ }^{134}$

Many neighborhoods in the suburban zone perceive spatial expansion of low population density at large agricultural areas and urban without proper equipment. In terms of gross densities has the largest municipality Center with 98 inhabitants / ha; followed municipalities Shuto Orizari with 89 inhabitants / ha; Chair with 82 inhabitants / ha; Karposh with 77 inhabitants / ha; Kisela Voda with 67 inhabitants /ha; Gorce Petrov with 58 inhabitants / ha; Saraj with 42 inhabitants / ha and Gazi Baba with 33 inhabitants / ha. ${ }^{135}$ (Fig.17)

\footnotetext{
${ }^{133}$ Under surfaces of housing means that thay occupy buildings housing a particular parcel of proper roads without the accompanying content areas (schools, health centers, etc.).

${ }^{134}$ The largest area under housing exists in general in Kisela Voda with $29.4 \%$ followed by municipalities Center with $18.5 \%$, with $16.8 \%$ Karposh, Gazi Baba with $16.6 \%$, Chair with $16.4 \%$, Gorce Petrov $13.1 \%$, Suto Orizari with $4.1 \%$ and $1.7 \%$ Saraj. (General Urban plan of the City of Skopje), June 2002, Skopje

${ }^{135}$ Net residential density refers to the number of residents in terms of area under the surface of the housing without the associated functions of housing. Net residential density is greatest in Center (214 inhabitants / ha) , followed by Saraj with 198 inhabitants / ha ; Karpos with 156 inhabitants / ha ; Shuto Orizari 152 inhabitants / ha ; Kisela Voda with 150 inhabitants / ha; Chair with 139 inhabitants / ha ; Gazi Baba 120 inhabitants / ha and Gorce Petrov with 103 inhabitants / ha . Maximum net residential density noted in general in the local community Center Blagoja Despotovski - Shovelj with 455 inhabitants / ha and MZ Mirche Acev with 433 inhabitants / ha; and MZ 


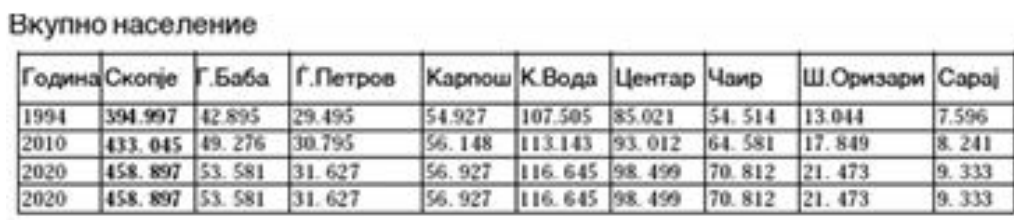

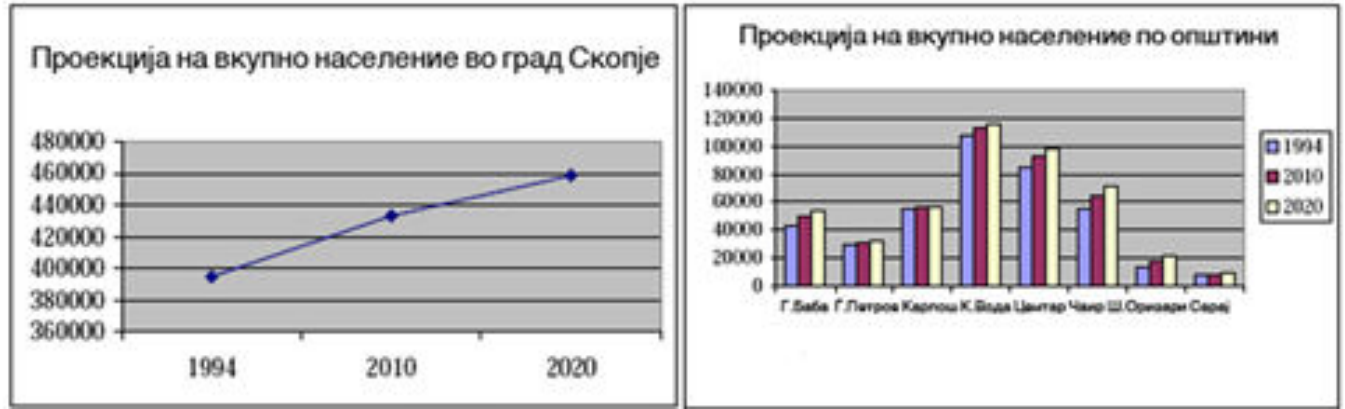

Fig.17. Projections of the population by 2020.

When discussing the situation with housing is important to mention the situation with illegal construction that are more and more spread out and more and more multiply. Illegal constructions engage urban land, space for public green areas, protected areas with special purpose as "Park - forest Vodno" room intended for industry and etc... Builds disorganized, unplanned at attractive surface and quality agricultural land, and organizes settlements that prevent further continuity in the urbanization of the city planning and development of the region and state. Illegal construction is a complex and difficult problem. The blame for this situation is not only large and unplanned migration in recent history of the city, also the omissions made in the untimely passing of planning legislation, but its implementation also and non-compliance and non-implementation of appropriate sanctions. Sociological category implies the quality of life, or the needs of various collectivities (housing, education, health, nutrition). Given the economic situation of the population in localities inhabited by illegal construction can be concluded that the quality of life in these areas is relatively low : lack of equipment with non-economic facilities, inability to build or upgrade and upgrade existing facilities for unregulated conditions construction, bad building, bad situation because of the proximity to busy roads localities, and in the industrial zones, railroad, highway, areas threatened with near dumps, areas directly affected by noise etc... ${ }^{136}$

The projected housing development in the planning period to 2020 should allow rational spatial organization of housing and increase the intensity of use of urban land. In this sense, the greatest densities and coefficients of utilization of construction land is reasonable to expect the municipality of Center that has a high value of urban land, as well as high

Avtokomanda (Gazi Baba) with 432 inhabitants / ha. Thirteen local communities have a population density in the range of 300-400 inhabitants / ha; 15 communes with a density of 200-300 inhabitants / ha; $31 \mathrm{MZ}$ with a density of 100-200 inhabitants / ha, and 16 local communities with densities below 100 inhabitants / ha. (General Urban Plan of the City of Skopje ), June 2002 , Skopje

136 Total number of illegal buildings constructed is 6 258th Most of the buildings are of solid construction 5709 and 549 of low construction. (General Urban Plan of the City of Skopje), June 2002, Skopje 
dynamics and public interest. That means the urbanization of central city neighborhoods , those of the old historic core and Skopje before the earthquake ( Debar Maalo, Bunjakovec, Dukjandzhik, Bit Bazaar, Clock Tower, Karadak Maalo , Old Topaana, Madzir Maalo , Novo Maalo), which reconstruct multi-family residential buildings and receive residential and business functions. Outside the downtown area, where there is less housing densities recommended strategy for the construction of multi-family residential buildings block the optimal amount flooring $\mathrm{G}+3$ and $\mathrm{G}+4$ floors in terms of meeting the hygienic and technical conditions and Privacy microclimate conditions. A major objective of housing is leveling the living conditions in all parts of the city, specifically linking all areas of housing infrastructure systems. That means inclusion of the residential area with low urbanity and some settlements in the total system of housing rehabilitation and reconstruction of urban space. ${ }^{137}$

In the system of settlements in the city of Skopje are functioning centers as part of the urban functions in the city. These are structures towards which gravitate a number of functions and are important for the attractiveness and appeal of the city. City center today engages over 250ha in the central part of the city. Centers of lower hierarchical level - regional or local major centers formed in

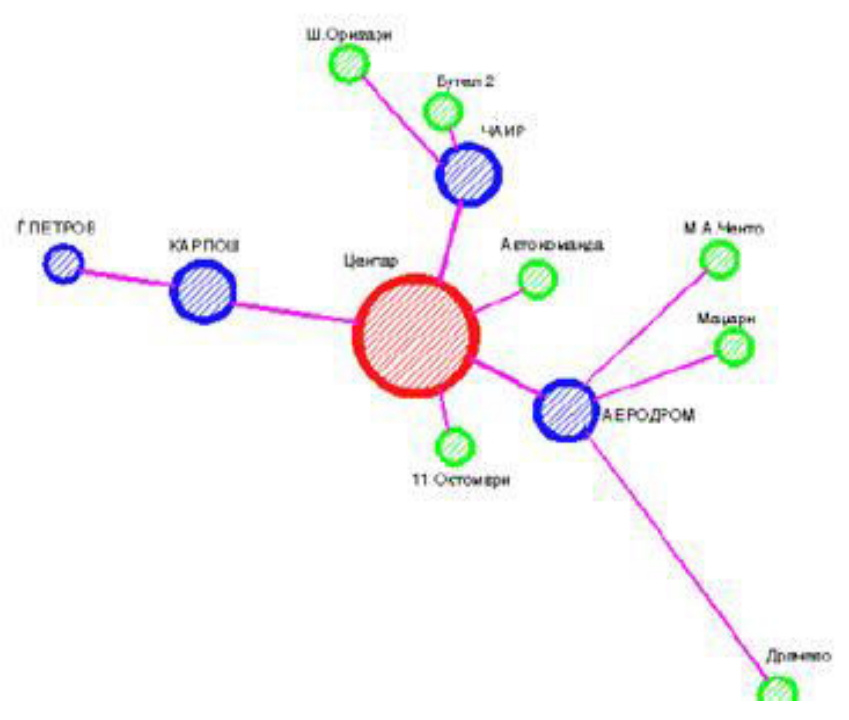

Fig.18. Regional centers in Skopje the following parts of the city: Center, Karposh 3, Airport Chair, G.Petrov, Chento, Drachevo, Avtokomanda, 11 October, Shuto Orizari total hire about 55 ha. (Fig.18) Although designed to meet the everyday needs of the population with different content : trade, crafts, tourism , hospitality, and even social activities, health, library, small sports content in regional centers ... today mainly there can be found only trade, service, administrative and service activities. At the same time the centers are set up so that the function introvert despite roads with parking space on the perimeter of the center. Thus always has a problem with parking, because there was not enough parking places for all visitors, a big noise that disturbs residents of nearby residential buildings. Regional centers such as those in the settlements Karposh 3 and Aerodrom are placed along the boulevards Jane Sandanski and Partizanski odredi, which creates a problem for accessing easy, especially for residents of surrounding

\footnotetext{
${ }^{137}$ Parts of Gazi Baba, Keramidnica, Triangle, Madzari, Kisela Voda, Prvomajska, Skopje Sever, part of the Chair, Dizhonska, Momin Potok, Shamak, Trndol, Kamnik, Pintija, Pripor, part of Gorce Petrov, Shuto Orizari , Butel ... (General Urban plan of the City of Skopje), June 2002, Skopje 
settlements who need to cross the boulevards and move across the street and nearby parking space to come to the center, without the possibility of free movement and access.

Objects of non-economic activities should to create the population have equal opportunities for social development and equal opportunities to live. These include facilities for education, health, science, culture and other social public institutions. Within contemporary social protection includes: special protection of children and family ( editing relations of parents and children, adoption , guardianship ), protection of disabled workers , protection of persons with physical and mental defects, blind, deaf , defective ) protecting the elderly etc... Culture is the totality of material and spiritual values that created man in his social and historical life. These are two interrelated areas: material culture (means of production and other material works) and spiritual culture (generality of the results of science, art, philosophy, morals, customs and traditions). Facilities in the culture in the city of Skopje are libraries, cinemas, theaters, houses of culture, museums and galleries.

Protection of cultural heritage means linking the created elements belonging to a single system at different epochs. The introduction of the new in the old, modern architectural form can be part of creatively composed "new" structure "Old Town" (the site "Skupi "Zajcev Rid ) Skopje, without disturbing its authenticity and un-compactness. Expressed individuality of Old Skopje, with its multitude of forms also form strong impressions derived from spatial and morphological differentiating units ( Fortress, Stone Bridge , Undertown, hill " Virgin " at the Clock Tower , Skupi - Zajcev Rid etc... ), contributes to create dynamic panorama , fragmented and individual experiences.

\subsubsection{Urban greenery, sport and recreation}

The planning of green areas should aim to the creation and promotion of a healthy environment. According to the concept of functionality and spatial structure of the city, depending on climatic and environmental conditions is adopted a yield of $15 \mathrm{~m}^{2}$ per capita greenery. Green territory which belongs to the city for its function and content is divided in urban and suburban green foliage, or public greenery and foliage of limited use. City foliage is composed of city parks, squares, and blocks the green linear foliage. It is called public urban greenery. Foliage with limited use is green areas around social objects, botanical gardens, zoos, etc... Suburban green areas have spatial framework, its particular border area and consists of: buffer zone, forests, meadows and more...

The plan was made by following division:

- Public green: green housing 276.70 ha; regional parks 3.38 ha; urban parks 54.82 ha; Playground 0.75 ha; central amusement park 2.97 ha; 17, 47 ha sports pitches.

- Foliage limited use: public buildings 15.58 ha; science and culture 8.09 ha; health 18.48 ha; schooling 56.73 ha; high schooling 32.10 ha; 14.00 ha botanical garden.

- Sports and recreation centers that are outside the metropolitan area used by citizens for recreation include: Saraj 25.00 ha; Kanjon Matka 22.00 ha; Hippodrome 19.00 ha; Kamnik 2.70 ha.

- Suburban greenery: Water 4573.00 ha; Reed Zajcev 7.00 ha.

- Protect vegetation: Gazi Baba 130.00 ha; Karposh 28.27 ha; Kisela Voda 8.56 ha. 
The plan provides much of the existing green areas to reconstruction and rehabilitation in terms of vegetation, grass areas and urban equipment. Blocks foliage predicts about all new residential structures. The total area planned in the neighborhoods under foliage should be at 390 ha, according to yield $8.5 \mathrm{~m}^{2} / \mathrm{inh}$. Within the block foliage is necessary to predict children's playground and mini parks parties, with appropriate horticultural projects. It is greenery in regulationof traffic and shaping of the square. The total area of the squares in the city can reach up to 1.5 ha. The total area envisaged under Regional public green areas and public green areas of general importance downtown, parks, city parks, river foliage, etc., are projected at 642.45 ha, according to yield $14 \mathrm{~m} 2$ / inh. Natural phenomenon in Skopje valley, which should be to consider are: rivers Vardar, Treska, Lepenec and Kadina Reka, created green riparian buffer zones, connect the protective foliage with communal greenery in town. These protective belts are of paramount importance to the favorable development and promotion of biological balance, both in the region and in the city, or to enhance and enrich the quality of the overall landscape in Skopje valley. The total new area planned for river foliage is incorporated in yield for the park and it is about 200 ha. ${ }^{138}$

For the sports center is taken yield of $1.2 \mathrm{~m} 2$ / inh. means that in the planning period will require an area of 55 hectares for recreational sports centers. Some recreational sports centers are located located near the city: Saraj, Ezeroto Matka, Hippodrome, Kamnik i Lake Treska.

\subsubsection{Infrastructure, categorization and concept of traffic network}

A basic indicator for the development of traffic level in a region, city or township is the motorization, and it is the ratio between the total population and the total number of registered vehicles. The development of motorization of Skopje can be tracked through the analysis from 1965 to $1996 .{ }^{139}$

The average daily mobility of the inhabitants of the city of Skopje is 2.11 trips per capita of whom 0.71 trips per capita is

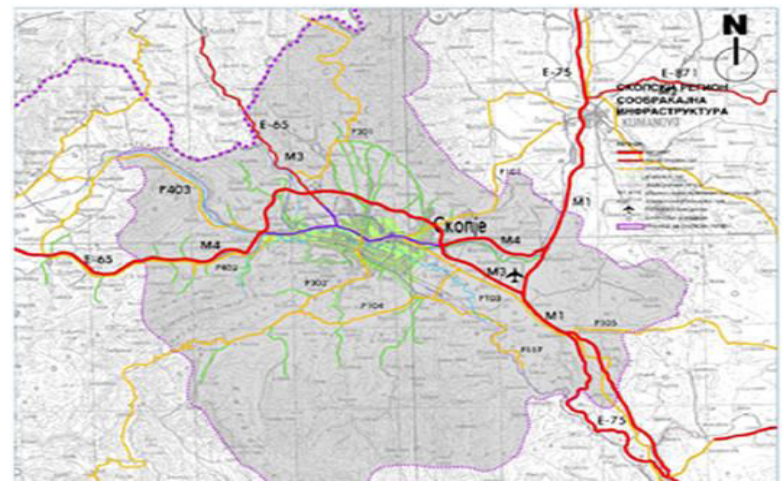

Fig.19 Transport infrastructure for the Skopje region

\footnotetext{
${ }^{138}$ The special kind of fall foliage in green: Zoo provided with an area of $11.5 \mathrm{ha}$; flower nursery with $15.5 \mathrm{ha}$ Botanical Garden 3.4 ha; cemetery with $96 \mathrm{ha}$. To that should be added greenery erected in the area of Vodno and 4.573ha Zajcev Rid area of 7ha. (General Urban Plan of the City of Skopje), June 2002, Skopje ${ }^{139}$ In 1965 were only 10,577 registered motor vehicles, after which planners predicted that in 1981 would be approximately 62,000 registered vehicles, ie in 1991 approximately 84,000 vehicles. Meanwhile, apparently the development of motorization of the city exceeded forecasts, so that in 1991 registered 104,133 vehicles or more than 20,000 vehicles than predicted by urban plan of 1965. (General Urban Plan of the City of Skopje), June 2002, Skopje 
achieved with pedestrian movement and 1.40 trips per capita generated by the aforementioned vehicles.

In Skopje were performed field studies and post processing of survey material resulted in the following global conclusions:

- from the 113,091 families in Skopje, surveyed 7036 or $6.20 \%$;

- from the 444,299 inhabitants of Skopje, surveyed 17,369 residents;

- respondents exercised 28,920 average daily trips;

- from the respondents: $50.02 \%$ are employed; $21.41 \%$ are students or students ; 11.09 $\%$ are unemployed ; and $17.48 \%$ are others ( pensioners, elderly people, housewives and others);

- the average number of passengers in vehicles is 2.1 passengers, including the driver;

- the distribution of trips by purpose of travel, expressed as a percentage of the total population is as follows : for going to work $22.3 \%$; education $8.6 \%$; buying $8.7 \%$; recreation, entertainment and other $13.2 \%$; returning home to $47.2 \%$;

- distribution of trips by mode of exercise is: walking with $33.5 \%$; bike with $1.9 \%$; car with $28.4 \%$; using public transport - bus $34.0 \%$; fees $1.5 \%$; other vehicles $0.7 \%$.

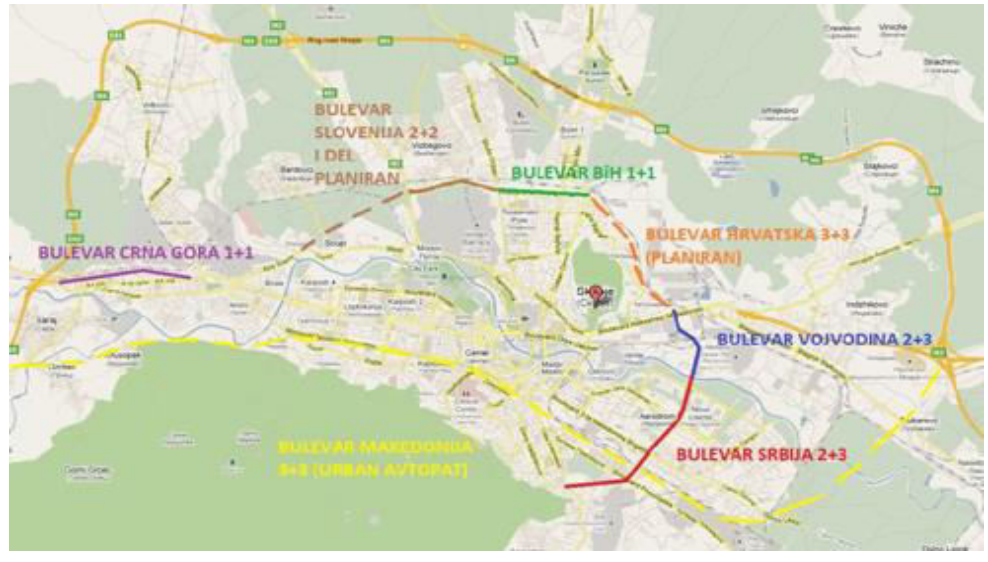

Fig.20 Planned traffic network in Skopje

The plan retained the division of the traffic system from The Urban Plan of the city of Skopje from 1985 where primary (basic) traffic network in city includes: express roads; arterial roads; collector roads. According to the Law on public roads, the traffic network in the settlements includes: roads, highways; collective streets; service areas; residential streets. The primary traffic network in the city was founded as a radial-concentric system of roads (fig.19). This model consists of a circular ring around the center and radial directions aimed at the city center. The primary road network of the city interacts with the external road network in the country. The Plan provides for construction of the highway at south mountain range of Vodno built over the existing structure as the completion of the second circular ring of the city (fig.20). The Plan also provides changing the boundary of urban settlement Radishani towards the north-west, the range of 30 ha. 


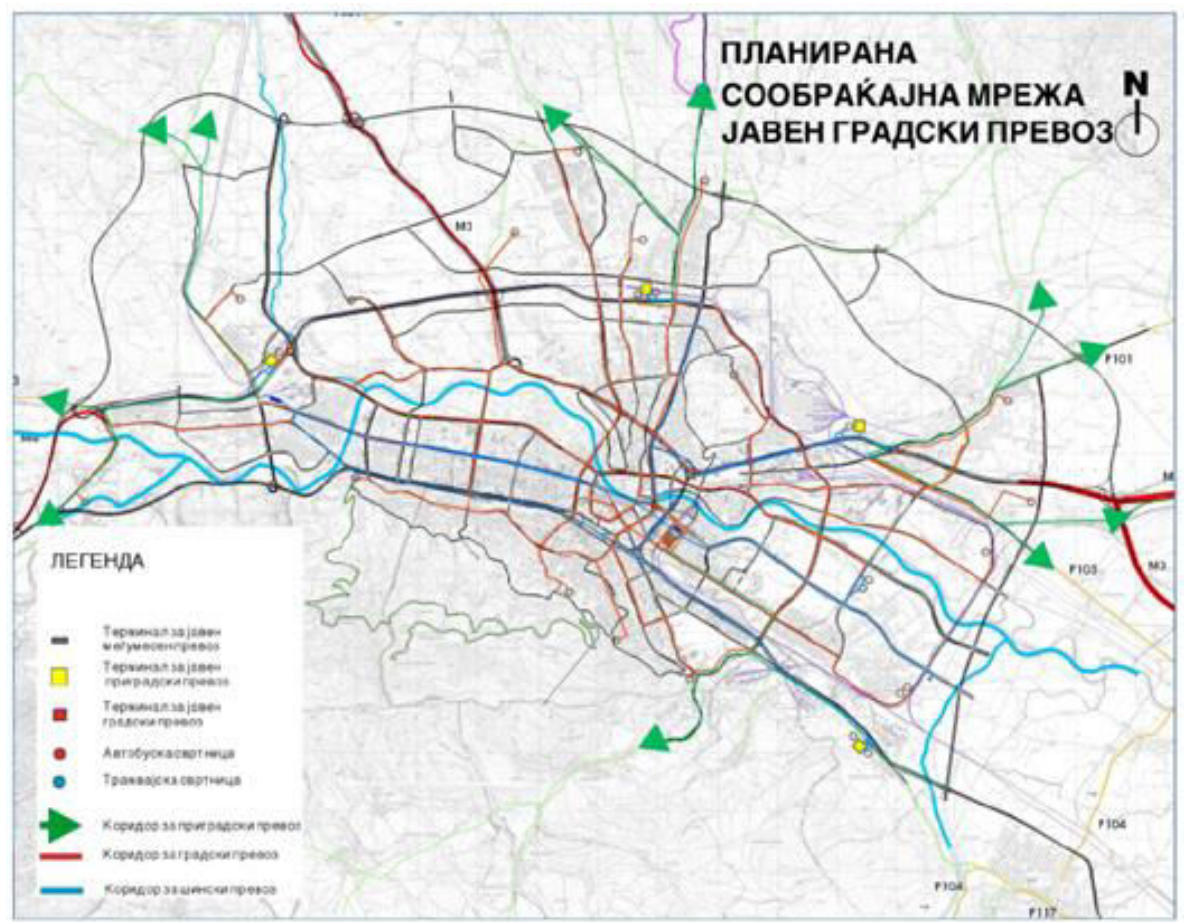

Fig.21 Planned network of public transportation in Skopje by GUP

Public urban and suburban traffic in the city is planned as a combined, or should be pursue by railway, tram and bus -rail vehicular subsystem through an organized system of terminals and network transport lines ( fig.21). The bus subsystem performs transportation in the city and suburban public transport of passengers. For the purposes of public urban and suburban bus transportation in the city of Skopje built auto-bases in Avtokomanda and Gorche Petrov, and plans to build another auto-base with an area of 4ha in Chair directly to the location of special -purpose street Shuto Orizari. The railway subsystem uses existing rail infrastructure - followed up: built railroads, rail stops and railway stations. This system will be carrying the passengers to suburban traffic. Tram -rail vehicular subsystem as the main provider of public passenger transport in urban traffic, according to the results of such research and analysis required to be built and put into operation by 2020 . It will comprise two depots (Gorche Petrov and Novo Lisice), terminals and related incidental stops with a network of lines and contact lines for power supply. The railway node in the area of the city of Skopje and the degree of development fully meets the needs of the planning period, ie only have to complete The Transport center of Skopje anticipated features and content. Concept development of the railway system in the planning period relies on the need to modernize the railways in general. On the other side, rail transport could play a significant role in the organization and in completing the network of suburban traffic in the city of Skopje. 


\subsection{State of the city through study and observation of indicators for sustainable development}

\subsubsection{Built of the urban environment}

The latest plans, the expansion in the city was mainly to establish space through legalization of the illegal settlements and commercial areas. This approach created another less sustainable urban development that encourages informal settlements and rural- urban settlements that illegally occupy land, because one day they will legalize. Today the city has an elongated shape in the north - south axis with a length of $14 \mathrm{~km}$, and in the west - east axis $28 \mathrm{~km}$. This extension of the city -wide only $4 \mathrm{~km}$ creates problem to solve traffic infrastructure. Elongation of the city and creates problem in elongation of traffic and network infrastructure in the city. There are no concentric connections between them , and as a result of further elongation of the town on the east - west axis within the city includes rural areas that comes to mixing the character of neighborhoods, urban and rural. While simultaneously extending the city, much of the planned locations in the city remain completely unformed. It is planned locations for specific purposes. The expense of it, there is occupying new locations for planning new development. The problem occurs when a location is occupied with other purpose than that for which it was intended. Especially troubles are in the provision of infrastructure and transportation network, and providing tracking and navigation activities. If that unplanned residential development then there is a lack of provision of facilities for education, health, culture, etc... Or if it comes to economic development there is unplanned absence of adequate infrastructure for commercial and industrial buildings.

In Skopje, there are huge supplies of urban land that is unused (50\% of the city's land is unused), which provides an opportunity for future growth without expanding the city limits. In particular it is important to know in what condition it is land whose ownership is to be included in the planning purposes or if not be altered unless it is used for the intended purpose. Throughout the development period of the city are only preferred construction of new land without a reconstruction and filling of abandoned and vacant spaces in the devastated city. Rare are the examples of reuse of land in the city as exemplified by Kapishtec settlement built on the territory of the old railway. Everything else is built on completely new urbanized land settlements Lisiche, Drachevo, Radishani, Aerodrom, Kisela Voda, Chair, Butel, Karposh, Chrome, Vlae etc... (fig.22) 

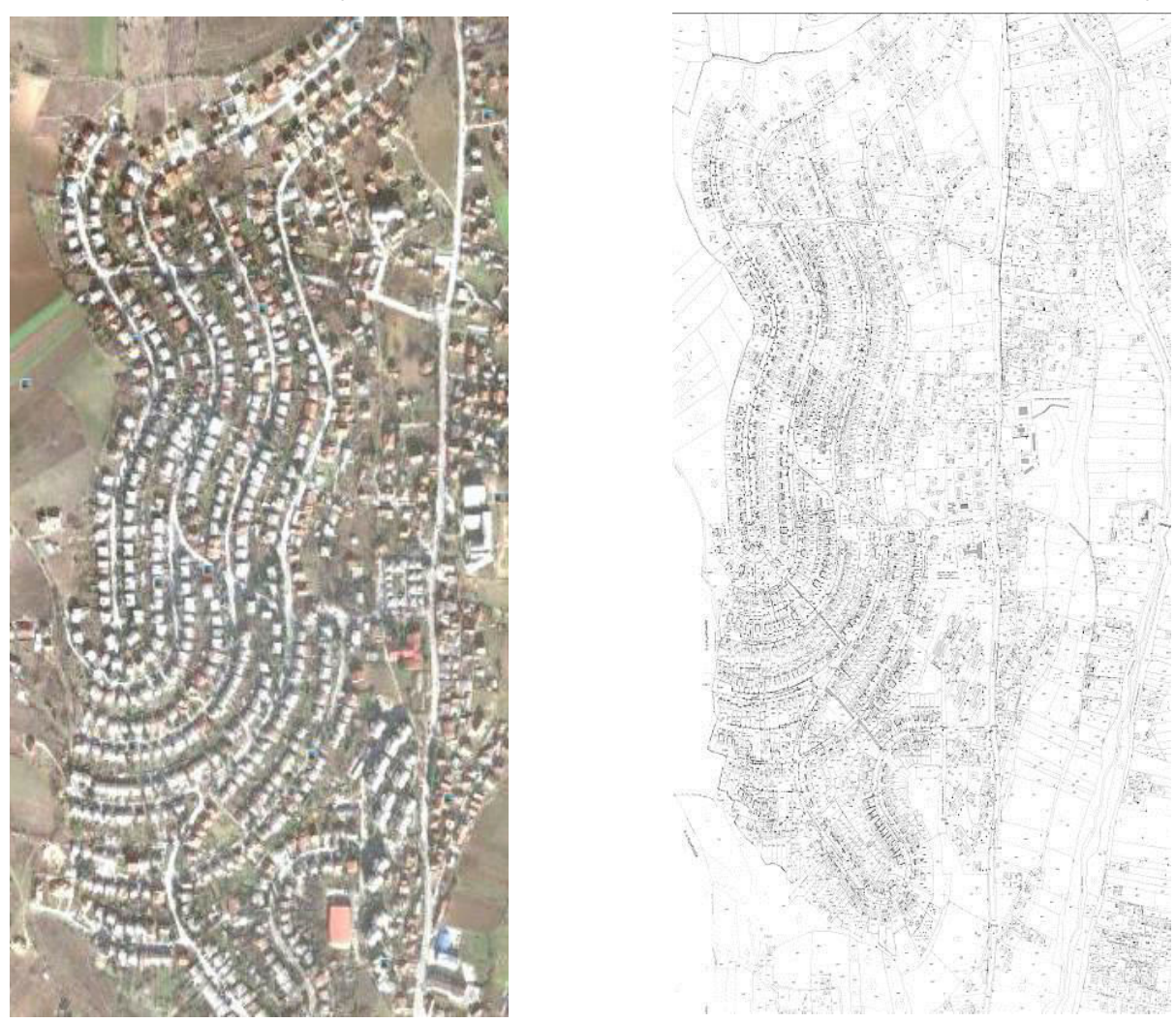

Fig. 22 Radishani

The resulting set of broad city limits, where even includes a great deal of unused and devastated areas, industrial and commercial zones, etc.., is the problem of dispersion of the settlements and the need for increased use of vehicles traveling from one place to another in the city. This situation can be used in favor of sustainable development in a way that will encourage construction of unused land will encourage increased density, without being destroyed and open green spaces that exist in the city.

\subsubsection{Usage of space and land use}

Division of Skopje as intended and land use has marks from the Ottoman urban model where existed town centre, military fortress and defensive center. Toward that were affiliated neighborhoods as residential commercial communities organized with proper administration and divided along ethnic and religious grounds. The main craft and trade center was a bazaar shops. The image of the city further change historically and slowly entered the European urban model with several centers of trade, commerce, service and service purposes, and culture, education, health, sport and recreation, and industry. The old railway station was setting normally to the current street straight to Macedonia Square, through the Stone Bridge, the Old Town to the Bit Pazar area. At these axes appear trade and financial services, and the first industrial park is located on the space between Kumanovo and Vardar, along the railway to Salonika. Sports and recreation center was located in the City Park. Further plans this split of purposes had rigorously divided into appropriate zones: administrative, sales, service, residential, educational, health and 
recreational facilities, and the development of industrial zones (Eastern, South Eastern and Western Industrial Zone) and development open spaces for recreation and greenery beside the city park, mountain Vodno, the coastal zone of the Vardar River and hill Gazi Baba.

Today's situation is not much changed from the last plan in the $80 \mathrm{~s}$ of last century. The city center is the most attractive place in which houses all purposes: trade, sale, housing, culture, entertainment, education, health services, service, hospitality, and greenery and parks. Downtown is located City mall and relatively new shopping-center "Ramstore". These

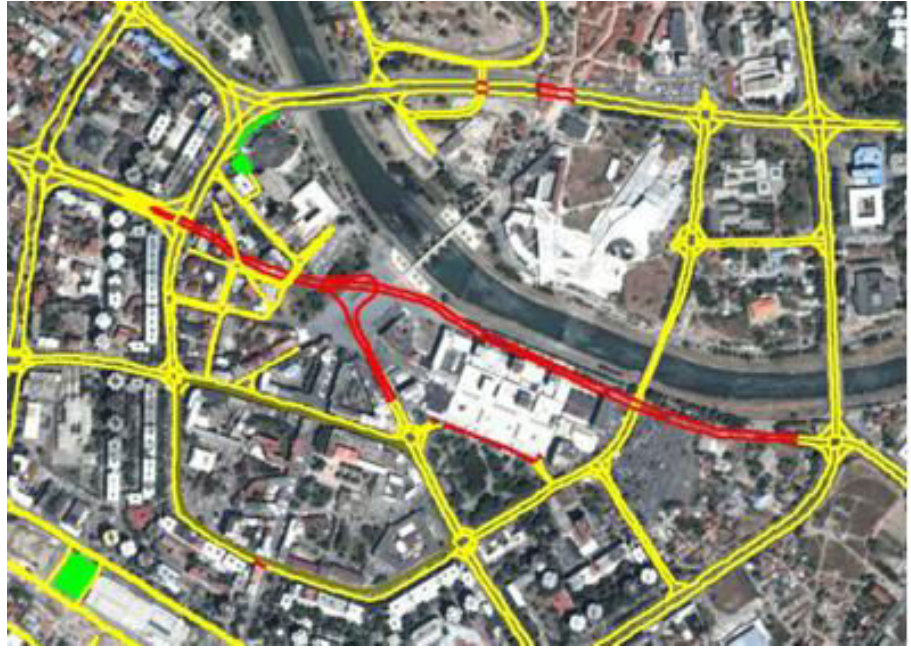

Fig.23 Small Ring in Skopje are two major centers of trade purpose but it also cultural, service and hospitality content. City Mall is open and it included even residential buildings associated with the environment with direct access from the main square and the park Female Fighter, while mall "Ramstore" is introvert space at a facility that contains all the elements of commerce, entertainment and services. These centers not only serve the surrounding residential communities but are important objects that determine the significance of the city center. Within the Small Ring the city center serves neighboring communities because it is not closed and access to the cities immediate and closes (small distances in radus of $400 \mathrm{~m}$ ). (fig.23) It provides a solid basis for establishing sustainability in terms of compactness with regulated traffic and opening opportunities for using alternative transportation opportunities ( hiking, organized public transportation, bicycles, etc. ). Neighboring communities attached to the Small Ring at the end distance of $1 \mathrm{~km}$ or $10-15$ minutes walk. At Small Big is affiliated Large Ring with designated residential buildings of the City Wall with the main purpose of housing. Closeness to the center allows residents to use all content and accompanying sense of life in the city. Within the center is located and the main administrative and social content: Government and Parliament, the House of Army , EVN , Complex banks, museums, cinemas, theaters, many hotels etc... All content in the center, specifically in the areas of small and large Ring are allocated in perimetric blocks accessible from the street. The remaining areas are largely residential community of neighborhoods that have Regional centers that should meet the daily needs of the population: sales, trading and service, as well as education, health, sport and recreation. The most important are regional centers Karposh, Aerodrom Chair and Gorce Petrov. It is planned to Regional centers serve a population of 80000-140000 people. In each of these centers there are some drawbacks. Almost all have inadequate number of parking spaces 
according to the capacity to serve the centers (except in the regional center in Aerodrom where recently there parking garage). There are left part of the content that should be there, so there are no daily content for health care, social content for the elderly, some cultural content (cinemas, theaters, etc.). Nor childrens and sports playgrounds have appropriate dimension, usually are too small.

Access to residential neighborhoods requires better organization of conveyor systems with better developed public transport and providing enough parking spaces. The regulation and planning are covering some of those features in transport. The result is a decentralized urban structure, apart from the center of the city is characterized by a particular "spunk".

The situation with residential uses in the city concluded by the capacity of housing and it equals the total number of 444760 inhabitants $20.49 \mathrm{~m}^{2} /$ capita housing space, ie the average number of people per apartment 3.27 and an average apartment size of $66.6 \mathrm{~m}^{2}$. It is obvious that a large number of the population has owned more than one apartment.

Some interesting information when it comes to analyzing purposes. Provided under the standard regulations for the schooling area in Skopje is $7 \mathrm{~m}^{2} /$ student indoors and $30 \mathrm{~m}^{2} /$ student yard and kindergartens $8 \mathrm{~m}^{2} /$ child indoors and $24 \mathrm{~m}^{2} /$ child yard. The situation is such because a school and a kindergarten serving more neighborhoods or parts of neighborhoods, ie a distance greater than $400 \mathrm{~m}$ standard. Similar is the case of secondary schools, where found $6.71 \mathrm{~m}^{2} /$ student indoors and $11.19 \mathrm{~m}^{2} /$ student yard radius and the handling of $1200 \mathrm{~m}$, while the capacity of the university faculties distributed in several locations in the city amounted to $9.71 \mathrm{~m}^{2} /$ student indoors and $15.67 \mathrm{~m}^{2} /$ student yard.

The situation with health services is still alarming, namely the city has 69 ambulances, so that each serves residents in 6446 and while they are not evenly distributed on settlements (eg in a Chair Clinic serves 10,563 residents, while the Gorche Petrov Clinic serves 37,961 per capita). Cultural Centers are at the lowest level. The city has only 4 museums, 3 galleries, 4 theaters, 4 cultural centers, 23 libraries, 13 cinemas, which are mostly located in the center which required travel.

When it comes to use of space and use of land in the city of Skopje all purposes are mainly concentrated in the center which indicates the failure of the regional centers that should meet the needs of residents in the respective districts in terms of trade, culture, sport, recreation etc... Only in every neighborhood is satisfactorily presence of accompanying content of education, welfare and health. In order to ensure sustainable development, it is necessary to complete the function of the regional centers in the respective areas in order to satisfy the principle of decentralization of purpose and ability to reduce the population travel to meet the respective needs of life. The center thus will not lose its attractiveness as a place to visit, live or work, but many will ease unnecessary travel by residents of settlements that in certain parts have population density as a small town. The city should encourage the development of the regional investment centers and services that are less profitable, but are 
certainly needed for many of the population. Also decentralized condition that characterizes the city will gain more vitality and attractiveness through the variability of uses.

\subsubsection{Population density and built up}

From the period of the Byzantine and Ottoman influence is recognized under sections Kale, Dukjandzhik, Old Town and Gazi Baba where they meet residential floors with $Q+1$

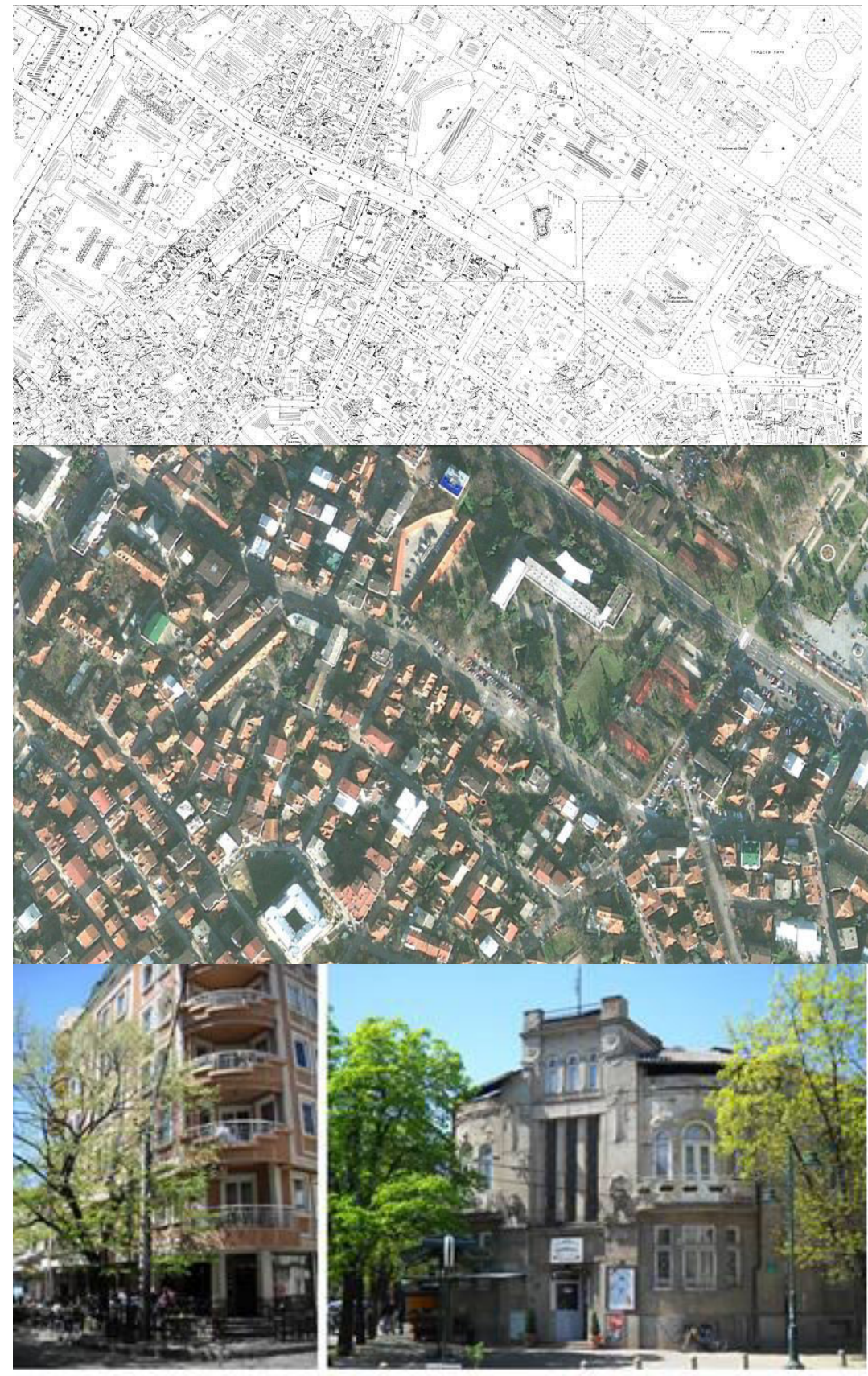

Fig.24 Debar Maalo

branched organic organized along streets. The population density ranges from 195 inhabitants / ha, and 52 residential units / ha to 250 inhabitants/ha or 69 residential units / ha. This house on the ground floor almost always occur shop that had crafts-selling activity. The oldest urban structure organized by regulation line formed urban block is seen in Debar Maalo (fig.24) and Bunjakovec where is clear plots, proper road network and access to each parcel from the street. The population density ranges from 162 inhabitants / ha, with 45 
residential units / ha in Bunjakovec to 177 inhabitants / ha and 49 residential units / ha in

Debar Maalo. These include the urban residential houses with floors of $Q$ to $Q+1+2$ today been transformed into objects with upgrades which increases the density of development and population.

There is a part of town where it is established urban structure according to the principles of modern, as is the case with settlements Karposh, Chair, Topaansko Pole , Prolet , Kisela Voda, free standing multi- floor facilities $Q+4$ placed in areas with greenery.

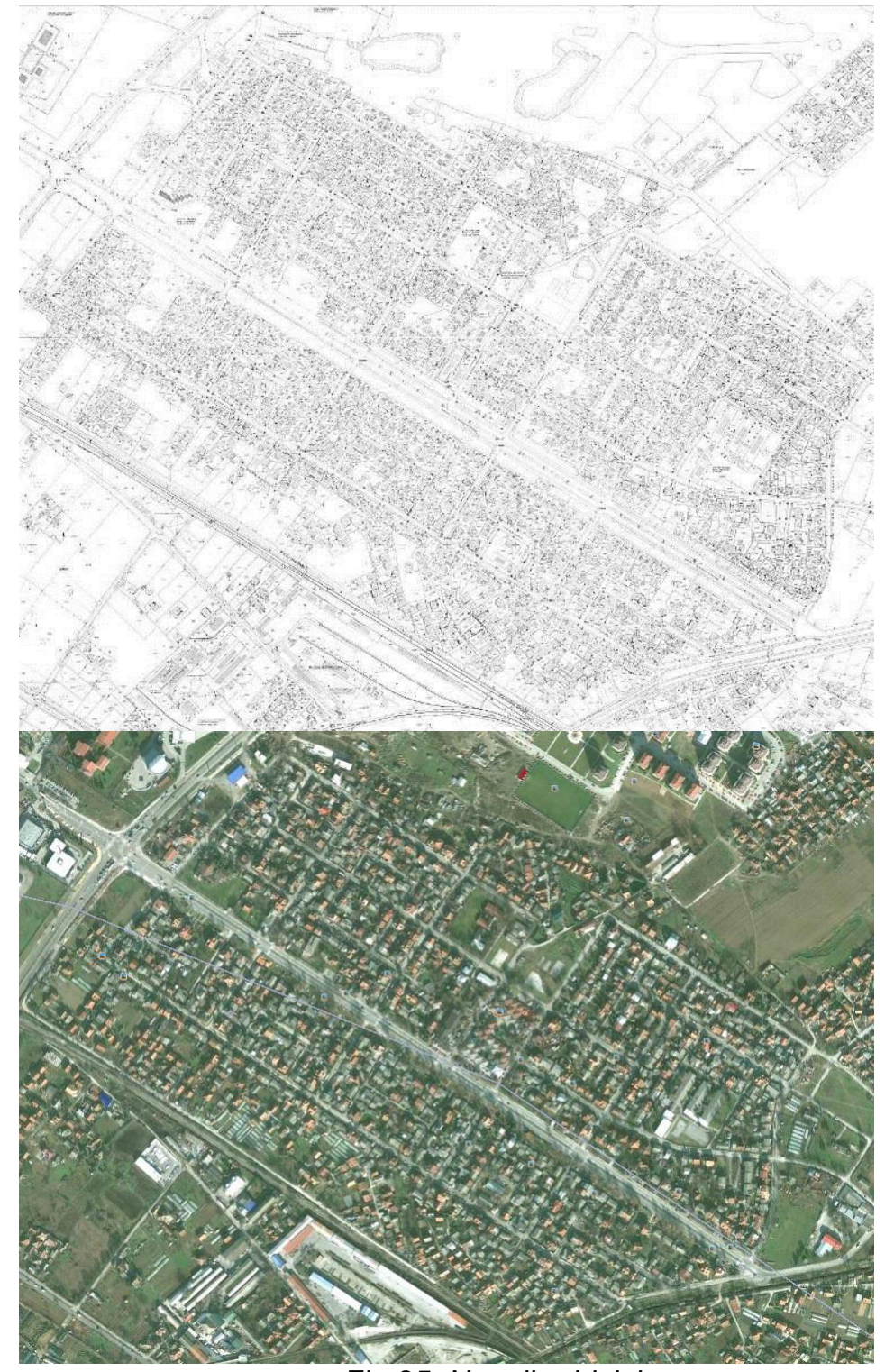

Fig. 25 Naselba Lisiche

The population density ranges from 161 inhabitants / ha, with 45 residential units / ha in some parts of Kisela Voda to 324 inhabitants / haa or 90 residential units / ha in Topaansko Pole. Average settlements in these density ranges from 220 inhabitants / ha, or 77 residential units / ha. Also, there are areas where population density is low and where the urban structure consists of one- house yard. Such settlements are Crniche, Madzari, Lisiche , Butel ... Average density in these settlements ranges from 128 inhabitants / ha, or 36 residential units / ha. (Fig.25) 


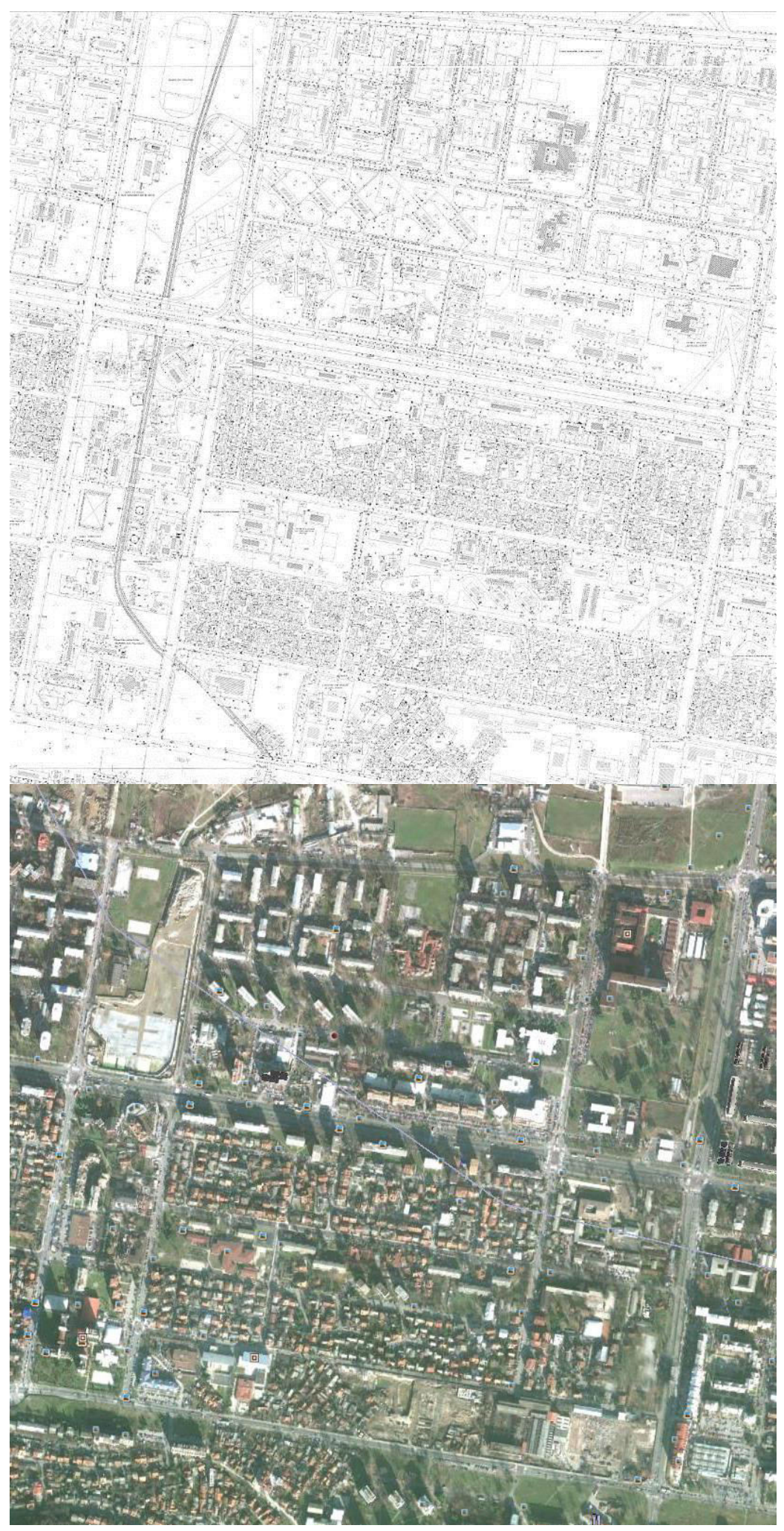

Fig.26 Karposhi Taftalidze

Similar to the structure and settlements Taftalidze, Vlae, Zdanec, Vodno and Przino have urban structure that received the urgent care building quickly after the earthquake in prefabricated houses with one-yard proper orthogonal scheme. (Fig.26) This structure exists to this day with some increase in density for updates and additions to houses. The population density ranges from 75 inhabitants / ha, respectively 21residential units / ha in Przno, 110 
inhabitants / ha or 31 residential units / ha in Taftalidze 1, to 135 inhabitants / haand 38 residential units / ha in Zdanec.

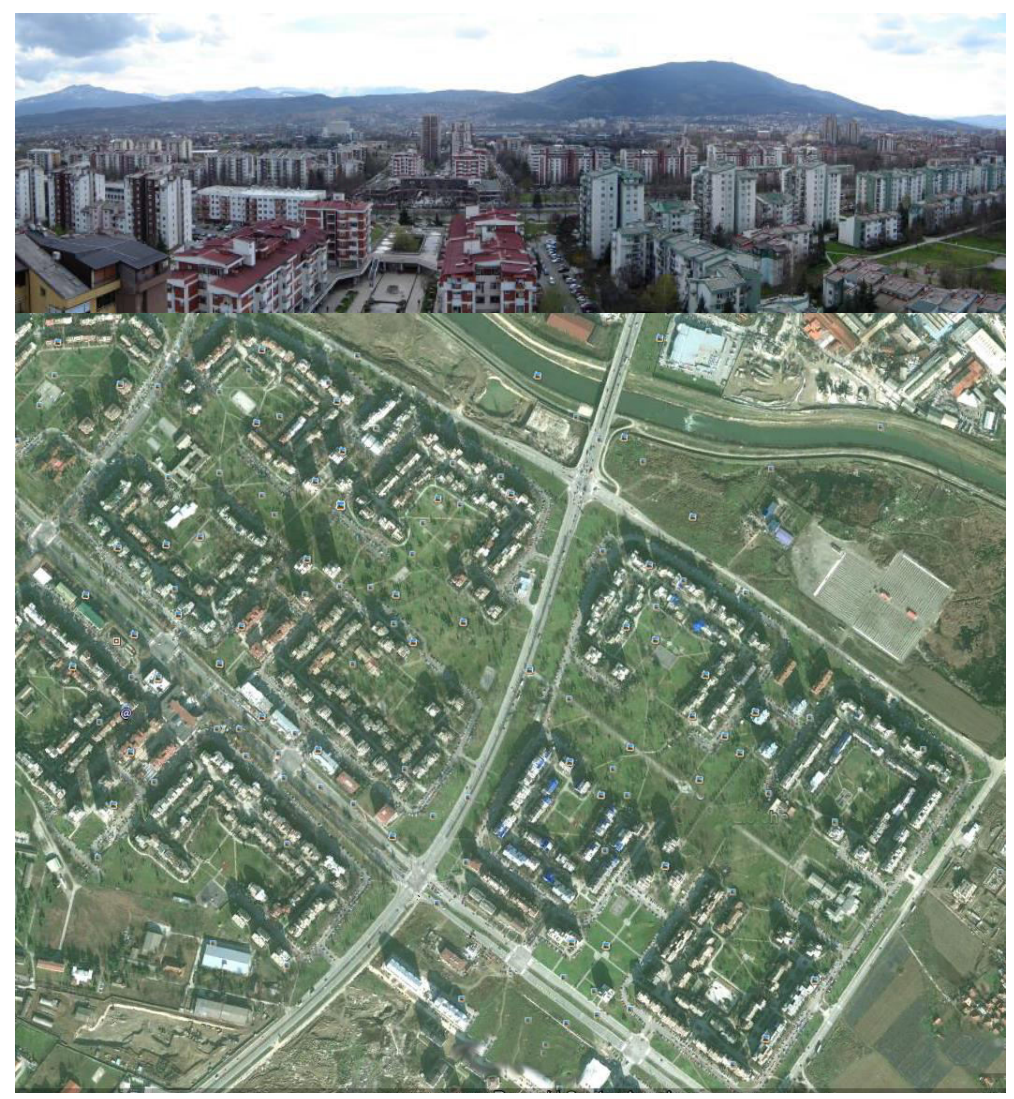

Fig. 27 Aerodrom

The latest residential neighborhoods Kapishtec, Aerodrom and N.Lisice were built again with the familiar principles of modern urbanism as free-standing multi-floor buildings with $Q$ +4 to $Q+7$ (in some parts of the buildings to $Q+15$ ) in locations without plots created with common open spaces and planned contents. The population density ranges from 219 inhabitants / ha, and 61 residential units / ha in N.Lisice, 325 inhabitants / ha, or 90 residential units / ha Kapishtec to 343 inhabitants / ha, or 95 residential units / ha Aerodrom. (Fig. 27)

When it comes to sustainable density and type of residential structure important are the following parameters:

- density of 35 dwellings / ha or 100-150 inhabitants / ha for the floors of Q;

- density of 45 dwellings / ha or 130-180 inhabitants / ha for houses with garden and floors $Q+1$;

- density of 50 dwellings / ha or 150-200 inhabitants / ha for multi-family buildings with floors $Q+2$;

- density of 55 dwellings / ha or 165-220 inhabitants / ha for multi-family buildings with floors $Q+3$; 
- density of 65 dwellings / ha or 200-260 inhabitants / ha for multi-family buildings in the floors through $\mathrm{Q}+4 ;^{140}$

In Skopje almost no part of the city where the density is in sustainable limits, but below the minimum viable density. As these parts can not exist independently are associated with adjacent residential communities and share the accompanying content. On the other hand, the supplementary facilities do not exist in sufficient numbers that would be required in a sustainable density, it mean the lack of a sufficient number of health facilities, facilities for sports and recreation, open courts, post offices, banks, and service etc... Unsustainable urban structure in density is visible and physically. The neighborhoods that are most distant from the center of the city (Aerodrom, N.Lisice and Karposh) are characterized by the greatest density that is contrary to the notion of compactness. It entails the decentralization problem, rather a problem in providing transportation, infrastructure, jobs, and services.

Due to the condition of the improper density in much of the city and unsustainable distribution of density in urban structures, Skopje needs increased density or compactness. In some ways the process of increasing the density is in progress by being doubled surfaces built with upgrades and additions in Bunjakovec, Debar Maalo, Taftalidze and Kisela Voda etc... Process is changing housing typology of one-house $Q+1$ in multi-residential buildings with $Q+3$ to $Q+5$. This trend leads to the merging of objects and creating parametric blocks with front on the street as recognizable city structure. Towards this trend of compactness, should encourage construction in plots that would be filled, but not at the expense of public open spaces and greenery.

The urban structure of the city implies possibilities for calculations with the density of population and construction. Traditional parametric city block that is placed on a plot of land with famous owners allows easy change that currently happens in the city, through the increase of the constructed additions, upgrades, which was relatively easy and individual transformations. Modern concepts of urban structure composed of partially freestanding or free-standing residential buildings on land without plots and numerous owners of apartments in the most thankless structure that can transfrom over time. If exercised a greater change and densification of only extension and upgrade, I showed real problem with the property and the displacement of many people. The settlements are built on that model is difficult to adapt to sustainable densification, and to apply that principle as a model for sustainable development should be carefully selected future urban structure of the city of Skopje, particularly one that can transform over time and increases density without leading to problems in the neighborhood.

\footnotetext{
${ }^{140}$ Barton H. Grant.M ang Guise.R, Shaping Neighbourhoods, A Guide for Health, Sustainability and Vitality (Spun Press, an imprint of Taylor \& Francis Group,London, UK, 2003 


\subsubsection{Traffic organization}

Main vehicle in Skopje is a car $(28.4 \%$ of trips), which makes the city completely unsustainable in its behavior when it comes to traffic and transportation. (Fig.28)

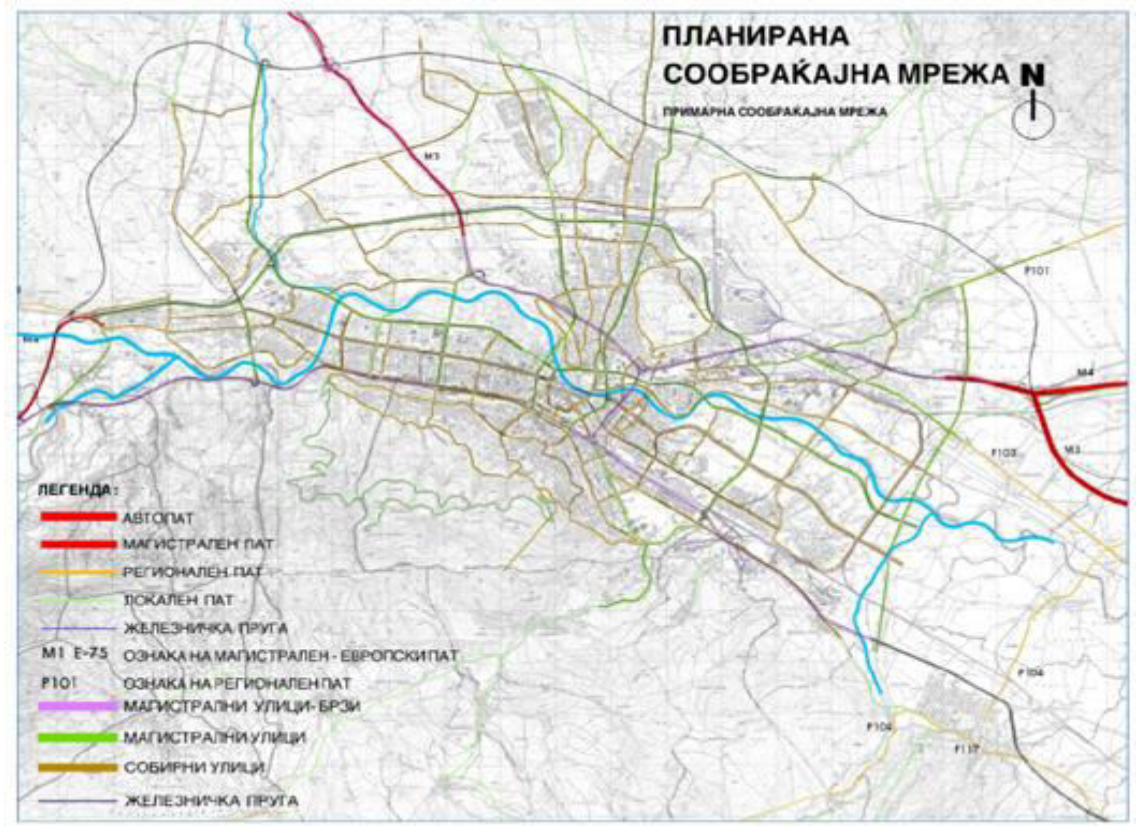

Fig.28 Network traffic according to GUP Skopje 2001-2020 year.

The increase in the number of vehicles each year is higher ( in 1965 number of cars was 7265 , and the last measurement in 1996 the number was 111,151 car ), although there are conditions for use of public transport ( $34 \%$ of trips ), walking ( $33.5 \%$ of trips ) and cycling ( $1.6 \%$ of trips ) as alternative transport. The car gets its primacy in the plans of road networks after 50 s of last century, although early motor traffic occur urban public bus transport. Plans in 1985 in Skopje road networks are designed to express, arterial, collector and local roads designed for a capacity of vehicles for 5 people per car. The introduction of the tram as a public transport was mentioned, but that idea never realized. In this regard, it should be noted that rail transport is completely excluded from public transportation in Skopje, and is only used as long distance transportation of passengers from other cities. An interesting initiative is to revive the bicycle traffic with the opening of bicycle paths along the southwest- southeast in the town in recent years. It should be emphasized that walking is also very common in Skopje, especially for passage of small distances in the city center and around the settlements, suggesting specific sustainable behavior is a good basis for deepening the behavior.

Automobile traffic and use of a car (taxi - $1.5 \%$ of trips) in Skopje reaches limits of concern and alarm. The streets are not instantaneous, air pollution is high and above the permissible limits, and there is still noise and disorganization of traffic. Many of the streets of lower rank and ending blindly and not finished. It is especially tricky for the operation of public transport. Until public transport is concentrated on the main road axes: Blvd. Jane 
Sandanski, Blvd. Partisanski Odredi, Blvd. Krste Petkov Misirkov, Blvd. Cvetan Dimov, Blvd.

Goce Delchev, Blvd. Aleksandar Makedonski, Blvd. Ilinden, st. Anton Panov and st. Prvomajska. There is a need to improve public transport and to think about ecological vehicles for public transport as a viable alternative transport.

Traffic delays are also common and mostly in the downtown area: ul. Kuzman JosifovskiPitu (the complex of banks), st. Krste Petkov Misirkov (in Court Palace and the Bit Pazar), st. Kocho Racin (in Jugodrvo), Bivd.Partisanski Odredi (the Cathedral), Blvd.Ilinden (the Government), st.Dimitrije Cupovski (the former Putnik), and st.October 11(the Green Market). Traffic congestion is directly associated with air pollution and noise.

The problem with parking spaces and facilities on roads is expected given that neither is planned and built for a capacity of 3.8 inhabitants per vehicle or 1.3 vehicles every family in Skopje. If you add to that the need to provide parking space for functions commerce, hospitality, administration, entertainment, culture and etc... situation is worrying. Sustainable transport in Skopje can be seen and developed through positive data using walking as $33.5 \%$ and public transport as $34 \%$ of the total transport in the city. Despite the large percentage of car use in Skopje, the facts that are used a lot of old cars is additional burden when it comes to air pollution.

Perhaps the most untenable situation in the city of Skopje occurs in relation to traffic. It is clear that there is opportunity for urban public transport, but it is evident poor quality and creates major problems in the traffic. Sustainable development is possible if the traffic give more space for cycling and pedestrian movement, improving urban public transport using modern environmentally friendly vehicles and good organization by opening and completion of the street network. It is good to think about the possible implementation of rail type of

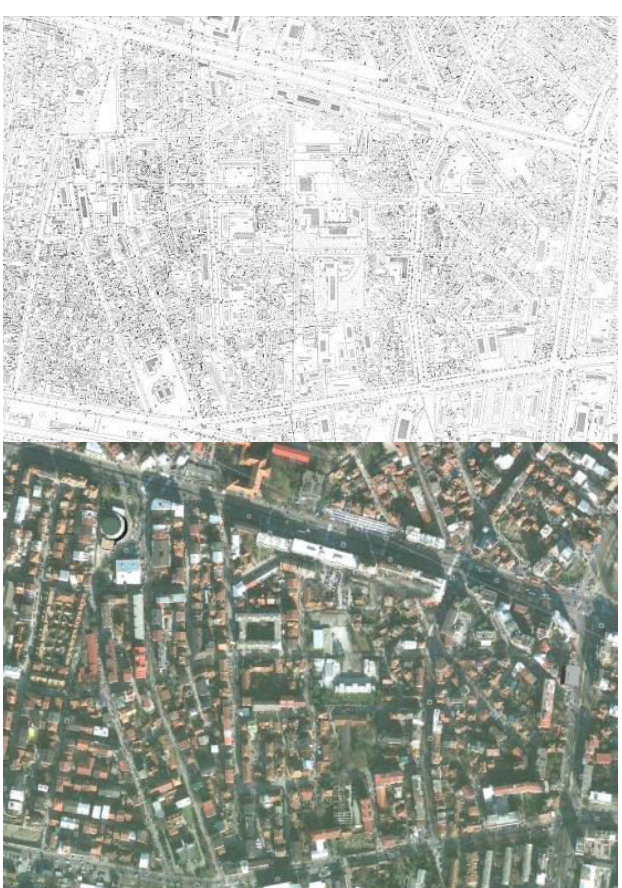

Fig.29 Urban matrix in the center of Skopje public urban transport, which is very pure kind of traffic.

\subsubsection{Identification, recognition and adjustment of built structures}

Skopje has a distinctive urban model that is connected to its historical development. The oldest urban matrix that still recognizes the city's medieval organic matrix that follows the topography of the terrain to houses with yards in organized communities called neighborhoods - "maala". These houses throughout history have changed their features and appearance, with additions, expansions, and even changes in the parcels. In communities like that 
existed an oriental introversion and good neighborly relations.

First organized urban neighborhood in orthogonal form with blocks that follow the street front with access to each plot appears in the plans of 1876 in Madzar maalo. And these facilities over time have changed density upgrades and additions, but the organization remains recognizable. This model continues the urban matrix early in the last century to be recognized in Bunjakovec and Debar Maalo, and is observed in settlements built after the earthquake as editing (Fig.29). These are neighborhoods with proper orthogonal street grid and creating the right blocks of plots with narrow street front. Today they are the strongest parts of the city have been transformed with additions and updates tend to be closed as perimetralen towering city blocks. Urban perimeter block is a feature of the town center in the area of The Small Ring structures with floors of $Q+4$ and street fronts and internal courtyard. The period of the 50s in Skopje brings modern urban model of open blocks without parcelaci with shared network traffic related to the primary and secondary town internally handling between blocks combined with open parking spaces. Today these neighborhoods experience transformation and increased density with additions and updates. The problem occurs in the absence of a clear plot of land and property. The latest residential neighborhoods from the 80 s are semi-closed blocks organized as residential complexes with common open space as public and semi public spaces together with supporting content for the community. And here, today we face the problem of lack of clear parecels and ownership.

Basically in Skopje there are two types of recognizable urban matrix. One type is characterized by perimetric blocks where there is accurate and clear plots that are simple for future transformation (additions, updates, rebuilding, increasing block objects or grinding etc. .) where it will not disturb the existing concept and image of the neighborhood. Such urban matrix is easily adjustable, so it is suitable for thickening and changes that enable sustainable development. The other type is half closed and open blocks set in green, no express parcels and property, as a remnant of the plans in the previous system, where the state apartments were sold. Interventions in such shaped neighborhoods are very difficult. It is impossible to achieve adaptability of urban image and thereby to perform some type of reconstruction. Possible extension of a sweat roof spaces and free spaces can not be predicted in order to fill thickening of the settlement, because that in most cases are already organized free parking spaces, sports fields and greenery. Thus variability for sustainability in Skopje is impossible in urban matrices is of recent date of planning and construction. The transformation that occurs in neighborhoods near the center ( Bunjakovec, Debar Maalo, Kisela Voda etc... ) provides of recognizes the concept of compactness as a good concept for sustainable urban centers. 


\subsubsection{Recognition of the value of biodiversity}

Skopje is located in Skopje valley surrounded by mountain ranges Vodno, Suva Gora, Zeden, Skopska Crna Gora and Kitka. In the city are some hills Zajcev Rid, Kamnik, Gazi Baba ... and flowing rivers Vardar, river Lepenec and Markova Reka. Such geographical picture conditioned also climate characteristics of the city, and specific flora and fauna. Today's state of biodiversity is such that the existence of urban greenery is divided as follows: public greenery which is composed of residential green 276.70 ha, regional parks 3.38ha and 54.82ha city parks; vegetation within the public facilities (health, education, science, culture, botanical gardens ...)144.98ha; suburban foliage (Voodno, Zajcev Rid...) 40 580ha; recreational sports centers (Saraj, Canyon Matka, Hippodrome, Kamnik) 68.70ha and protect foliage 166.83ha. According to the analysis of the total urban greenery belong $14.54 \mathrm{~m} 2$ per capita in Skopje.The position of the city is enabling the natural context and biodiversity.

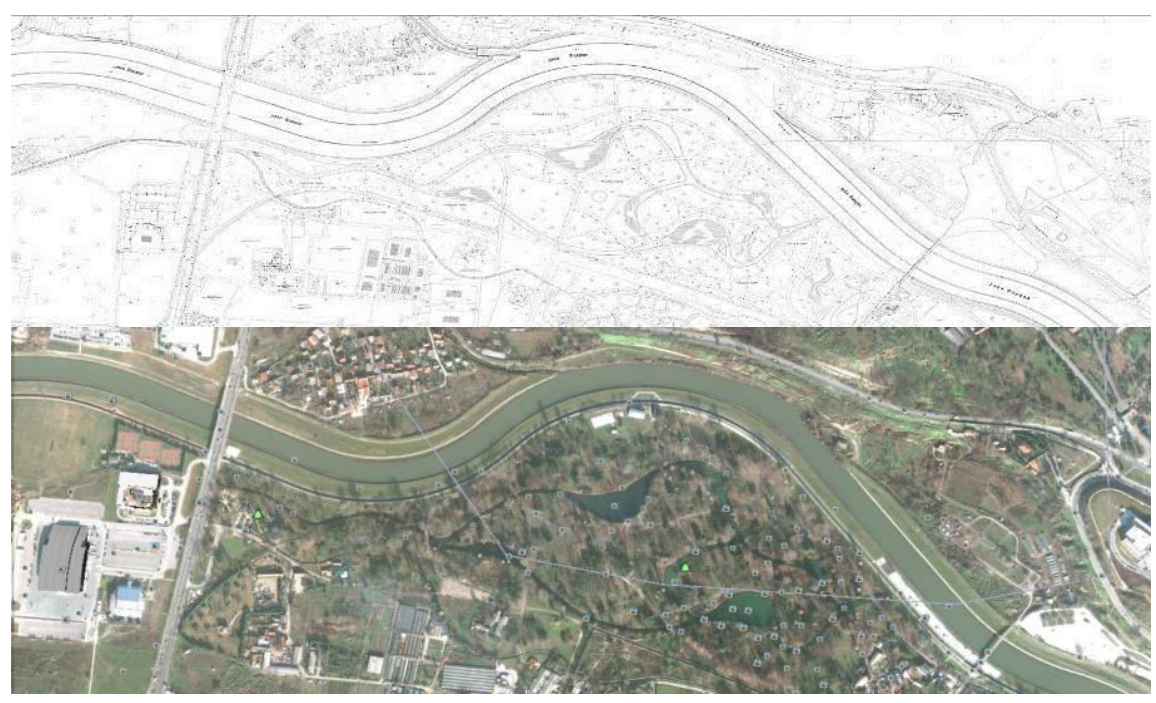

Fig.30 The City Park

Skopje should continue to nurture their natural context of environmentally friendly way. It means to preserve and develop the ecosystem in the city: the river Vardar, mountain Vodno, the city park, the hills Kale, Gazi Baba, Zajcev Rid, etc.(Fig.30). Except preservation, cleaning, arranging of these natural resources, in order to encourage sustainable development is necessary to increase the green area in the city with new avenues, parks, squares, especially in populated areas outside of the downtown area.

\subsection{Possible future models of sustainable urban development Skopje}

Our country has accepted the concept of sustainable development, is a signatory to numerous international declarations, charters and documents from the district and the capital Skopje is where sustainable development should be operationalized. In planning documentation of the GUP 2001-2020 sustainable development is declarative introduced 
RELEVANT FACTORS IN SUSTAINABLE URBAN DEVELOPMENT OF URBAN PLANING METHODOLOGY AND IMPLEMENTATION OF CONCEPTS FOR SUSTAINABLE PLANNING (PLANNING DOCUMENTATION FOR THE MASTER PLAN SKOPJE 2001-2020)

without notice planning documents for development, which requires a specific methodological framework of analysis derived from models that are discussed in this paper.

\subsubsection{Polycentric model of sustainable urban development of the city of Skopje}

Skopje has all the prerequisites to develop decentralized due to the large influx of population, and in order to strengthen the capital intensive which has the sole purpose as a system to create more consumption, and thus new construction. The new transitional conditions create a dynamic picture of the city with unstable jobs require constant education and mobility. Polycentricity model therefore implies the notion of dominance more than one center. Skopje has already created such a predisposition for development, especially the development of the planned regional centers. Decentralization should include decentralization of economic activities in the settlements is a prerequisite for increasing mobility of capital, greater availability of jobs by place of living of the population. Such a development would lead to some urban spatial hierarchy through a system of networked urban downtown, urban neighborhoods, suburban towns, and rural areas that gravitate towards the city. Such polycentricity and good transport and trade connectivity also conditions sustainable development in the rest of our country, namely connectivity with other cities in the country that can properly and complementary to develop according to their own predispositions as separate administrative units. Thus to allow concurrent development of cities, and the population would not have a significant need to move to Skopje. Decentralisation could include urban areas that gravitate towards Veles (Lisiche, Avtokomanda, Patrovec...), further settlements gravitate towards Tetovo (Vlae, Gorce Petrov, Saraj...) and to develop a section of suburbs behind mountain Vodno: Sopiste, Sonje, Jabolce... It would mean the development of new urban structures with decentralized administrative authority and good relationship with the city of Skopje and other cities (Veles, Tetovo, etc...).

Skopje in its polycentric development should be designed according to development scenarios for different needs. With its industrial zones can develop oriented production and in regional centers in mostly residential neighborhoods can develop service-oriented economies, while in the center to organize administrative activities and cultural activities.

\subsubsection{Model of sustainable urban development of the city of Skopje as a compact} city

The compact city is a model of sustainable urban development where the concept of concentration greatly reduces motor traffic which is blamed for pollution in cities. Increased population density implies social sustainability, but as noted a lack poor quality of life and lifestyle. Given the high density of population due to intensive migration to the city of Skopje, compactness is possible concept for future sustainable development, especially when it comes to the central area. Compactness in Skopje would be particularly important for the intensity of process of building as objective able to create urbanity for abandoned, 
devastated and unused spaces in the central area of the city. Skopje as a compact city would function autonomously in its use of resources and would be homogeneous. Besides intensification of the constructed, it is necessary to intensify the activities, but only to the extent of something utilitarian or belonging. Excessive intensification would mean pressure on infrastructure and thus sustainable development is impossible.

The compact model Skopje would protect rural areas that gravitate towards urban sprawl of the city and would have been preserved natural resources of the environment and protection of ecosystems and resources. On the other hand, Skopje compact city can provide quality social and economic interaction and its resident's easy access to services. And most importantly for the future sustainable development of the city's compactness perform reduction needs of motor transportation in Skopje whose situation is already alarming. Compactness provides excellent opportunities for promotion and development of alternative types of traffic in urban areas, such as the use of bicycle and pedestrian movement.

The model of compactness in Skopje can be implied because there is a historical core of the center, the city is increasingly developing high population density, the new market system is a prerequisite for the development of different urban functions, and in the downtown area are the largest services (state and city hospital campus, city park, administrative and political centers of the country, etc...). The neighborhood is compact which reinforces social activities and meetings of people, on the other hand is a characteristic part of the mentality of the population in Skopje. Meetings and informal gatherings are part of the local culture and identity of the city of Skopje picture, especially related to public open spaces. Skopje in the social sense is alive and warm city, and compactness will further emphasize the use of parks, squares, streets and walking areas for city residents.

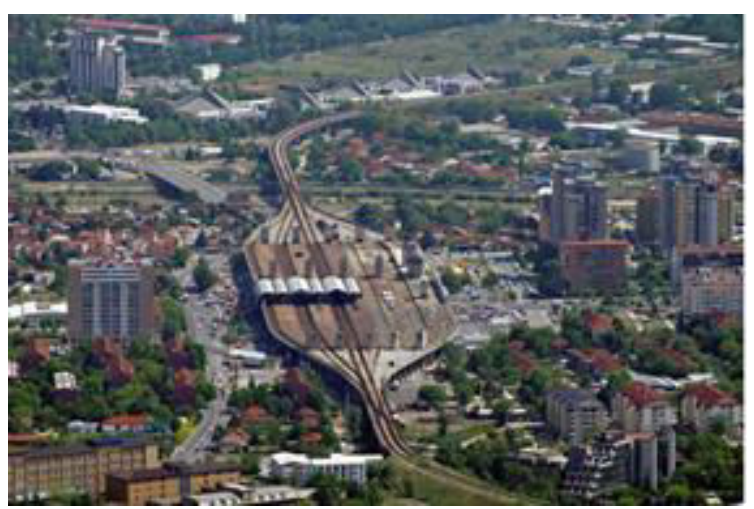

Fig.31 The transit area around the railway station

4.3.3 Transport oriented model of sustainable urban development of the city of Skopje

When considering the two extremely opposite opportunities for urban development Skopje as decentralized or compact city, should considering also for the urban development of the city as transit centers. In Skopje, as in every other city in the world, there is a category of the population living in the city center, and a category of people living in suburban areas. It is important for urban development to take into account those people who live in the transit centers. Downtown is getting more and more of an administrative role and business area around which social action moves and resettle residents. In the interstices of the center to the suburban neighborhoods migrate new people and form new so-called transit zones. Often the population in these transit zones is affected 
by poverty, and similar is the case with a multitude of transit spaces that are inhabited by a population of low social layer. Such spaces in Skopje usually draw with property issues and are filled with illegal poor quality of construction. Such parts are found in areas around the Complex Banks, regarding the Old Pad to Kisela Voda, parts of Suto Orizari, Bit Pazar and around campus and in the area around Skopje railway and bus station (Fig.31). Solving the social problems of these people should be required in the transit zone. These areas are particularly important for infrastructure suburban parts of the city connecting the city center. The best way is if this zone is achieved by combining the activities and good transport connections to neighborhoods and to the center, so population can peaceful be incorporated in the lifestyle group and the one and the other.

\subsubsection{Model of sustainable transport in the city of Skopje}

Traffic in Skopje is perhaps the biggest problem in terms of future sustainable urban development. All previous models of sustainable development are an emphasis on transportation, whether it is for modernization and improvement of transport infrastructure, or compression in order to reduce the need for motorized traffic. That is why, it is particularly important to provide modern transport technology.

Traffic is directly related to population density and size of cities. The most important thing is to find a method and model that encourages the population to less use cars as transportation, and to strengthen the planning and design of public transport services that are energy efficient and clean. They transport projects should include easy access to public transportation for all residents of the cities and even those who live in distant suburban areas of the city. In that sense it is good in Skopje to plan urban form of use of rail transport from long distance can cross the city public transport in the form of subway, tram or other clean transport.

Skopje should encourage the trend of collectivization of the transport system. Rapid and accurate public transport is needed for good networking suburban neighborhoods, while reducing the use of own cars is important to concentrate economic and administrative activities so that employees will enable reduced travel by car and automatically reduce the consequences on air pollution, and in that case people use public transportation or alternative transport modes (walking, cycling, etc.). 


\section{CONCLUSION}

The city is a phenomenon that is difficult to define and directly reflects society and all its changes. Socio - economic trends that cities face today are related to globalization, an aging population, the growth of social inequality, reduction of public resources and disruption of cities. Urbanism as a discipline that deals with the spatial development of the city generally covers four basic functions: housing, work, rest and movement or communication as factors that make society: economic, social, political and administrative, geographical and geological, demographic and environmental factors. Cities are faced with mainly three challenges: demographic change, climate change and changes in the economic structure. Cities are responsible for $3 / 4$ of the world energy consumption, so urban development need to go more and more through energy efficiency programs. Cities are also keys when it comes to the implementation of the declaration on sustainable development and the driving force of economies. According to internationally accepted global sustainable urban development policy of the city should be planned trought: ${ }^{141}$

- The capacity of natural resources, renewable and non-renewable and their alternatives ;

- The economic situation at the local level - decentralization ;

- Existence of natural environment in the city as an aesthetic element ;

- Investment in human resources through education, education, health, etc. ;

- Social status of residents in the city in terms of family and friendly relations association in social groups and associations who jointly commit to development of the city ;

- Increase the quality of life through built capital in terms of facilities, infrastructure, public spaces ( playgrounds, parks ...) ;

- The approach to urban space of the current residents and responsibility to future generations ;

- Interaction and equal treatment of the factors of sustainability : energy, economics, ecology and social efficiency - social action.

The basic questions that were asked in the research are: How to recognize the city as a sustainable system? How to achieve sustainable development in the city? Through which urban indicators can recognize or implement sustainability in the city? And who are the models of sustainable urban structure?

The city of the 20th century was the condition for development of the global economy, while the tendency of cities in the new millennium is to encourage global sustainability. Cities, apart of been socio - economic systems, they must establish a clear link with bioregion and become self-regulating ecosystems with flow of energy, matter and information, and to establish interaction between natural and human parts of the system. In the challenge, how to address the issue of finding a sustainable model and how to start sustainable urban development, this research contains a chronicle of the most important periods in the historical development of cities around the treatment of environmental aspects and relationship to the natural environment. In order to stop the terrifying future of the world in the late 20th century began with a serious activity in the analysis of the alarming state of

\footnotetext{
${ }^{141}$ European Commission, Group Urban evolving capacities, Urban dimension in EU policies 2010, (European Commission, B-1049 Brussels - Belgium);

http://ec.europa.eu/regional_policy/sources/docgener/guides/urban/pdf/urbanguide1_en.pdf
} 
the environment and the idea of sustainable development. This research explicitly provides an overview of the most important international environmental declarations. Multitudes of international documents define the criteria and factors of sustainability almost more than half a century of pioneering makes the first charters. Given the complexity and sheer volume of documents of this type, a number of declarations, treaties, regulations, laws and statutes, in this study the greatest emphasis are placed on environmental concepts relating to development of the urban thought. Here takes place and the European strategy for sustainable development, for significant and one of the leading roles that the EU has in global politics, but for our country's ambitions to position the European model of integration. Global policy through international documents actually reexamines the development goals of humanity. International document also encourages States to establish appropriate strategies for dealing with problems: migration, inadequate settlement, land use, resource use, transport infrastructure etc... At the same time, for the first time in history talking about global awareness of sustainability, efficient use of energy resources, promote renewable energy as a priority and intensify cooperation between all countries to establish global urbanization , technology transfer and knowledge, strengthening local capacities, private - public partnership and definition of integrated models with a common methodology . Integrated urban development policy means integration of architecture, urban planning and infrastructure in an environment that provides a high quality of life and sustainability. It covers the city that would regenerate, naturally focusing its urban planning model to a sustainable form of capital, innovation, rehabilitation of certain urban areas and sustainable urban infrastructure. It suggests and promotes new models of urban development. It requires measures of urbanization to be reoriented from the usual methodology of planning and require the establishment of urban structure. Clearly is talking about the operationalization of sustainable urban development through the definition of models of sustainable cities. This research provides an overview of several models. Polycentric urban development is actually a decentralized urban development. Polycentricity basically has the idea of spreading around multiple centers that will develop social and economic activities. The idea of compactness and concentration gives the compact city model. It is intense urban structure dynamics of development need to set boundaries according sustainable growth. Today's urban structure in the world is such that it is rarely possible implementation of one model of city. The model of transport-oriented development focal points gives a kind of sublimation. Modern cities are economic agglomerations with continuous pumping. The development of transport facilitates decentralization and migration boosts concentration. Always Between these two extremes there are centers and transit zones are always those which are planning, economic and social uncontrolled. The model of sustainable transport has a dimension of city transport as the basis for integrated planning. Sustainable transport can therefore be viewed in two ways: by reducing travel or limiting the impact of increased traffic flow by 
developing the capacity of the streets, the combined use of transport means, change the transport modules and finally technological change in transport equipment (hybrids, electric vehicles, etc...)

Cities differ among themselves by their size, the number of inhabitants and population density, urban structure and in physiognomy and the way in which we live with them in terms of the culture of life. Sustainable urban development should be implemented based on the participation of the community aware of the natural environment, while at the same time local government and public planners should identify community needs. It could be called and environmentally conscious urban development. Summarizing the analysis of international documents gives principles and criteria for sustainable city development, and the sustainability indicators suggests in the planning and design. Sustainable urban planning therefore sees the city as a system where will have interaction between the factors of sustainability: energy, economics, ecology and efficiency, social interaction and venture into the capacity of natural and human resources.

Sustainability can be operationalized in urban structure by analysis of indicators that consider the condition of the city. The indicators provide a basis for qualitative and quantitative conclusions and parameters for future planning. Indicators that relate to the physical structure of the city were analyzed in this study, as part of the methodology of urban planning. The size, shape and coefficient of built up are indicators that are necessary for making a decision on the need for expansion of the spatial scale of the city limits of growth , and thus increase the impact on the natural environment. This indicator is directly related to both models of sustainable urban form, urban concentration (compact city) and urban dispersion (decentralized city). The balance between the one and the other model seems like a good solution, which provides urban structure that is composed of a compact urban community with dense built structure, planned foliage and pedestrian zones associated with efficient transport of the dispersed medium- dense communities that containing all tracking content, structures , services , and infrastructure services .

The purpose and use of space and land is an indicator that suggests the various functions available to all city residents. From sustainable aspects, it is important equally to distribute individual urban functions in all parts of the city and provide mixing instead zoning of purposes. Space in the city should include all functions: housing, works, education, culture, recreation and etc..., but not by way of zoning, which is responsible for the unsustainability of urban form. Moreover, urban structures with variety of uses, enables rich social life that is sustainable feature.

Organization of traffic is an important indicator of sustainability. It is associated with the model of sustainable transportation. Transport infrastructure is the culprit for today's unsustainability of cities. It is a space dominated by cars, which reflects the level of pollution. Inadequate space zoning is main culprit to encourage travel. In achieving sustainability, it is 
necessary to include diverse traffic patterns: walking, using a bike, public transportation ... Public transportation that would be efficient and environmentally friendly (with design and technological inoviteti in the use of fuel) could serve the population suburban areas. To all that should be added and transit traffic model would be a combination of effective traffic model: car, rail, public urban transport in a continuous motion.

Indicator that is particularly important for urban form is one that relates to the transformation of the urban matrix that will not lose "the spirit of the place". That means residents identify with their city which has some historical and cultural continuity through time. In this context, adaptation for achieving sustainability (additions, clustering and concentration of the constructed ...) has to achieve compliance with the new developments in social, cultural and natural context that exists in the city. If sustainability is built into the social behavior of the community, if they are involved in its values, traditions, institutions, people are motivated to regeneration and development. Thus increasing awareness and concern for the environment and the context of the natural environment contributes to a sense of belonging.

Urbanization as process causes changes in the ecosystem. Sustainable development is a primary goal for provide a balance between man and his action and natural environment. This research indicates the state of the ecosystem and biodiversity in terms of urbanization as one of the situations where man uses power and "freedom "to manage natural resources. Simultaneously all urban activities depend on a healthy ecosystem and biosphere. For this purpose requires strategies for protecting biodiversity in urban areas. The easiest way is facilitated through the city landscape and daily activity with parks and greenery. Sustainable lifestyle in recent times to that includes other forms of interaction: urban eco-villages, city agriculture etc...

Our country is a signatory to numerous international documents pertaining to sustainability; hence the interest in this research is focused on how to implement sustainable urban development in the capital Skopje. The analysis made in this regard relate to the model of urban development given in the GUP for Skopje 2001-2020. In order to find an appropriate model and methodology of a future city planning were used sustainable development indicators by which to determine the relevant factors for a possible sustainable development and urban planning. The city of Skopje is placed in scenarios of possible models for sustainable urban development with appropriate criteria and strategies.

Skopje has a centralized role in the development of our country and a city that is attractive to live because of it is a commercial, economic, industrial, educational, cultural, sports center. Chronological city goes through several stages of urban structure and cultural change. Given that this research takes as a basis of planning documentation GUP Skopje 2001-2020 year, the analysis which is made gives the condition of the city. According to this 
analysis, confirms Skopje as an urban agglomeration with high concentration and high dynamics of development. It is a city that is extremely important position in terms of traffic and transit place where cross communication corridors internationally. Skopje is demographic centralized city that is a direct consequence of the migration policy of the state.

Industrialization and the economy are responsible for the expansion and development of the city in this framework that meets today. However, given the long-term transition monitored the restructuring of ownership and privatization.

Housing is the most eloquent element in modeling of urban structure. Skopje is characterized by a diverse structure of the housing stock of individual free standing objects, to large apartment blocks and town closed and semi-closed perimetric blocks, average housing area of $66.60 \mathrm{~m}^{2}$. In Skopje, $45 \%$ of the space is used for housing. A serious problem is the illegal construction that takes city building land provided for another purpose. These buildings are unstructured and difficult problem except that brings harm to compensation for utility costs and the city still encourages the migration process. Ignoring and legalization of illegal construction only encourages residents to continue with such behavior and is directly related to degradation, destruction and breach of the values of the landscape and an indicator of unsustainable situation of the city. The state of the environment of the city shows that in Skopje there are various sources of pollution (industrial, energy, utility, transportation, etc...).

In this study is made an analysis of sustainable urban development of Skopje by understanding of sustainability indicators that are defined on the basis of physical structure. According to the state of construction of Skopje urban environment is characterized by spatial favored building a new land that not only leading to increased physical city but also the formation of elongated shape. Rare are the examples where the filling is done and abandoned devastated free spaces in the city, reconstruction and reuse of urban area. Land use indicates a situation in which most mixed uses are only in the city center. This means that the planned centers in major settlements are not sufficiently developed to meet the needs of culture, commerce, sports and so on. The settlements are found in the solid state relative to the existence of facilities for education, health and social care. There are defined planning industrial and commercial zones that are inefficient to transport links that would provide connections between zones and work zones for housing. Concentration of uses in the town center provides a solid basis for establishing sustainability in the compact city model. The center of Skopje serve to adjacent residential neighborhoods that are directly and closely attached to it which allows concentration of population and the use of alternative means of transport ( walking, cycling ... ) and efficient urban traffic for outlying residential communities, thereby encouraging the construction and operation regional centers and outlying residential communities can be part of sustainable decentralized urban structure . 
Analyzed population density and construction of Skopje indicates a relatively low density because of insufficient organization of land and low land use. This situation confirms the fact that was never realized sufficiently filled urban spaces and distinctively communities with low - density. This leads to the possibility in future development to include intensification of construction especially in those parts where possible upgrading, upgrading, reconstruction etc... , should be preserved in mainly two types of urban block: perimeter (closed or semiclosed) block which has formed the front streets and plot of land, and open block that actually free-residential buildings without the land plot. Perimeter block in terms of sustainable urban planning in relatively easy way transform to the additions, updates, and even the demolition and replacement, as opposed to the open block that is almost impossible to transform without large investments in specific interventions that would any necessary displacement of tenants, demolition, etc... Sustainable urban development implies easily adaptable without conflict in the housing community.

Traffic situation in Skopje is unsustainable. Priority traffic means a car, but unlike other cities in the world, in Skopje observes significant percentage of use of alternative types of transport such as walking, using a bike, and use of public transportation. Transport infrastructure has been developed to meet the motor traffic. Public transport is also a city with a large poor quality, inefficient, irregular and highly polluting in the city. Traffic network in Skopje is not established and conditions congestion at intersections and traffic jams especially in the center and the characteristic axis of the city. This condition produces slowness of movement of traffic jams, little pollution emissions from combustion of fuels and high noise. Future sustainable development should focus on improving the organization and efficiency of public transport, completion of the street network and the creation of transport corridors, safe and pleasant movement of pedestrians and cyclists.

Skopje has a distinctive relationship to the natural context. In the city it is mostly grasslands that occur in residential neighborhoods, parks and avenues of trees, which in most cases are poorly maintained and destroyed. Towards this should highlight the existence of ecosystems: Gazi Baba, Zajcev Rid, Kamnik, Kale, Vodno, river Vardar. They are accessible and affordable for the city, but mostly care for the natural environment is low.

Skopje identifies the urban matrix that historically developed in different cultural contexts. The parts of the medieval city recognized organic matrix of organized communities (neighborhoods). Later, as a developed city received urban matrix with distinctive urban perimeter block that forms the street fronts and in recent history the city has emerged modern open block without plots. Apart from the cultural and historical context, to discontinuity in the urban development of the city affect a multitude of natural disasters faced by Skopje in its existence.

The analysis of possible sustainable urban development of the City in this paper is the simulation of several possible models derived from declarative methodological framework 
and world experiences that were discussed earlier. Polycentric model of sustainable urban development can be easily adopted for cities such as Skopje, which has a dynamic development and permanent influx of new inhabitants. Polycentricity model favors the idea of having more than one center. But it is also not just physical decentralization, but also economically what would have developed suburban neighborhoods as separate communities that provided all uses and efficient traffic related to the rest of the city. That would give way for flow of ideas, capital and competitiveness which is a prerequisite for development.

The model of the compact city is the most popular model of sustainable urban development and the basic idea is by concentrating the population and built to reduce motor traffic which is the biggest polluter. When it comes to Skopje, it is an acceptable model for the downtown area and it is especially important to encourage intensification of the abandoned building, devastiranite and unused areas. It intensification should be implemented to the extent of benefit that would protect rural areas who gravitate toward the city from urban sprawl of the city and attack the ecosystem. The model of compactness of Skopje can provide special and economic interaction of residents, concentrating on different urban functions and services, reducing of motor traffic and boosting meetings and informal gatherings of inhabitants which as a social feature is recognizable to the local culture and identity of the city .

Skopje is a city dominated by traffic and the possibility of traffic transportation strengthens the process of suburbanisation and the formation of de -focused neighborhoods. The pattern of development of the city transit centers refers to those parts of the city that develop spontaneously in the interstices of downtown neighborhoods. A transit zone is often a place where settles population that faces low social standard. In Skopje, it is the parts that have unresolved property issues, illegal and ghetto areas without proper infrastructure. A transit zone is especially important to link the center with suburban neighborhoods and the population living in the transit zone to include one or the other group with an efficient and sustainable transport context.

The model of sustainable transportation is embedded in all previous models and is especially important in Skopje. If Skopje wants to ensure future sustainable urban development should ensure improvement and expansion of transport infrastructure and allow traffic modes that would reduce the need for motorized traffic. To that should be added and encouraging use of public transport vehicles that are energy efficient, clean and cheap. Skopje should develop a model of continuous traffic movement as to include the use of public transport to the outermost parts, combining rail public transport in urban transportation and the transportation system, reduce the use of cars by concentrating on commercial and administrative activities to reduce motor movement in favor of the alternative types of transport and the use of modern transport technology (hybrid and electric vehicles). 
According to the analysis Skopje is city with unsustainable behavior, but has the potential that can ensure sustainable development. The Skopje has resources of unused land (devastated and land that can be re-used), should enrich purposes missing or insufficient in certain parts of the city, to allow concentration and increased density in the central area with good transport resolved formed network traffic and to facilitate the development of suburban areas. The implementation of sustainable urban development is undoubtedly strongly associated with lifestyle change that would be more responsive in terms of the state of the natural environment, setting different economic, social and political priorities and most importantly changing urban thought and methodology of planning following the global objectives for sustainable development. 


\section{BIBLIOGRAPHY}

Aalborg Commitments Tools and Resources -ACTOR Project. The Aalborg Commitments Implementation Guide. A 5-step approach. European Commission, Directorate General for Research, 6th Framework Programme, 2006-2007, (pdf.)

Adams, W.M. The Future of Sustainability: Re-thinking Environment and Development in the Twenty-first Century. Report of the IUCN Renowned Thinkers Meeting, The World Conservation Union, 29-31., January, 2006, (pdf.) <www.iucn.org>

Adams, W. M. and S. J.Jeanrenaud. Transition to Sustainability:

Towards a Humane and Diverse World. IUCN, Gland, Switzerland, 2008, ISBN: 978-2-83171072-3, (pdf.) < www.iucn.org/publications>

Alexander, Christopher. Notes on The Synthesis of Form. Harvard University Press,Chambrige, Massachusetts, Seventh printing,1973

Арсовски, д-р. Владимир. Влијанието на пешачките комуникации врз просторната организација на урбаната средина, Дис., Универзитет “Св.Кирил и Методиј”, Архитектонски фракултет, Скопје, 2000

Association of University Leaders for a Sustainable Future (ULSF). The Talloires Declaration: University Presidents for a Sustainable Future, Talloires, France, 1990 $<$ http://www.iisd.org/educate/declarat/talloire.htm>, $<$ http://www.ulsf.org/talloires_declaration.html>

Bacon, Edmund N. Design of Cities. Thames and Hudson, 1975

Barton. H, M.Grant and R. Guise. Shaping Neighbourthoods. A guide for Health,

Sustainability and Vitality. Spun Press, an imprint of Teylor \& Francis Group, London, UK, 2003

Broadbent, Geoffrey. Design in Architecture: Architecture and the human sciences. John Wiley\&Sons, London, 1973.

Broadbent, Geoffrey. Emerging concepts in urban space design. E\&FN Spon, Chapman \& Hall, 1990

Club of Rome. The Limits of Growth, Abstract established by Eduard Patel. A report to The Club of Rome, 1972

Ching , Francis D.K. Architecture: Form, Space \& Order. Van Nostrand Reinhild Company, New York, 1979.

Conclusion of the Association of Commonwealth Universities. The Swansea Declaration. Fifteenth Quinquennial Conference, Swansea, Wales, August 1993.

$<$ http://www.iisd.org/educate/declarat/swansea.htm>

Convention of the Recourse of the Biosphere, ED 047 952, SE 010 790, Paris, France, September 4-13, 1968, (pdf.)

Commission on Sustainable Development (CSD), Division for Sustainable Development, http://www.un.org/esa/dsd/csd/csd_index.shtml

Commission of the European Communities, Green Paper on The Urban Environment, Brussels 1995 
Commission of the European Communities. Commission staff working paper

Public consultation, Review of the EU Sustainable development strategy, SEC(2004)1042,

Brussels, 30 July 2004 (pdf.)

Commission of the European Communities. Commission staff working document Annex to the: The 2005 Review of the EU Sustainable Development Strategy: Stocktaking of Progress, \{COM(2005)37 final\}, SEC(2005) 225, Brussels, 9.2.2005, (pdf.)

Commission of the European Communities, Commision staff working paper-Consultation paper for the preparation of a European Union strategy for sustainable development, SEC (2001)517, Brussels 2001

Commission of the European Communities. Communication from The Commission, $A$ Sustainable Europe for a BetterWorld: A European Union Strategy for Sustainable Development (Commission's proposal to the Gothenburg European Council), COM(2001)264 final Brussels, 15.5.2001 (pdf.)

Commission of the European Communities. Communication from The Commission to the European Parliament, the Council, the Economic and Social Committee and the Committee of the regions, Towards a global partnership for sustainable development, COM(2002) 82 final, Brussels, 13.2.2002 (pdf.)

Commission of the European Communities. Communication from the Commission to the Council and the European Parliament, On the review of the Sustainable Development Strategy, A platform for action, $\operatorname{COM(2005)} 658$ final, Brussels, 13.12.2005, (pdf.)

Commission of the European Communities. White Paper, European transport policy for 2010: time to decide, $\operatorname{COM}(2001) 370$ final, Brussels, 12.9.2001, (pdf.)

CO-operation Programme in Europe for Research on Nature and Industry through Coordinated University Studies (COPERNICUS). The University Charter for Sustainable Development, Geneva, May 1994, <http://www.iisd.org/educate/declarat/coper.htm>

Costanza, Robert. The Early History of Ecological Economics and the International Society for Ecological Economics (ISEE). International Society for Ecological Economics, Internet Encyclopaedia of Ecological Economics, <http://www.uvm.edu/giee>

Галиќ, Риста. Урбано зонирање. Македонска книга, Скопје, 1980

Генерален Урбанистички план на град Скопје - 2001 - 2020 (ГУП), Документациона основа. Книга 4, Јавно претпријатие за просторни и урбанистички планови на РМ, Скопје

Dodds, Felix, Rosalie Gardiner, David Hales, Minu Hemmati and Gary Lawrence, Stakeholder Forum for Our Common Future. Post Johannesburg The Future of the UN Commission on Sustainable Development. Paper \# 9, WHAT Governance Programme A Joint Initiative of the World Humanity Action Trust (WHAT), Stakeholder Forum for Our Common Future and Global Legislators Organisations for a Balanced Environment (GLOBE) Southern Africa, November 2002, <www.earthsummit2002.org>

Доксијадис, Константинос. Човек иград. НОЛИТ, Београд, 1982

Дошеновиќ, Лилјана. Методолошки пристап во утврдување на рекреативните вредности на шумските комплекси во процесот на урбанизација на градовите труд на научна конфреренција, Владеење со шумските екосистеми на национални парковии другите заштитени подрачја, Јахорина НП, Сутјеска , 2006 
Ѓукановиќ, д-р.Мара. Еколошки димензии во изградбата на просторот. Београд, Архитектонски фракултет, 1984

Здружение на урбанистите на Србија. Промоција на одржлив урбан стил на живот. проект, Београд, 2007

European Commission, Directorate-General for Regional Policy. Promoting sustainable urban development in Europe. Achievements and Opportunities. Unit C2 - Urban development, territorial cohesion, Unit B1 - Information, communication, relations with third countries, European Communities, April 2009, (pdf.) < http://ec.europa.eu/regional_policy>

European Urban Audit. State of European Cities Report. Adding value to the European Urban Audit. State of European Cities Report - Adding value to the European Urban Audit, Study contracted by the European Commission, Contract $\mathrm{N}^{\circ}$ 2005CE160AT012, April 2007, (pdf.) <http://ec.europa.eu/regional_policy/>

Holmberg, John Ulrika Lundqvist, Karl-Henrik Roburt and Mathis Wackernagel. The ecological footprint from a systems perspective of sustainability. International Journal of Sustainable Development and World Ecology 6:17-33., (pdf.)

International Association of Universities, the United Nations University, the Association of Universities and Colleges of Canada, and Dalhousie University, Canada, The Halifax Declaration, Dalhousie University, Halifax, Canada, the 11th day of December, 1991 <http://www.iisd.org/educate/declarat/halifax.htm>

Ivanić,Valentina. Inkluzivni grad?. Centar za strateška ekonomska istraživanja „VojvodinaCESS", CESS magazin, broj 8, jun 2008, ISSN 1820-600X

Jenks, Mike, Elizabeth Burton, Katie Wiliams The Compact city: a sustainable urban form. Oxford Brooks University, Oxford, UK. E\&FN Spon, Chapman \& Hall, 1996

International Council for Local Environmental Initiative (ICLEI). Local Government and the Johannesburg Summit. Publisher: Secretary General, International Council for Local Environmental Initiatives, November 2002, <http://www.city.sendai.jp/kankyou/toshisuishin/kokusai-e/pdf/LG_summit.pdf> (pdf.)

Каролиќ, Ратко. Елементи на редефиниција на домувањето. Тематска сесија: Приказ од резултатите на научно-истражувачкиот проект: "Унапредување на домувањето и станбените содржини" (1986-1990), Библиотека: архитектоника, Архитектонски факултет, Белград, 1990

Kates, Robert W., Thomas M. Parris, and Anthony A. Leiserowitz. What is sustainable development? Goals, indicators, values, and practice. Environment: Science and Policy for Sustainable Development, Volume 47, Number 3, pages 8-21, April 2005, (pdf.)

$<$ http://www.heldref.org/env.php>

Kinsley, Michael J. and L. Hunter Lovins. Paying for Growth, Prospering from Development. September 1997,

<http://www.natcapsolutions.org/publications_files/PayingForGrowth_ChronPilot_Sep1997.p df $>$

Kinsley, M. Sustainable development: Prosperity without growth. Rocky Mountain Institute, Snowmass, Colorado, USA, 1997, (pdf.)

Kongres lokalnih i regionalnih vlasti Savet Evrope. Evropska urbana povelja II. Manifest za novi urbanitet, Rezolucija 269 (2008), 15. plenarna sednica, dokument CPL(15)4RES, nacrt rezolucije predstavio je C. A. Pinto (Portugal, L, EPP/CD), izvestilac, i W. Borsus (Belgija, L, ILDG) i M. Konstantin (Francuska, L, SOC), ko-izvestioci Strazbur, 27-29. maj 2008, (pdf.) 
LEIPZIG CHARTER on Sustainable European Cities. document of the Member States, Informal Ministerial Meeting on Urban Development and Territorial Cohesion in Leipzig on 24 / 25 May 2007, <http://www.infocooperare.ro/Files/LEIPZIG\%20CHARTER\%20on\%20Sustainable\%20Europ ean\%20Cities_20.pdf>

Lahti, Torbjorn and Sarah James. The Eco-municipality Model for Sustainable Community Change. A systems approach to creating sustainable communities. May 17, 2005, (pdf.) <http://www.sustainablelawrence.org/ecomunimodel.pdf>

Managing energy efficient economy and improve environment quality. Collection of Conference Papers, Cosmo Energy Efficiency Conference 2008, Ckonje, 2008

Millennium Ecosystem Assessment Board. Ecosystems and Human well-being, Biodiversity Synthesis, A Report of the Millennium Ecosystem Assessment, World Resources Institute, Washington, DC. 2005. (pdf,) < http://www.maweb.org/en/index.aspx>

Криер, Роб. Градски простор. ГК,Београд , 1991

National Academy of Sciences. Our Common Journey. Executive Summary, Courtesy of the National Academy Press, Washington, D.C., 1999 $<$ http://www.nap.edu/catalog.php?record_id=9690>(pdf.)

Newman, Peter, Isabella Jennings. Cities as Sustainable Ecosystem, Principles and Practices. Island Press, 1718 Connecticut Ave., NW, Suite 300, Washington, D.C. 20009, 2008

Норберг-Шулц, Кристијан. Становање. Electa Editrice, Milano, 1984, Прев. Ода-МаријаНике Карапешиќ, Граѓевинска књига, Београд, 1990

Норберг-Шулц, Кристијан. Егзистенција, простор и архитектура. Прев. Милутин Ј. Максимовиќ, ГК,Београд, 1975

Пенчиќ, м-р. Дивна. Урбаната фрорма според критериумите и параметрите на одржлив развој со оценка на можностите за одржлив развој на Скопје, магистерски труд, Скопје, Архитектонски фракултет, 2005

Plan of Implementation of the World Summit on Sustainable Development. sine anno. <http://www.un.org/esa/sustdev/documents/WSSD_POI_PD/English/WSSD_PlanImpl.pdf>

Попис на населението, домаќинствата и становите во Република Македонија, 2002, <http://www.stat.gov.mk/publikacii/knigaXI.pdf>

Ott, Konrad. The Case for Strong Sustainability. <http://umwethik.botanik.unigreifswald.de/booklet/8_strong_sustainability.pdf>

Стојановски, Тодор. Sustainable cityscape. Future stady of one neighbourhood in the city of skopje with a story and three essays, Stocholm, 2007

Супек, Руди.Град по мјери Човјека. ИТРО Напријед, Загреб, 1987

Sustainable Jordan Workshop , The Sustainable Jordan Declaration 2009. 15 June 2009 <http://www.slab.com.au/Sustainable_Jordan_Declaration_2009.pdf >

The Financial Instrument for the Environment (LIFE ). LIFE in the City. Innovative solutions for Europe's urban environment. European Commission and Environment Directorate- 
General (LIFE Unit - BU-9 02/1), Office for Official Publications of the European Communities, Luxembourg, 2006, ISBN 92-79-02254-7, (pdf.) http://ec.europa.eu/ecolabel/

The Mayors, Leaders and representatives of the cities and local governments of the world, and of their international and national associations. Local Government Declaration to The World Summit on Sustainable Development. Meeting in Johannesburg on the occasion of the 2002 World Summit on Sustainable Development (WSSD), Johannesburg, South Africa from 2-4 September 2002, (pdf.)

The Ninth IAU Round Table, Kyoto Declaration on Sustainable Development, in Tokyo, Japan,19 November 1993,

http://willarddc.com/sd/docs/Kyoto\%20Declaration\%20on\%20SD\%20November\%201993.pdf $>$, <http://www.iisd.org/educate/declarat/kyoto.htm>

Turner, Graham. A Comparison of the Limits to Growth with Thirty Years of Reality. CSIRO Sustainable Ecosystem, 2007, (pdf.) <http://www.csiro.au/>

United Nations Educational, Scientific and Cultural Organization (UNESCO). Intergovernmental Conference of Experts on the Scientific Basis for Rational Use and Conservation of the Resource of the Biosphere, Paris, France, 4-13 September 1968, ED 047 952, SE 010790

United Nations Educational, Scientific and Cultural Organization (UNESCO). The Biosphere Conference 25 years later. Paris, France, October 1993 (pdf.)

UN Framework Convention on Climate Change web: http://unfccc.int

UN Document. Kyoto Protocol to The United Nations Framework Convention on Climate Change, United Nations, 1998 (pdf.) < http://unfccc.int/kyoto_protocol/items/2830.php>

UN Document. The Millennium Development Goals Report 2010, MDG Report 2010 En 20100604 r14 Final.indd, New York, 2010

<http://www.un.org/millenniumgoals/environ.shtml> (pdf.)

United Nations Human Settlements Programme (UN-Habitat). Planning Sustainable Cities, Global Report on Human Settlements 2009, ISBN: 978-92-113-1929-3 (UN-Habitat series), $<$ www.unhabitat.org>

United Nations Department of Economic and Social Affairs (DESA). Programme for the Further Implementation of Agenda 21, Conference Paper, General Assembly, Nineteenth special session Agenda item 8, Distr.General, 19 September 1997.

< http://www.un.org/documents/ga/res/spec/aress19-2.htm>

United Nations Department of Economic and Social Affairs (DESA). Resolution adopted by the General Assembly [without reference to a Main Committee (A/55/L.2)]

55/2. United Nations Millennium Declaration, United Nations A/RES/55/2, Distr.General, 18 September $2000<$ http://www.un.org/millenniumgoals/environ.shtml>

United Nations Department of Economic and Social Affairs (DESA). Report of The United Nations Conference on Environment and Development, Non-legally binding authoritative statement of principles for a global consensus on the management, conservation and sustainable development of all types of forests, Conference Paper, General Assembly, 14 August 1992. <http://www.un.org/documents/ga/conf151/aconf15126-3annex3.htm> 
United Nations Department of Economic and Social Affairs (DESA). Rio Declaration on Environment and Development, Conference Paper, General Assembly, Distr.General, 12 August 1992.

< http://www.un.org/documents/ga/conf151/aconf15126-1annex1.htm>

United Nations Environment Programme (UNEP). United Nations Conference on The Human Environment. Action plan for The Human Environment, Stockholm,1972, plan-txt. <http://fds.oup.com/www.oup.co.uk/pdf/bt/cassese/cases/part3/ch17/1204.pdf> UN Documents, World Commission on Environment and Development (WCED), 1983 The Report of The Brundtland commission, Our common future, 1987

UN Document. World Population Prospects, The 2008 Revision. Department of Economic and Social Affairs, Population Division, United Nations ,New York, 2009, ESA/P/WP.210, (pdf.) <http://www.un.org/esa/population/publications/wpp2008/wpp2008_highlights.pdf>

UN Document. World Urbanization Prospects, The 2009 Revision. Department of Economic and Social Affairs, Population Division, United Nations ,New York, 2009, ESA/P/WP.210, (pdf.)

< http://esa.un.org/unpd/wup/Documents/WUP2009_Highlights_Final.pdf>

Van Schyndel Kasper, Debbie. Redefining Community in the Ecovillage. Research in Human Ecology, Department of Sociology, Sweet Briar College, Human Ecology Review, Vol. 15, No. 1, 2008, < http://www.humanecologyreview.org/pastissues/her151/kasper.pdf>

Wines, James. Green architecture. Taschen, 2008

WWF-World Wide Fund For Nature (formerly World Wildlife Fund) Living Planet Report 2008, Gland, Switzerland, October 2008, ISBN: 978-2-88085-292-4, (pdf.) 